\title{
Rui Manuel Rodrigues Pereira
}

\section{Avaliação do crescimento facial em dois protocolos para cirurgias primárias em pacientes com fissura labiopalatina unilateral: ensaio clínico randomizado}

Tese apresentada à Faculdade de Medicina da Universidade de São Paulo para obtenção do título de Doutor em Ciências

Programa de Clínica Cirúrgica

Orientador: Prof. Dr. Nivaldo Alonso

(Versão corrigida. Resolução CoPGr 6018/11, de 1 de novembro de 2011)

SÃO PAULO

2016 
Não, não vou por aí! Só vou por onde me levam meus próprios passos...

Se ao que busco saber nenhum de vós responde.

Por que me repetis: "vem por aqui!"?

Prefiro escorregar nos becos lamacentos, redemoinhar aos ventos, como farrapos, arrastar os pés sangrentos, a ir por aí...

Se vim ao mundo, foi só para desflorar florestas virgens, e desenhar meus próprios pés na areia inexplorada!

O mais que faço não vale nada...

Fosé Régio, in 'Rantico Megro'

Caminhante, não há caminho. Faz-se o caminho ao andar.

$$
\text { Mntonio Machadoy ORuiz }
$$

Não quero que me respeitem a mim, quero que respeitem a honestidade do meu trabalho

António Sabo Antunes 
A Graça e Maria Tereza, que sempre me viram dividido entre o amor e o dever, que também é sofrer, que também é prazer, que também é amor! As horas que esta minha paixão vos roubou, algumas centenas estão nestas páginas que não são só escritas nos últimos meses, mas, vividas ao longo de quase quarenta anos de vida profissional.

A meus tios, Renato (in memoriam) e Lourdes, que no início de minha vida adulta, me prestaram todo o apoio e dedicação, me abriram portas, me deram de novo uma família, fantástica, em que o amor unia mais que as diversidades apartavam.

Ao Prof. Fernando Figueira (in memoriam), figura ímpar da Medicina Pernambucana, que me deu a oportunidade de crescer profissionalmente a seu lado junto a um corpo clinico em que a dedicação ao paciente e a busca do conhecimento eram a sua principal remuneração.

Ao Prof. Perseu Lemos (in memoriam), pioneiro da Cirurgia Plástica Brasileira, que pacientemente me guiou pelos escaninhos da especialidade e que me incutiu esse fascínio pelas malformações craniofaciais.

E finalmente, dedico aos milhares de pacientes afetados por essas patologias e suas famílias, que tive o privilégio de tratar e percorrer esse caminho de aprendizado e de solidariedade, em especial aqueles que de forma desinteressada e altruísta participaram deste estudo. 


\section{AGRADECIMENTOS}

Ao Prof. Dr. Nivaldo Alonso, um homem da Ciência, acadêmico que não se isolou da atividade clínica, pelo incentivo, paciência e carinho durante a orientação desta tese, nestes anos de convivência que só fizeram aumentar meu apreço e respeito.

Ao Prof. Marcus Castro Ferreira, que me possibilitou esta oportunidade, abrindo as portas da Faculdade de Medicina da Universidade de São Paulo para que pudesse desenvolver esta pesquisa.

À Prof. ${ }^{a}$ Niedje Siqueira, que embora de forma oficiosa, incorporou a função de coorientação, generosa e eficiente, cientificamente rigorosa, mas simultaneamente afável e carinhosa.

À Professora Edna Costa, incansável, pertinaz, solidaria, que além de ter ajudado na primeira formulação deste projeto, foi fulcral nas atividades de captação, confecção dos modelos, organização do estudo, sempre com um sorriso no rosto e um conselho para dar!

À Professora Dione do Vale, que em tantos momentos difíceis me ajudou a coordenar as atividades do Centro, assumindo responsabilidades diversas, além da ajuda na elaboração desta pesquisa, facilitou acesso a tecnologias inacessíveis ao serviço público.

Às sempre importantes, decisivas, solidárias, prestativas, determinadas e são apenas alguns desses encômios que posso apontar a Amanda Oliveira, espírito irrequieto e pertinaz, Daniela Melo, sempre alegrando quem a rodeia, Stella Brandão e Cristina Alcântara, sempre prontas para colaborar.

Às fonoaudiólogas do Centro, coordenadas pela Prof. ${ }^{\mathrm{a}}$ Micheline Coelho, importantes desde a primeira hora, acompanhando e avaliando os pacientes e que irão por certo prosseguir estes caminhos que este estudo começa a desbravar. 
A todos os residentes que nestes anos me ajudaram na condução destes pacientes, representados pela Dra. Bruna Silveira, que colaborou na confecção do projeto inicial ao Dr. Jorge Matta, que desenhou as ilustrações para o artigo a ser publicado.

À Aline, que assumiu a tarefa de arquivar todas as informações e de assessoramento, à Tec. Enfermagem Ana, a "anjo da guarda" a que os pacientes primeiro se socorrem.

A todos os outros colaboradores do CADEFI, que no meio das dificuldades hoje atravessamos continuam com dedicação impar permitindo que nossos pacientes tenham acesso ao processo de reabilitação.

Ao Dr. Daniel Farinha e equipe da FaceImagem, que possibilitou o escaneamento e digitalização dos modelos de estudo de forma inteiramente gratuita.

Ao Professor Edmilson Mazza, pela assessoria estatística, sempre primando pelo rigor de suas observações e excelência técnica de suas analises

À Eliane Gazetto, secretária da pós-graduação, meu porto seguro, pelo auxílio em manter os prazos e a burocracia institucional em ordem.

À Maria Helena Vargas, pela ajuda na estruturação e confecção desta Tese.

E a todos que, de alguma forma, contribuíram para a realização deste sonho. 
Esta tese está de acordo com as seguintes normas, em vigor no momento desta publicação:

Referências: adaptado de International Committee of Medical Journals Editors (Vancouver).

Universidade de São Paulo. Faculdade de Medicina. Serviço de Biblioteca e Documentação. Guia de apresentação de dissertações, teses e monografias.

Elaborado por Anneliese Carneiro da Cunha, Maria Julia de A. L. Freddi, Maria F. Crestana, Marinalva de Souza Aragão, Suely Campos Cardoso, Valéria Vilhena. $3^{\text {a }}$ ed. São Paulo: Divisão de Biblioteca e Documentações; 2011.

Abreviatura dos títulos dos periódicos de acordo com List of Journals Indexed in Index Medicus. 


\section{SUMÁRIO}

Lista de abreviaturas e siglas

Lista de quadros

Lista de figuras

Lista de tabelas

Lista de gráficos

Resumo

Abstract

1 INTRODUÇÃO

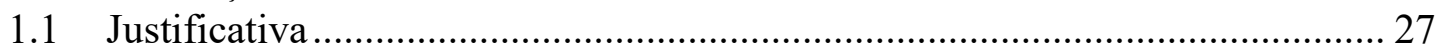

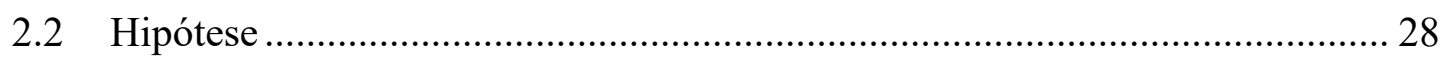

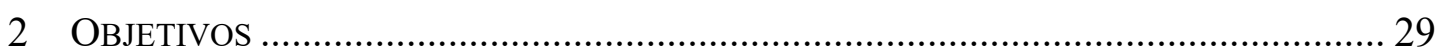

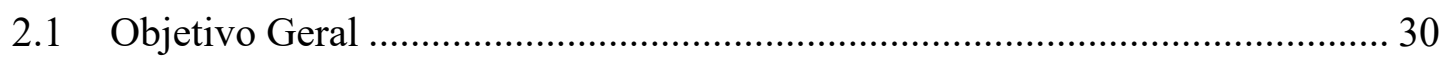

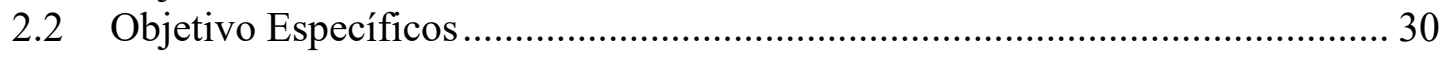

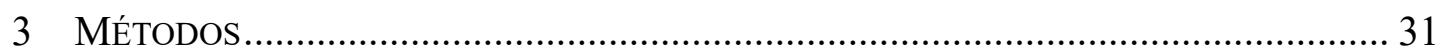

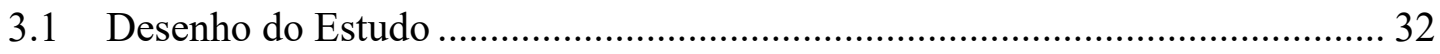

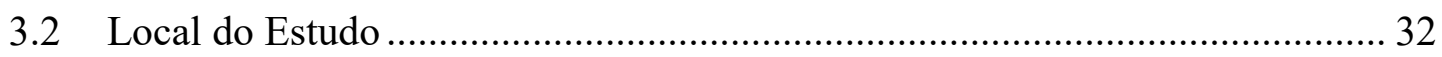

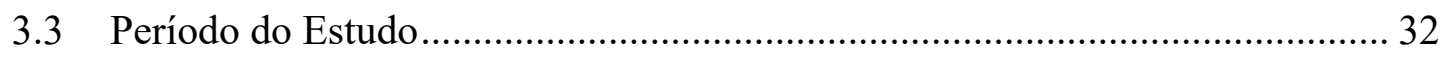

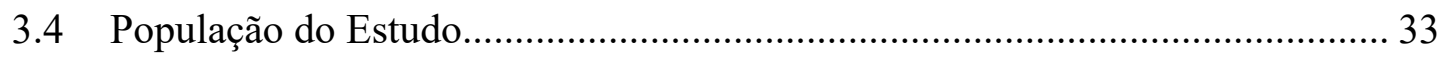

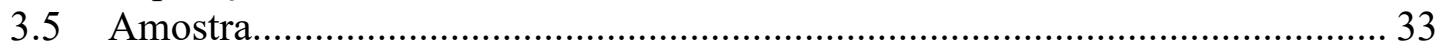

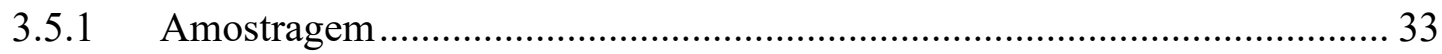

3.5.2 Tamanho Amostral.................................................................................... 33

3.6 Critérios e Procedimentos para Seleção dos Participantes ................................ 34

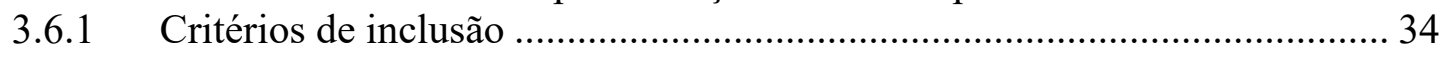

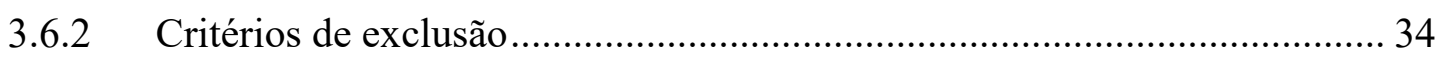

3.7 Variáveis de Análise ..................................................................................... 35

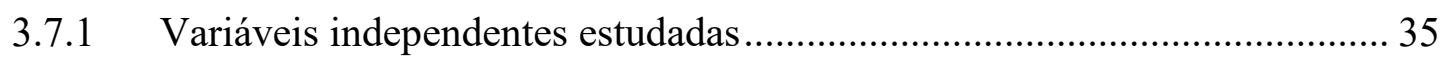

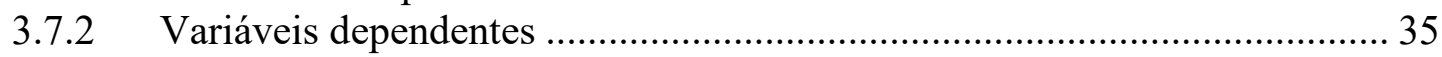

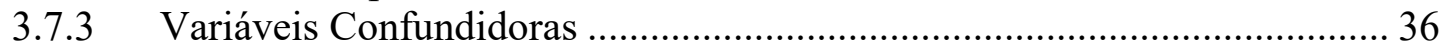

3.8 Definição e Operacionalização dos Termos, Critérios e Variáveis ................... 36

3.9 Procedimentos para Captação e Acompanhamento dos Participantes ............. 39

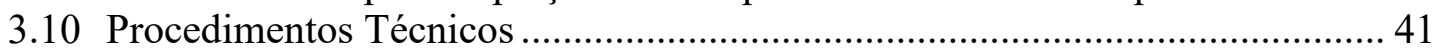

3.10.1 Procedimentos cirúrgicos ..................................................................... 41

3.10.2 Procedimentos para Avaliação da Largura da Fissura e das

Dimensões Transversais e Anteroposteriores do Arco Dentário

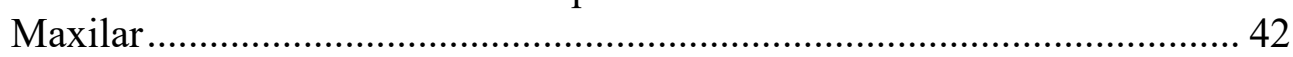

3.10.2.1 Obtenção dos modelos de estudo ........................................................ 42

3.10.2.2 Avaliação da largura da fissura do recém-nascido.................................. 43

3.10.2.3 Avaliação das dimensões transversais e anteroposterior da maxila do recém-nascido........................................................................ 44

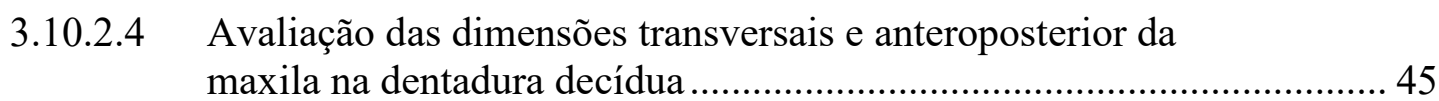


3.10.2.5 Avaliação da relação maxilo-mandibular na dentadura decídua 46

3.11 Instrumento para Coleta dos Dados ............................................................. 48

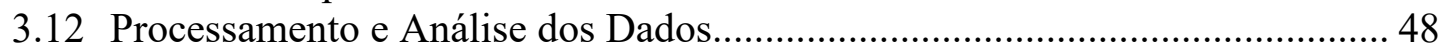

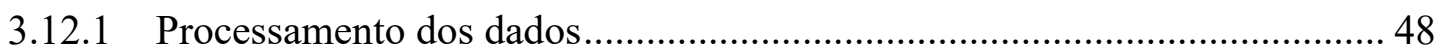

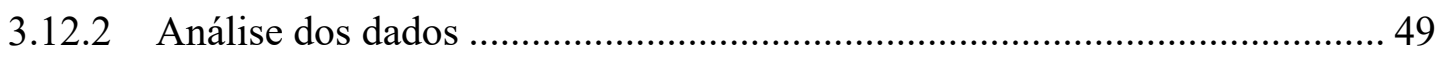

3.13 Captação e Acompanhamento dos Participantes ............................................. 50

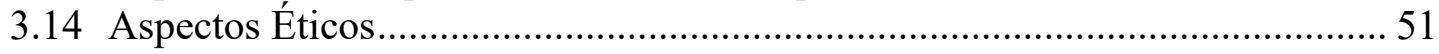

3.14.1 Termo de Consentimento Livre e Esclarecido .......................................... 53

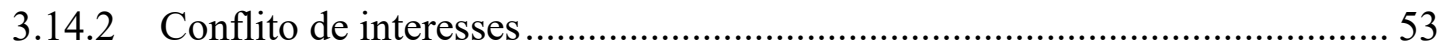

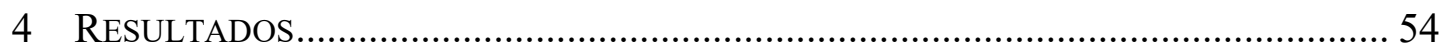

4.1 Avaliação dos resultados intergrupos por meio dos scores do índice FYOI atribuídos pelos examinadores 61

4.2 Avaliação dos Resultados Intergrupos Relacionados à

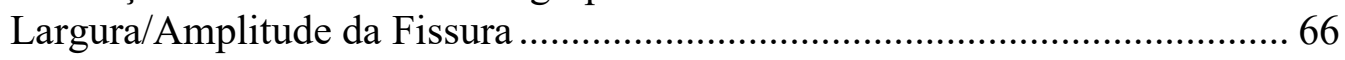

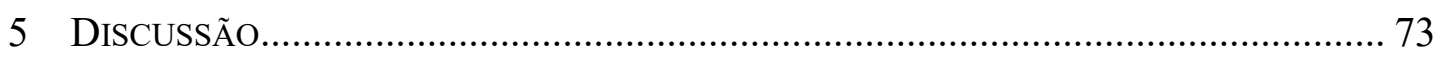

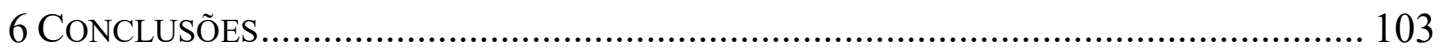

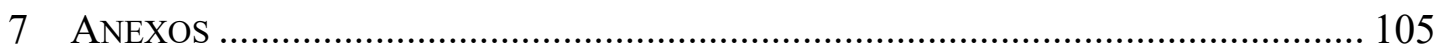

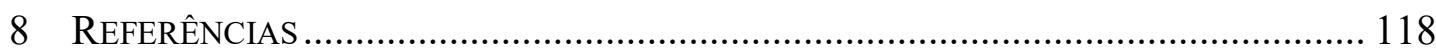




\section{LISTA DE ABREVIATURAS E SIGLAS}

ACF - Anomalias craniofaciais

ACPA - Cleft-Palate Craniofacial Association

CADEFI - Centro de Atenção aos Defeitos da Face do Instituto de Medicina Integral Prof. Fernando Figueira

CCUK - Cleft Care UK Study

CSAG - Clinical Standards Advisory Group

DC - Distância intercranianas

DM - Distância intermolares

EUA - Estados Unidos da América

FLP - Fissuras labiopalatais

FLPU - Fissura lábio palatal unilateral

FON - Fistulas oronasais

FTPD - Fechamento tardio do palato duro

FYOI - Five Years Old Index

GC - Grupo controle

GI - Grupo de intervenção

IMIP - Instituto de Medicina Integral Prof. Fernando Figueira

IP - Comprimento do arco alveolar maxilar

IVF - Insuficiência velofaríngea

NHS - Sistema de Saúde Pública do Reino Unido

NIDCR - National Institute for Dental and Craniofacial Research

OMS - Organização Mundial da Saúde

RCT - RandomizedClinicalTrial

ReBEC - Registro Brasileiro de Ensaios Clínicos

RR - Risco relativo

RRTDCF - Rede de Referência no Tratamento de Deformidades Craniofaciais do Ministério da Saúde

SIH-SUS - Sistema de Informações Hospitalares do Sistema Único de Saúde

SINASC - Sistema de Informações de Nascidos Vivos

SUS - Sistema Único de Saúde

TCLE - Termo de Consentimento Livre e Esclarecido 


\section{LISTA DE QUADROS}

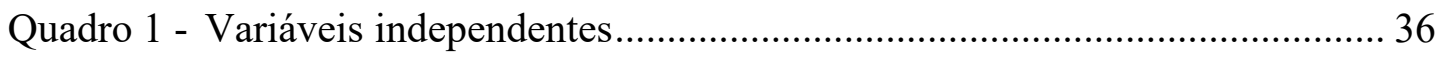

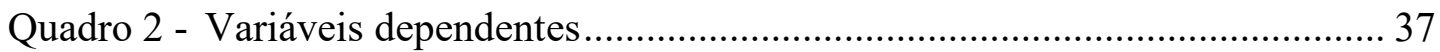

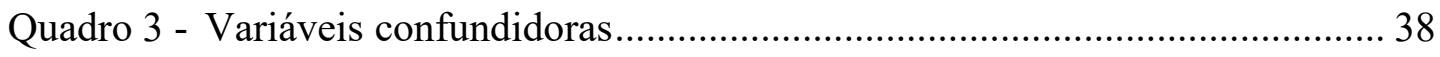

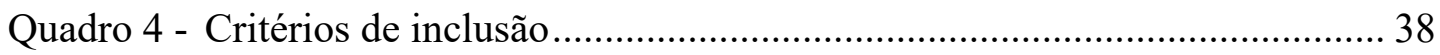

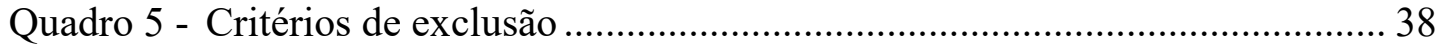

Quadro 6 - Classificação das características oclusais pelo índice FYOI................... 47 


\section{LISTA DE FIGURAS}

Figura 1 - Dimensões transversais e anteroposterior da maxila do recémnascido

Figura 2 - Dimensões transversais e anteroposterior da maxila na dentadura decídua

Figura 3 - Modelos dos arcos dentários superior e inferior em oclusão para avaliação do índice FYOI

Figura 4 - Fluxograma de captação e acompanhamento dos pacientes ................. 50

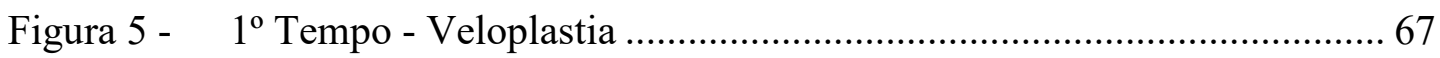

Figura 6 - $\quad 2^{\mathrm{o}}$ Tempo - Fechamento do palato duro (Langenbeck

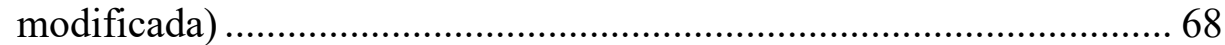

Figura 7 - Grupo GI - Admissão (Paciente: D. T. N.) …….................................. 69

Figura 8 - Grupo GI - FYOI 1 (Paciente: D. T. N. - 5a 5m).................................. 69

Figura 9 - Grupo GI - FTPD - Modelo FYOI 1 (Paciente: D. T. N.) .................... 69

Figura 10 - Grupo GI - Admissão (Paciente: L. L. F. N.) ….................................. 70

Figura 11 - Grupo GI - FYOI 4 (Paciente: L. L. F. N. - 5a 2m) …......................... 70

Figura 12 - Grupo GI - FTPD - Modelo FYOI 4 (Paciente: L. L. F. N.) ………..... 70

Figura 13 - Grupo GC - Admissão (Paciente: L. G. O.) ......................................... 71

Figura 14 - Grupo GC - FYOI 2 (Paciente: L. G. O. L. - 4a 2m) ........................... 71

Figura 15 - Grupo GC - FYOI 2 após palatoplastia (Paciente: L. G. O. L.) ........... 71

Figura 16 - Grupo GC - Admissão (Paciente: P. J. O. F.) ....................................... 72

Figura 17 - Grupo GC - FYOI 4 (Paciente: P. J. O. F. - 3a 7m)............................. 72

Figura 18 - Grupo GC - FYOI 4 (Paciente: P. J. O. F.).......................................... 72 


\section{LISTA DE TABELAS}

Tabela 1 - Características da amostra pesquisada segundo o grupo ...................... 55

Tabela 2 - Avaliação da presença da banda cutânea segundo o grupo ................... 56

Tabela 3 - Média e desvio padrão das dimensões transversais e anteroposteriores da maxila: largura anterior do arco alveolar (C-C'), largura posterior do arco alveolar (T-T', distância intercaninos pós tratamento (DC), distância intermolares póstratamento (DM) e comprimento do arco maxilar pós tratamento (IP) segundo o grupo

Tabela 4 - Média e desvio padrão das medidas da largura anterior da fissura (G-L) e da largura posterior da fissura (A-A') segundo o grupo

Tabela 5 - Média e desvio padrão das medidas: distâncias C-C' e T-T' a ocorrência de Banda Cutânea por grupo

Tabela 6 - Média e desvio padrão da idade nas datas das cirurgias e na obtenção do modelo segundo o grupo

Tabela 7 - Características da técnica cirúrgica (incisões laterais) 59

Tabela 8 - Avaliação das complicações segundo o grupo 60

Tabela 9 - Presença de complicação (fistula) após Palatoplastia Completa com a execução ou não de incisão liberadora no grupo GC

Tabela 10 - Presença de complicação (fístula) após a palatoplastia anterior com a execução ou não de incisão liberadora no grupo GI

Tabela 11 - Avaliação da concordância entre e intra avaliadores em relação ao escore ATTACK

Tabela 12 - Média, desvio padrão e mediana dos escores do Índice FYOI segundo o grupo

Tabela 13 - Resultados de todas as avaliações do Índice FYOI segundo o grupo

Tabela 14 - Resultados de todas as avaliações categorizadas do Índice FYOI segundo o grupo

Tabela 15 - Resultados das medianas entre avaliadores do escore Índice FYOI segundo o grupo 
Tabela 16 - Resultados das categorias das medianas entre avaliadores do escore Índice FYOI segundo o grupo

Tabela 17 - Resultados das categorias das medianas entre avaliadores dos escores 1 e 2 (Boa) e 4 (Ruim) do ATTACK segundo o grupo 66

Tabela 18 - Correlação de Spearman com a mediana dos escores com cada uma das medidas G-L e A-A' 66 


\section{LISTA DE GRÁFICOS}

Gráfico 1 - Resultado da avaliação de 62 pacientes, realizada por três examinadores, utilizando o Índice FYOI nos grupos GI e GC

Gráfico 2 - Resultado da avaliação de 62 pacientes, realizada por três examinadores, utilizando o Índice FYOI, agrupadas em três categorias, nos grupos GI e GC

Gráfico 3 - Percentagem dos escores do índice de 5 anos de 1 (excelente) a 5 (muito pobre) dentro de cada ensaio 95

Gráfico 4 - Protocolos com fechamento do palato Duro aos $12 \mathrm{~m}$ e tardios (após 36m) 96

Gráfico 5 - Protocolos palatoplastia tempo único .99 


\section{RESUMO}

Pereira RMR. Avaliação do crescimento facial em dois protocolos para cirurgias primárias em pacientes com fissura labiopalatina unilateral: ensaio clínico randomizado [tese]. São Paulo: Faculdade de Medicina, Universidade de São Paulo; 2016.

Introdução e Objetivo: Nos pacientes com fissura labiopalatina unilateral (FLPU) as cirurgias primárias afetam, em graus variados, o crescimento da face, comprometendo a estética facial e a oclusão dentária. Diversos estudos enfatizam a necessidade de se estabelecer protocolos cirúrgicos que apresentem repercussões positivas no crescimento facial e no desempenho fonoarticulatório dos pacientes, visando a diminuição do custo biológico, social e financeiro do tratamento integral. Este estudo objetivou comparar os efeitos de dois protocolos cirúrgicos para palatoplastia primária, em um e em dois tempos cirúrgicos, este com o fechamento tardio do palato duro (FTPD) sobre o complexo maxilo-mandibular de pacientes com FLPU completa. A hipótese do autor é que o protocolo com FTPD propicie um melhor crescimento dentofacial. Métodos: Foi realizado um ensaio clínico randomizado no qual 64 pacientes, atendidos em um centro de referência no nordeste do Brasil, foram divididos em dois grupos que receberam tratamentos cirúrgicos distintos. O grupo de intervenção (GI) foi constituído por 32 pacientes submetidas à palatoplastia em dois tempos cirúrgicos: veloplastia realizada entre os 6 e 9 meses de idade e FTPD realizado entre 36 e 48 meses de vida. O grupo controle (GC) foi constituído por 30 pacientes submetidos a palatoplastia completa entre os 9 e 15 meses. A relação entre os arcos dentários foi avaliada, de maneira cega, por três ortodontistas calibrados usando o índice FYOI (Atack,1997). Também foram investigadas as alterações dimensionais na maxila, a gravidade da fissura e as complicações pós-cirúrgicas em relação aos dois protocolos cirúrgicos. Resultados: Os modelos de gesso para avaliação pelo FYOI foram obtidos dos pacientes de ambos os grupos com idade média de 55,5 meses. O grau de concordância foi 
excelente $($ Kappa $=0,76-0,90)$ entre os examinadores e bom intra-examinadores $($ Kappa $=0,67-0,87)$. Os escores médios do índice FYOI variaram de 2,04 no GI a 2,76 no GC, com diferença estatisticamente significante $(\mathrm{p}=0,007)$. Quando os scores foram agrupados em três categorias, bom (escores 1 e 2), Regular (escore 3) e ruim (escores 4 e 5) verificou-se diferença significativa $(p<0,006)$ na categoria bom (escores 1 e 2$)$ entre os grupos GI $(74 \%)$ e GC (52\%). Ao serem comparadas as distribuições pela mediana, foi encontrada diferença significativa $(p=0,024)$ entre os escores 1 dos grupos GI (31,2\%) e GC (3,3\%). A correlação entre a largura da fissura e a relação maxilo-mandibular avaliada pelo FYOI não foi evidenciada pelo método de Spearman. A ocorrência de fístulas oronasais foi de 9,4\% no GI e 6,7\% no GC, sem diferença significativa entre eles. Conclusões: a palatoplastia realizada em dois tempos cirúrgicos com FTPD, apresenta melhores desfechos relativos ao crescimento dentofacial em crianças com FLPU. Não foi encontrada associação entre a gravidade da fissura e os desfechos relacionados ao crescimento maxilar. Não há diferenças estatisticamente significantes entre os dois protocolos cirúrgicos em relação à ocorrência de fístulas e à diminuição da distância intercaninos e diminuição do comprimento do arco maxilar.

Descritores: Fissura labial. Fissura palatina. Fissura labiopalatina. Maxila/crescimento e desenvolvimento. Maxila/cirurgia. Ensaio clínico randomizado. Relação interarcos dentários. Índice FYOI. 


\begin{abstract}
Pereira RMR. Evaluation of facial growth in two primary protocols used in the surgical treatment of unilateral cleft lip and palate patients: a randomized clinical trial [thesis]. São Paulo: "Faculdade de Medicina, Universidade de São Paulo"; 2016.
\end{abstract}

Background and Objective: An adequate growth of dentofacial structures is one of the most important goals of unilateral cleft lip and palate(UCLP) treatment and has a definitive role in getting good aesthetic and dental occlusion outcomes. To the present date several papers highlight the need of evidence-based studies to find surgical protocols that can improve facial growth and speech results aiming to reduce the burden of care of overall treatment. This study has evaluated and compared the dental arch relationship at 5 years of age after two treatment protocols, one submitted to one stage cleft palate repair (CPR) and the other to a two stage CPR with delayed hard palate closure (DHPC). The author's hypothesis is that the DCHP protocol provides a better dentofacial growth. Methods: A randomized clinical trial was held to evaluate the maxilo-mandibular relations in two groups of initially 32 patients each, randomly chosen. The GI group $(n=32)$ was submitted to veloplasty between 69 months of age and a DCHP palatoplasty between three and four years of of age. The immediate complications were evaluated, oronasal fistulas, and cleft severity and their relationships to the surgical protocols. The dental arch relationships were assessed by a blind panel of three independent orthodontists using the FYOI index. The Kappa statistics were calculated to ensure the level of confidence. The results were statistically tested by $\mathrm{t}$ and Q-squared tests. Results: The GI group consisted of 32 patients while the GC group consisted of 30 patients. The oronasal fistulas incidence rate was $9.4 \%(\mathrm{GI})$ and $6.7 \%(\mathrm{GC})$, and there was no association to surgical techniques. Study models of 62 patients at the average age of 55.5 months were available for assessment. Good to very good levels of intra- and interrater reliability were obtained $(0.67-0.87$ and $0.76-0.90)$. The mean index scores varied 
between 2.04 (GI) and 2.76 (GC) with a statistically significant difference ( $\mathrm{p}=0.007)$. When all evaluations were distributed between indexes good (1 and 2), regular (3) and bad (4 and 5); a statistically significant difference was observed between the GI and GC groups $(\mathrm{p}=0.006)$. The GI Group presented a $74 \%$ rate of good scores, while the GC Group rated 52\% in good scores. When comparing the distributions by median, a difference $(\mathrm{p}=0.024)$ was found between scores 1 of the GI $(31.2 \%)$ and GC (3.3\%) groups. The correlation between the cleft severity and the dental arch relationships assessed by the FYOI was not evidenced by the Spearman method. Conclusions: The ECR results provide statistical evidence that the DCHP protocol delivers better outcomes related to dentofacial growth. There was no correlation found between the cleft severity, palatal width and the results related to maxilar growth. The prevalence of oronasal fistules is similar in both surgical protocols.

Descriptors: Cleft lip. Cleft palate. Cleft lip-palate. Maxilla/growth and development. Maxilla/surgery. Randomized clinical trial. Relationship between dental arches. FYOI index. 
1 INTRODUÇÃo 
As fissuras orofaciais, das quais as fissuras labiopalatais (FLP) apresentam maior prevalência, são anomalias congênitas que se caracterizam pela falta de continuidade das partes moles e/ou esqueléticas faciais, ocasionadas pela falha de fusão ou penetração das proeminências faciais, durante o período embrionário. Este processo é caracterizado pela ruptura de múltiplos processos de indução, migração celular, crescimento local e penetração mesenquimatosa. No caso da fissura labial unilateral, esta é resultado da falta de penetração mesenquimatosa das proeminência nasal medial e maxilar de cada lado da linha media ${ }^{1}$.

A prevalência das fissuras orofaciais é bastante diversa conforme o publicado por Petersen $e t a l .^{2}$, que analisa os relatórios da Organização Mundial da Saúde (OMS) ${ }^{3}$ sobre saúde oral, que mostra ${ }^{4}$ taxas estimadas nas várias regiões do mundo que vão desde $0,82 / 100$ a 4,04/1000 nascidos-vivos entre os asiáticos a 0,9/1000 a 2,69/1000 entre os caucasianos e mais baixas entre os africanos com 0,18/1000 a 1,67/1000.

Dados levantados por Kling et al. ${ }^{5}$ estimam que no ano de 2009 teriam nascido cerca de 250.000 indivíduos com fissuras lábiopalatinas, sendo que 70\% deles nascidos em países em desenvolvimento. No Brasil, Wehby ${ }^{6}$ calcula que existem entre 2900 a 4400 recém-nascidos com fissuras orais em 2011, com base nos trabalhos de Campana et $a .^{7}$ e de Souza e Raskin ${ }^{8}$. No entanto, são dados bem segmentados e os outros publicados também são relativamente antigos ${ }^{9,10}$ - do século passado - e reportando situações muito regionalizadas o que poderá ter influenciado nas conclusões então encontradas. 
Rodrigues et al. ${ }^{11}$ em 2009, com base em dados levantados nos sistemas administrativos do Governo Federal*,encontra prevalência de 0,43 por 1000 nascidos-vivos. No entanto deve ser considerado com reservas em virtude da provável subnotificação, compatível com dados encontrados em trabalho apresentado no Cleft $2013^{\dagger}$. Esse achado também é encontrado em outros países como, por exemplo, na China onde a cobertura a vigilância epidemiológica gira em torno de $40 \%$ dos $\operatorname{casos}^{12}$. Alguns países têm experimentado uma redução na sua prevalência, talvez relacionado com uma maior miscigenação da população, principalmente, com afrodescendentes ou pela opção da interrupção da gravidez em virtude de diagnósticos fetais cada vez mais precoces e acurados ${ }^{13-17}$. No entanto, os números impactantes da prevalência destas deformidades em amplos contingentes populacionais e a tendência crescente que o perfil sanitário dos países em desenvolvimento assemelha-se cada vez mais ao dos países desenvolvidos, em que as causas de morbidade e mortalidade, no primeiro ano de vida, são relacionadas às deformidades congénitas, das quais entre $40 \%$ a $60 \%$, são relacionadas ao segmento craniofacial $^{13}$, demonstram ser um dos desafios mais marcantes que se colocam para os sistemas de saúde nacionais e agencias internacionais, e assume uma importância maior nos países em desenvolvimento, tornando-se um grave problema de Saúde Pública, em virtude dos custos e disponibilidade que o seu tratamento requer.

O longo tempo de tratamento, que independe de qualquer protocolo, embora este último possa influenciar a frequência com que procedimentos mais complexos e tardios se façam necessários ${ }^{18}$, caracteriza este grupo de forma especial, pois além

\footnotetext{
* Sistema de Informações Hospitalares do Sistema Único de Saúde (SIH-SUS), Sistema de Informações de Nascidos Vivos (SINASC) e Atlas de Desenvolvimento Humano do Brasil.

$\dagger 12^{\text {th }}$ International Congress on Cleft Lip/Palate and Related Craniofacial Anomalies. ACPA. Orlando, USA: International Confederation of Cleft Lip and Palate and Related Craniofacial Anomalies 2013.
} 
dos recursos financeiros e humanos especializados que exige ${ }^{19}$, demanda do paciente e seu agregado familiar um comprometimento e adesão importantes, podendo levar muitas famílias ao que Blocksma et al. ${ }^{20}$ definiram como financial exhausting syndrome. Esses custos, mesmo em países pobres, são relativamente elevados o que ocasiona múltiplas vezes tratamentos incompletos ou malconduzidos, acarretando assim maior dificuldade na reabilitação do paciente e sua integração social.

O paciente com fissura orofacial, conforme um estudo caso-controle publicado por Wehby et $a l^{21}$, apresenta durante a infância e adolescência um número três vezes maior de internamentos do que o seu controle, o que demonstra a necessidade de ser acompanhado de forma especial tendo em conta o desgaste emocional e físico que internamentos repetidos requerem. Wehby et $a l^{22}$, acompanhando um grupo de pacientes com fissura entre os anos de 1983 e 2003, no estado de Iowa, Estados Unidos da América (EUA), constataram um desempenho escolar inferior em todas as áreas do conhecimento, o que pode ser atribuído ao tempo dedicado ao tratamento, além das caraterísticas da própria deformidade e seu tratamento com alterações fonoarticulatórias, auditivas e comportamentais. A importância econômica e social do impacto do tratamento ou a sua ausência é documentada por diversos autores ${ }^{23-27}$.

Conscientes deste problema de saúde pública, alguns países e a comunidade que se dedica ao tratamento destas deformidades - sociedades medicas, paramédicas, multidisciplinares e outras, nacionais ou internacionais - nos últimos anos do século passado, promoveram várias reuniões de consenso e alertadas para o consequente aumento das necessidades de ampliar os recursos materiais e capacitar os recursos humanos, levaram a que o Programa da Genética Humana da OMS e com recursos financeiros do National Institute for Dental and Craniofacial Research (NIDCR) a 
desencadear um projeto colaborativo ${ }^{3}$ para tratar dos assuntos relacionados com esta área. Entre os objetivos destacava-se a criação de uma rede internacional para construção, planejamento e desenvolvimento de protocolos visando a realização de estudos colaborativos nas áreas biomédica, epidemiológica e comportamental em anomalias craniofaciais (ACF).

Em 2002, a OMS publica o Global strategies to reduce the health care burden of craniofacial anomalies que direciona, de forma consequente, a abordagem destes temas ao redor do mundo ${ }^{2,3}$. Em relação ao tratamento, este relatório consubstancia como objetivos primordiais:

- Identificar e divulgar protocolos clínicos ideais para a correção de anomalias craniofaciais (cuidados baseados em evidências).

- Identificar e divulgar estratégias para otimizar a qualidade dos serviços que prestam assistência (melhoria da qualidade).

- Identificar e divulgar estratégias para aumentar a disponibilidade de cuidados a todos os cidadãos afetados no mundo (acesso e disponibilidade).

A pesquisa nesta área de conhecimento, como constatado por Roberts et al. ${ }^{28}$, que contabilizava cerca de $95 \%$ dos artigos publicados tinham metodologia baseada em estudos retrospectivos, transversais, séries de casos ou coortes prospetivos, em que inúmeros vieses poderiam ser identificados, assim sendo com baixos níveis de evidencia clínica ${ }^{29-31}$.

Estes inúmeros vieses, donde será importante destacar que na prática clínica diária, em que muitos destes trabalhos retiraram as amostras avaliadas, a alocação de pacientes para cada grupo poderá ser seletiva a partir dos diferentes graus de dificuldade que cada caso poderá apresentar, além da escolha poder também ser 
influenciada pela etnia, idade, sexo ou disponibilidade de recursos humanos. Escassez de registros adequados e insuficiência de informações, assim como a falta de critérios objetivos e uniformes para inclusão/exclusão dos sujeitos, além de diferentes proficiências cirúrgicas, tratamentos adjuvantes, cirurgias secundarias, mesmo analisados com recursos estatísticos mais sofisticados, interferem nas análises em estudos observacionais que se dedicam a este tema.

No entanto, e devido à prevalência destas malformações, aliada ao longo tempo de tratamento e a falta de evidencias dos resultados dos protocolos adotados, tem instigado vários pesquisadores ao redor do mundo, centros de pesquisa e instituições governamentais e agencias internacionais a construir projetos de pesquisa que avaliem retrospectivamente os tratamentos e suas consequências. Os clássicos estudos realizados por Bardach et al. ${ }^{32}$ e $\operatorname{Ross}^{33}$ com metodologia mais apurada que estudos realizados anteriormente se propunham a sistematizar essa pesquisa ${ }^{34}$.

Assim, em 1992, surgem os primeiros estudos colaborativos entre vários serviços do norte da Europa ${ }^{35-38}$, em que compararam os desfechos de seus protocolos de tratamento com pacientes com fissura labiopalatal unilateral (FLPU) aos nove anos de idade, em relação ao crescimento maxilar, desempenho fonoaudiológico e aspeto nasolabial, que se tornaram marcos importantes e balizadores desta determinação. Com este trabalho pioneiro foi encontrada uma nova modalidade de avaliação e pesquisa nesta área, onde passaram a ser comparadas populações recrutadas consecutivamente, com critérios mais uniformes de inclusão e com registros clínicos detalhados. No entanto, as conclusões daí obtidas em relação aos desfechos estudados, não foram conclusivas, em virtude das múltiplas variáveis inseridas como diferentes técnicas cirúrgicas, sequenciamento e faixas etárias em que foram realizadas, tratamentos adjuvantes e 
profissionais diferentes. Posteriormente, o mesmo grupo publicou novos estudos em que avaliam e comparam os desfechos do tratamento realizados nesses pacientes com FLPU em posteriores avaliações realizadas aos 12 e 17 anos de idade, em que encontra consistência entre os achados reportados em ambos os relatos, assim reforçando a convicção de que avaliações precoces, usando os instrumentos adequados poderão servir de guia para auditagens internas e frequentes ${ }^{39-44}$.

O marco desempenhado por estas publicações foi identificado, embora com quase duas décadas de distância como o de servir para controle comparativo para outros estudos, em vários centros ou regiões ao redor do planeta. Iniciativas inspiradas pelo Eurocleft foram desenvolvidas em outras localizações como aquela patrocinada pelo American Cleft-Palate Craniofacial Association (ACPA) - o projeto Americleft ${ }^{45-}$ 50 - que estabeleceu metas ainda mais ambiciosas em seus objetivos, como avaliar objetivamente as vantagens do tratamento multidisciplinar e do custo econômico relacionando-o com os desfechos do mesmo. As normas editadas por este projeto estabeleceram critérios rígidos e claros para participação dos Centros que aderiram e, forneceu de forma bem precisa, as regras adotadas para o uso dos instrumentos de análise dos desfechos. Em outras regiões projetos têm avançado e algumas publicações já têm ocorrido com a mesma metodologia ou comparando os desfechos com os descritos pelas publicações do grupo Eurocleft, destacando os desenvolvidos na

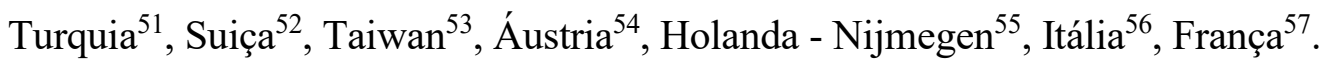

Também no Brasil foi publicado um artigo, em que foram comparados os resultados em 45 pacientes submetidos a tratamento de FLPU, no Instituto de Medicina Integral Prof. Fernando Figueira (IMIP) com os publicados anteriormente, pelo mesmo grupo acima citado ${ }^{58}$. No entanto tanto, Shaw et al. $^{39}$ quanto o Global Report ${ }^{3}$ 
constataram que devido à multiplicidade de protocolos e às inúmeras variáveis analisadas, tornam estes estudos, embora alguns deles extremamente bem delineados, de baixo valor preditivo, sendo no entanto importantes como instrumentos de auditagem e avaliação. O melhor exemplo do acima exposto, foi todo o processo decorrente do estudo desenvolvido pelo CSAG liderado por Jonathan R. Sandy, publicado em 200159-62 e que serviu de ponto de partida para que o Sistema de Saúde Pública do Reino Unido (NHS) alterasse a forma de atendimento aos pacientes com fissuras orofaciais, diminuindo o número de centros, de 57 em 1988 para 11 em 2011, capacitando-os com equipes multidisciplinares e restringindo a atuação a cirurgiões que executassem anualmente mais de 40 cirurgias primárias em fissuras orofaciais ${ }^{63}$. Estes estudos constataram uma melhoria dos serviços oferecidos e um aumento na produção cientifica nesta área de conhecimento.

Assim, tanto as conclusões dos artigos publicados por Roberts et al. ${ }^{28}$, Shaw et $a l .{ }^{38,39}$, Semb $^{64}$, Berkowitz ${ }^{65}$, Mossey et al. ${ }^{66}$ e outros, além das propostas peça Task Force da OMS, apontam a necessidade de serem realizados ensaios clínicos randomizados, para que se possam a partir daí estabelecer protocolos com níveis de evidencia clinica maiores, e que em decorrência possam oferecer condutas não só mais adequadas e com repercussões positivas nos desfechos do crescimento facial e desempenho fonoarticulatório, mas também minimizem os custos do tratamento e sociais, além de proporcionarem maior nível de satisfação aos pacientes e famílias ${ }^{38}$, independentemente da complexidade ou duração do tratamento. No entanto, há a necessidade do estabelecimento de tamanhos necessários às amostras populacionais que minimizassem erros nas conclusões obtidas, conforme o demonstrado por Moher et al. ${ }^{67}$ sugestivas de falsa efetividade. Neste mesmo estudo, publicado no Lancet os autores alertam para a 
qualidade metodológica das revisões sistemáticas de ensaios clínicos e o quanto essa falta de qualidade pode afetar em benefício da intervenção as conclusões então obtidas ${ }^{67}$.

A necessidade imperiosa de que a ciência tenha medições, parafraseando Lord Kelvin que "medir é conhecer" e "o que não pode ser medido, não pode ser melhorado", tem mobilizado vários pesquisadores e estruturas associativas ou acadêmicas para que fossem adotados medidores que tivessem confiabilidade e reprodutibilidade, além de serem objetivos e universais ${ }^{32}$.

Historicamente vários autores procuraram métodos, desde aqueles mais rudimentares em que se mediam faces normais ou "fissuradas"68 a outros mais consagrados como as análises cefalométricas, quer laterais quer anteriores, em que se pudessem identificar medidores para a avaliação de desfechos relativos ao crescimento da face em pacientes com FLP. No entanto estes e outros métodos adotados têm levantado, consecutivamente, várias objeções relacionadas à forma de coleta e confecção desses cefalogramas, assim como a multiplicidade de interpretações e os diferentes métodos de análise. Desta forma as eventuais conclusões e comparações tornam-se eivadas de vieses que leva a que estas pesquisas tenham pouca repercussão em virtude das questionáveis evidencias apresentadas, carecendo dos requisitos básicos de qualquer instrumento de pesquisa, isto é, reprodutibilidade, confiabilidade, objetividade e universalidade.

No final da década de 1980, pesquisadores de dois centros importantes no tratamento das fissuras labiopalatinas, Great Ormond Street, em Londres, Grã Bretanha, e o de Oslo na Noruega publicaram um estudo relatando sua experiência com um novo método de análise das relações interarco dentários, a que deram o nome de Goslon Yardstick $^{69}$. Este padrão proposto, vem na sequência de várias outras propostas 
anteriores, que apresentavam restrições importantes, principalmente de confiabilidade e reprodutibilidade e que vem conquistando adesões por todos aqueles que querem avaliar seus resultados e estabelecer comparações com outros centros especializados ${ }^{70-72}$.

Este método tem, além das características apontadas, a preocupação não só de referenciar as características anatômicas encontradas, mas a de correlacioná-las com a dificuldade da sua correção. A hierarquização dos achados anatômicos das relações intrerarcos dentários com a atribuição escalonada das suas perspectivas além de em cada um destes grupos, as características encontradas da mordida, relacionando sempre não de forma aleatória, mas pela dificuldade em tratar cada uma dessas situações ${ }^{69}$.

O fato deste método não ser apropriado para avaliações individuais, em virtude da forma grosseira, "coarse" no original, como algumas características são avaliadas, torna-o apropriado para avaliações interamostrais reduzindo a possibilidade de interpretações em relação a detalhes mais finos. Isto contribui para maior confiabilidade do método e da sua reprodutibilidade ${ }^{69}$.

Desde então múltiplas pesquisas têm sido realizadas usando o Goslon Yardstick dos quais a mais icônica é sem dúvida a desenvolvida pelo grupo do Eurocleft que tem vindo no decorrer dos anos a ser referenciada e usada como amostra comparativa para outras pesquisas ${ }^{43,48,51,53-55,73,74}$.

A necessidade de se detectar precocemente alterações referentes aos procedimentos cirúrgicos e seus efeitos, pesou na formulação de outros métodos de avaliação do crescimento maxilo-mandibular ${ }^{28}$. O método referido anteriormente, com índices preditores hoje comumente aceitos apresentava, no entanto, restrições relativas ao momento ideal para ser realizado em virtude de um grande número de pacientes ter já na altura da dentição mista, sido submetido a uma multiplicidade de 
tratamentos, que eventualmente aumentariam o grau de incerteza em relação aos desfechos obtidos.

Estudos conduzidos por Noverraz et $a .^{75}$, referiam a utilização do índice do Goslon Yardstick em diferentes faixas etárias e estágios de desenvolvimento dentofacial, com elevados graus de concordância inter e intraexaminadores o que consideravam, como susceptível de ser utilizado em estudos longitudinais de crescimento facial. Atack et $a l^{76,77}$ estabeleceram parâmetros seguros e credíveis em novo índice, Five Years Old Index (FYOI), que nos permite precocemente definir padrões de crescimento facial. Embora os autores criticassem o uso de imagens fotográficas para avaliação de resultados, em virtude de serem imagens bidimensionais documentando estruturas em três dimensões, o desenvolvimento tecnológico alcançado nas últimas décadas permitiu que, após o exame dos modelos físicos obtidos com sistemática defendida pelos autores acima citados, a introdução de imagens obtidas digitalmente pudesse ser considerada.

A partir dos estudos de Nolletet al ${ }^{78}$, onde avaliavam as imagens fotográficas de uma amostra obtida de forma rudimentar de modelos de estudo, foi verificada a confiabilidade do método fotográfico comparando-o, numa avaliação cega realizada por três ortodontistas, com os modelos físicos, e demonstrou ter alcançado graus de concordância elevados em ambos os métodos e entre os dois. Ali et al. ${ }^{79}$ e Liao et $a l .{ }^{80}$ enveredaram pelo mesmo roteiro de pesquisa tendo encontrado dados que comprovaram a confiabilidade do método fotográfico digital dos modelos em avaliações de pacientes com fissura labiopalatina unilaterais.No entanto, entre esses achados um dado ainda era questionável embora estatisticamente não significante - a sobre mordida difícil de avaliar por todo o painel de examinadores e essencial para 
uma definição entre os padrões 1 a 3 do Goslon Yardtsick, comprovado também por Maliket al.$^{81}$. Outros estudos mais recentes apresentando processos de digitalização e escaneamento, e que minimizam essa dificuldade, confirmaram esses achados, conferindo ao método altos níveis de confiabilidade e reprodutibilidade necessários para maior simplificação do processo ${ }^{78,81-83}$.

No entanto, embora o estudo da relação maxilo-mandibular forneça informações importantes, não só sob o ponto de vista preditivo, mas também o fato de analisar desfechos de uma amostra em relação a procedimentos terapêuticos posteriores não fornece informações importantes em relação à gravidade da malformação e sua evolução posterior relacionando-a com o protocolo cirúrgico adotado. Assim, a avaliação das medidas transversais e anteroposteriores nos modelos de estudo também pode dar respostas importantes às questões levantadas em alguns estudos que relacionam a severidade das fissuras à sua gravidade e posteriormente aos desfechos alcançados, após o tratamento. A metodologia para tomar as medidas transversais do arco dentário superior com avaliação das distancias intercranianas ( $\mathrm{C}$ e $\left.\mathrm{C}^{\prime}\right)$ e intermolares $\left(\mathrm{M}\right.$ e $\left.\mathrm{M}^{\prime}\right)$ foi usada por Mazaheri et al. ${ }^{84} \mathrm{a}$ metodologia para avaliação da relação dos segmentos fissurados e que foi utilizada nos estudos europeus do Dutchcleft, em $2003^{85}$.

Posteriormente, os recursos digitais disponíveis levam para esta dimensão a obtenção dessas medidas de forma bem mais simplificada, Dalstra e Melsen ${ }^{86}$ entre outros verificaram que os dados assim obtidos apresentavam uma variabilidade menor inter e intraexaminadores que os medidos nos modelos físicos. No entanto, dados levantados por Leifert et $a l .{ }^{87}$ questionam a concordância das medidas realizadas na maxila utilizando as medidas obtidas nos modelos físicos e virtuais, tendo encontrado 
diferença estatisticamente significante, embora salvaguardem os autores que seria uma diferença pequena e sem correlação clínica, o que não invalidaria o método. Também estas diferenças entre os vários estudos publicados podem estar relacionada com os softwares utilizados, pois alguns apresentavam maior dificuldade em realizar essa leitura ${ }^{79}$.

Estudos anteriores às publicações do Eurocleft ${ }^{63,29}$ apontavam que para ser realizado um ensaio clinico para analisar o tratamento e seus desfechos em fissuras labiopalatais, seriam necessários além de criação de banco de dados confiáveis e com formatos uniformes - com variáveis controláveis e que contemplem a heterogeneidade da deformidade - o uso de instrumentos de analise comuns e aceites pela comunidade terapêutica, a calibração adequada e sistemática quer dos instrumentos de analise quanto dos avaliadores, e a estandardização dos registros para que se torne viável financeiramente, principalmente em centros isolados. Objeções de ordem ética também foram levantados em virtude do possível uso de técnicas cirúrgicas que tragam um maior número de complicações, não tenham sido testadas de forma adequada ou que requeiram da parte do operador habilidades ou competências ainda não testadas, ou que necessitem de uma maior curva de aprendizado. Assim a irreversibilidade do ato cirúrgico requer o maior nível de evidencias quer em procedimentos já usados de forma continua quer daqueles que trazem inovação e mudança ${ }^{28}$. A participação de sujeitos num ensaio clinico pode trazer vantagens conforme o descrito por Stiller apud Roberts et al. ${ }^{28}$ disponibilizando novas terapêuticas mais efetivas ou trazendo um suporte assistencial inovador $^{88}$. No entanto, o maior obstáculo para o delineamento e execução de ensaios clínicos nesta área prende-se ao tamanho da amostra. Roberts et al. ${ }^{28}$ baseando-se em 
bancos de dados publicados por Bergland e o Oslo CLP Growth Archive estabelece números mínimos para o tamanho de amostra de ensaios clínicos que consigam estabelecer preditores de desfechos mais precoces exigindo menor número de participantes e diminuindo o tempo de seguimento.

O tamanho da amostra também foi abordado pelo Global Report ${ }^{3}$ onde mencionava cálculos baseados em estimativas então correntes que para avaliar condutas cirúrgicas num só subtipo de fissura não sindrômica - e delas a mais comum, a FLPU,-- seriam necessários dois grupos de 75 pacientes, o que levaria que pesquisar num universo de um milhão de nascimentos assumindo a prevalência de 1,5:1000 nascido-vivos com a adesão de $75 \%$ aos critérios de inclusão e exclusão e cumprimento de $90 \%$ ao Termo de Consentimento Livre e Esclarecido (TCLE). No entanto, com os trabalhos desenvolvidos pelo grupo Eurocleft e as conclusões publicadas por Shaw et al. ${ }^{38}$ demonstraram que para avalição do crescimento facial de forma precoce e seus efeitos preditivos como descreveu Mars et al. ${ }^{69}$ seria necessária um tamanho de amostra menor que outras propostas anteriormente, mesmo que este grupo apresente considerável variação entre os casos. A avaliação da relação das arcadas dentárias - Goslon Yardstick- foi o método encontrado que proporcionou essa possibilidade ${ }^{69}$. Meio ponto na escala de Goslon foi a amplitude da diferença entre os centros que se colocavam entre o topo e o meio da classificação e entre os centros classificados entre o meio e a parte inferior da tabela na coorte, avaliada aos nove anos de idade. Isso equivale a uma diferença de $20 \%$ na taxa de osteotomia da maxila, entre esses centros. Com $5 \%$ de probabilidade e desvio padrão de 0,8 e poder de $80 \%$, a detecção da diferença de 0,5 pontos na escala de Goslon intercentros na idade de nove anos requer amostras com as seguintes dimensões: 42 
casos de FLPU necessários em uma comparação de dois grupos, 63 necessários em uma comparação de um grupo de cinco em relação a uma referência, e 77 exigido em um grupo de seis para comparação mútua ${ }^{38}$. Os mesmos autores continuaram o follow up dessa amostra até aos 17 anos de idade e constaram a manutenção dos achados anteriores e a manutenção das posições relativas dos centros estudados ${ }^{39}$.

Assim além de organizar e executar ensaios clínicos na área de tratamento cirúrgico - e não só no dos pacientes FLPU - mas também aqueles relacionados aos tratamentos adjuvantes nas áreas de cuidados odontológicos, fonoaudiólogos, otológicos, e sobre o impacto psicológico, social e econômico da deformidade e seu tratamento, a concretização de estudos colaborativos intercentros, além do estabelecimento de registros mais completos e uniformes são outras metas a serem perseguidas nesta área.

Conforme o descrito anteriormente, os protocolos adotados para o tratamento cirúrgico primário em pacientes com fissuras labiopalatais, visando simultaneamente, o desenvolvimento adequado da voz e crescimento harmônico do esqueleto maxilofacial, são geradores de polemica ${ }^{89}$. A frequência na ocorrência de vários tipos de complicações entre as quais fistulas oronasais (FON), insuficiência velofaríngea (IVF) e a hipoplasia maxilar pode mostrar o desempenho de cada Centro ${ }^{90}$ embora tenham relação também com múltiplos fatores em que podemos destacar a severidade das fissuras, técnicas ${\text { cirúrgicas } \text { adotadas }^{91} \text {, idade e sequenciamentos cirúrgicos, proficiência do cirurgião }}^{92}$ entre algumas outras, mas parece claro que a correção cirúrgica da fissura é fator determinante na evolução da morfologia facial.

Múltiplos centros especializados no tratamento desses pacientes têm estudado os resultados do trauma cirúrgico no crescimento da face, principalmente no terço 
médio, e sua influência negativa no crescimento da maxila, evitando uma redução da largura e do comprimento dos arcos dentários ${ }^{50,66,69,70-72}$.

O crescimento da face e, mais especificamente, o do seu terço médio, correlaciona-se com múltiplos fatores e a compreensão da forma como eles atuam, pode fornecer informações que direcionem para protocolos de tratamento menos lesivos ao processo de crescimento. Os movimentos em que o crescimento facial se dá e a sua cronologia são decisivas para estabelecer estratégias de tratamento que procurem minimizar o impacto da manipulação cirúrgica. Os movimentos de migração e rotação anterior que se dão até em torno dos quatro anos de idade ${ }^{93}$, são influenciados pelo crescimento do osso frontal, da capsula e septo nasais o primeiro e a deposição óssea na região pterigopalatina no segundo ${ }^{93}$. Também o crescimento vertical que é mais intenso no decorrer dos primeiros quatro anos de vida e é influenciado pelo crescimento da orbita, dos globos oculares e do septo nasal. Após essa idade o crescimento da maxila se dá por aposição óssea na região posterior à tuberosidade pterigopalatina e reabsorção nos assoalhos nasal e orbitários e a pneumatização dos seios maxilares, assim como o surgimento dos germes dentários que estimulam a deposição óssea na região anterior da maxila. O crescimento na região da premaxila é influenciado pelo crescimento dento-alveolar e pelo septo cartilaginoso ${ }^{94,95}$ e suas conexões ligamentares à musculatura perioral, embora autores como Bergland et al. ${ }^{96} \mathrm{e}$ outros $^{97-99}$ minimizem a importância da ação dessa estrutura no crescimento da maxila. A compressão e tensão exercidas sobre as estruturas osteocartilaginosas exercidas de forma moderada estimulam o seu crescimento enquanto que de forma excessiva ocasionam efeito negativo. Também deverá ser considerada a influência exercida sobre a unidade esquelética dentoalveolar (periósteo e ligamento dentoalveolar), por 
estruturas anatômicas como dente oposto, língua, bochechas, lábios, que afeta o crescimento das estruturas ósseas da face.

O conhecimento da natureza da patogenia dos defeitos iniciais e das sequelas pós-cirúrgicas é fundamental para a sua correção, conforme postulam Delaire e Precious $^{93}$, e é indispensável para uma reflexão sobre os procedimentos adotados pelo cirurgião, e posterior tomada de posição sobre o protocolo de tratamento. $\mathrm{O}$ crescimento da face no indivíduo com fissura labiopalatina é dependente de três grupos de fatores hereditários, aqueles intrínsecos à patologia e que se relacionam principalmente à maxila, teratogênicos (funcionais), originados no período pré-natal e adquiridos (iatrogênicos), fruto de intervenções para correção da deformidade ${ }^{33,92}$ que atuam de forma conjugada, como o ilustrado por Ross ${ }^{33}$, mostrando a influência da língua após a correção da fissura palatina, sobre o crescimento e posicionamento da mandíbula, e alterando assim as proporções faciais ${ }^{33}$.

Embora a estrutura esquelética mais afetada pela ação conjunta dos fatores acima enunciados, seja a maxila, outros segmentos do esqueleto facial são afetados como a mandíbula, orbita e até a sela túrcica, como Ross ${ }^{33}$ encontraram, em analises cefalométricas de várias amostras em sujeitos submetidos a diferentes protocolos de tratamento. A caracterização da cleft face termo conceituado por Krauss e Polaczek ${ }^{68}$ e citado por Farkas et al. ${ }^{100}$, deverá ser avaliada tendo em conta:

1) O ângulo do osso nasal.

2) As dimensões e área maxilar.

3) A posição mandibular.

4) A altura do andar inferior da face.

5) A relação anteroposterior maxilo-mandibular. 
Secundariamente e em menor proporção deverão ser observados ${ }^{33}$ :

1) A altura da maxila e posicionamento posterior.

2) A posição da crista maxilar e orbita.

3) O tamanho da mandíbula e mento.

4) A sela turca.

Já em 1954, Slaughter e Pruzansky ${ }^{101}$, publicaram um estudo que reportavam a existência de alterações morfológicas em pacientes com FLP, mesmo quando inoperados, com diminuição nas dimensões verticais, anterior e posterior, e das dimensões anteroposteriores da maxila e que foram encontradas por outros autores ${ }^{102-108}$ Estas dismorfias levam a uma mudança de posição da mandíbula e assim alteram as proporções faciais. Outros como Will ${ }^{108}$, Mars e Houston ${ }^{109}$, Capelozza et al. ${ }^{110}$ e Shetye e Evans ${ }^{111}$ publicaram estudos evidenciando que sujeitos com fissura labiopalatina inoperados apresentavam um crescimento facial melhor que aqueles sujeitos a tratamento cirúrgico, o que Ross ${ }^{33}$ interpretava como manutenção do potencial de crescimento que permaneceria inalterado nesses pacientes.

O crescimento maxilar afetado, após a queiloplastia foi encontrado por vários autores como no trabalho de Ye et al. ${ }^{92}$ que comparou uma coorte de pacientes inoperados e outra de pacientes submetidos somente a cirurgia corretiva do lábio, tendo encontrado diferença estatisticamente significante com prejuízo no crescimento facial. Os trabalhos de Capelozzaet al. ${ }^{112}$ e Li et al. ${ }^{113}$ encontraram semelhanças no crescimento da maxila em pacientes operados só da FL e também da FLP o que os levou a concluir que a cirurgia reparadora do lábio ai interferiria negativamente. Ross ${ }^{33}$ sustenta que as alterações encontradas em pacientes operados somente de queiloplastia com colapso do arco dentário pode ser devido ao aumento 
importante da pressão da cinta muscular reconstruída. No entanto, Ye et al. ${ }^{92}$ levantam a hipótese que esse achado pode ter sido ocasionado pela displasia maxilar intrínseca (fatores hereditários e teratogênicos) à malformação. Autores como Ross ${ }^{33}$, Yoshida et al. ${ }^{103}$, Isiekwe e Sowemimo ${ }^{104}$ e Liao e Mars ${ }^{114}$, consideram que a cirurgia do lábio tem um impacto mínimo no crescimento maxilar, podendo haver alterações na inclinação dos incisivos mas não repercutindo no osso basal.

Estudos de Herfert ${ }^{115}$ realizados na primeira metade do século passado e citados pelo autor em seu artigo de 1963, constatavam alterações esqueléticas importantes na maxila em pacientes operados de palatoplastia, fato que não ocorria em pacientes com FLPU só operados de queiloplastia. A presença de tecido cicatricial nas regiões gengivais poderia explicar este achado ${ }^{33}$. Também a presença de tecido cicatricial na região posterior à tuberosidade pterigopalatina, interferindo na aposição óssea, assim como nas regiões dentoalveolares poderão interferir na erupção vertical dentária - o que explica a ocorrência de palatização dentaria - e provocar alteração do crescimento da face.

A hipótese levantada que o crescimento facial estaria relacionado à severidade da deformidade é defendida por Yoshida et al. ${ }^{103}$ e Schultes et al. ${ }^{116}$, que avaliaram os resultados relativos ao crescimento facial entre series de sujeitos com fissuras labiais e labiopalatinas. Peltomaki et al. ${ }^{117}$, Honda et al. ${ }^{118}$ e Chiu et al. ${ }^{119}$ comparam o crescimento facial entre sujeitos com FLP, submetidos a um mesmo protocolo de tratamento e encontram diferenças relacionadas à gravidade da malformação. Estes achados são, no entanto, contrariados por outras pesquisas desenvolvidas por Johnson et al. ${ }^{120} \mathrm{e}$ Wiggman et al. ${ }^{121}$, que não encontram evidencias dessa correlação entre gravidade da malformação e o crescimento 
maxilar. Esta autora atribui as diferenças encontradas aos diferentes tipos de acompanhamento longitudinal dos grupos estudados e a diferentes métodos de análise empregados.

Em pesquisa de Wiggman et al. ${ }^{121}$ que reuniu os grupos de Estocolmo e Oslo aponta que provavelmente o protocolo de tratamento seja crucial no processo de crescimento facial dos pacientes com FLP, submetidos ao processo de reabilitação, o que Ladeira e Alonso ${ }^{122}$ em revisão sistemática publicada em 2012, também postulam.

Diferentes protocolos têm sido propostos para determinar a melhor idade para a realização da palatoplastia visando resultados positivos em relação ao crescimento do terço médio da face e, consequentemente, um menor prejuízo estético e funcional. A partir dos estudos pioneiros de Herfert ${ }^{115}$ e Graber $^{123}$, que apontavam de forma inequívoca a influência deletéria da cirurgia corretiva da fissura palatina sobre o crescimento da maxila ${ }^{124}$ inúmeros artigos tem sido publicados se debruçando sobre este assunto. Desde a publicação do estudo de Gillies e Frye ${ }^{125}$ que demonstrou a importância do sequenciamento cirúrgico na obtenção dos desfechos relacionados ao crescimento facial, fala, mastigação e respiração, ficou evidenciado que o uso de protocolos que diferissem o fechamento do palato duro para oportunidade mais tardia ou inclusive propondo o uso de próteses obturadoras, traria vantagens evidentes para o tratamento dos pacientes com FLP. O protocolo cirúrgico ideal será aquele que restaure proficientemente as funções de fala, mastigação, respiração e estética, enquanto que preserva o potencial de crescimento da área envolvida ${ }^{126}$.

Assim a técnica cirúrgica escolhida deve ter como objetivos providenciar um palato mole que feche o espaço velofaringeo, atendendo aos requisitos de 
mobilidade, tamanho, responsividade e posição não interferindo com a respiração, além de separar adequadamente as cavidades nasal e oral e interferir minimamente no processo de crescimento facial. Para se adequar a esses fins deverá se pautar pelos seguintes critérios ${ }^{20}$ :

1) Perda mínima de tecidos.

2) Descolamentos mínimos.

3) Mínimas áreas cicatriciais.

4) Mínimo prejuízo ao potencial de crescimento da face.

5) Mínima exposição óssea.

6) Boa repercussão na fala deglutição e respiração.

7) Proteção ao tubo de Eustáquio.

Os trabalhos de Ross $^{33}$ foram decisivos na abordagem sistemática da influência das variáveis que interferem no crescimento facial em pacientes com FLPU. Foram avaliados por meio de estudos cefalométricos, 538 sujeitos em 16 amostras com critérios de inclusão em que se procurava minimizar diferenças de gênero e morfológicas que poderiam induzir confundimento na análise dos desfechos. Deve ser ressalvado que embora neste estudo não tivesse sido possível controlar algumas variáveis - tamanho das amostras, diferenças étnicas, técnicas radiográficas, diferenças etárias, tratamentos prestados, ele pode concluir que a palatoplastia induz uma menor translação anterior da maxila, diminuição da protrusão alvéolo dentaria, crescimento basal da maxila (leve) assim como diminuição da altura posterior da maxila.

Blocksma et $a l .{ }^{20}$ e Delaire et al. ${ }^{93}$, baseados nestas premissas sustentam que devem ser evitados descolamentos do vômer, desnudar o palato duro para obter alongamento do palato, evitar a exposição simultânea das mucosas oral e nasal assim 
como priorizar os resultados imediatos aos desfechos tardios a serem obtidos. Deve obedecer aos princípios básicos da boa cicatrização, fazer pequenas incisões liberadoras e evitar cirurgias ósseas antes dos cinco anos. No entanto, Semb ${ }^{127}$ contesta este ponto de vista ao analisar precocemente o crescimento facial em pacientes submetidos a palatoplastia com retalho vomeriano, apontando os excelentes resultados encontrados nas suas amostras.

Desde o já mencionado trabalho de Gillies e Frye ${ }^{125}$ que mostrava um menor prejuízo no crescimento facial, substituindo o fechamento do palato duro por placa obturadora, autores como Blocksma et $a .^{20}$, Slaughter e Pruzansky ${ }^{101}$, Schweckendiek et al. ${ }^{128}$, Hotze e Gnoinski ${ }^{129}$ e Friede et al. ${ }^{130}$ insatisfeitos com os resultados obtidos por protocolos tradicionais advogaram a postergação do fechamento do palato duro para idade mais tardia.

O conceito da palatoplastia em dois estágios, com múltiplas variações, tem sido utilizado em Centros na Europa - Shaw et al. ${ }^{40}$ referenciam cerca de 1/3 dos centros europeus - ou nos EUA, desde $1921^{125}$ até os dias atuais ${ }^{89,}$, 130-132 e com diferentes idades e técnicas usadas, que podem explicar a variabilidade dos desfechos encontrados.

A idade da execução da veloplastia difere entre os vários autores desde os três meses de idade ${ }^{28}$, como Robertson e Jolleys ${ }^{133}$, Tanino et al. ${ }^{134}$, Rohrich et al. ${ }^{135}$. Outros autores preferem alargar esse prazo até 24 meses, como Dingman e Grabb ${ }^{136}$, Blocksma et al. ${ }^{137}$, Gaggl et al. ${ }^{138}$, podendo ser realizada isoladamente ou concomitantemente com a queiloplastia ${ }^{89,130,132}$.

O fechamento do palato duro em diferentes faixas etárias também tem tido cronologias diferentes desde que Schweckendiek e Doz ${ }^{128}$ propuseram a realização da cirurgia somente depois dos 16 anos de idade, altura em que não interferiria mais 
no crescimento da maxila. Nos últimos vinte anos alguns protocolos vêm postergando o fechamento do palato duro (palatoplastia anterior) para a idade da dentadura mista (oito a nove anos) e, as variações do fechamento do palato anterior de seis $\operatorname{meses}^{139}$ a mais de 16 anos ${ }^{128,140,141}$. O grupo de Gotemburgo que originalmente $^{130}$ propunha a realização desta cirurgia entre os oito e nove anos de idade, propõe atualmente ${ }^{142}$ que seja realizada em torno dos três anos, afim de minimizar a repercussão sobre o desempenho fonoarticulatório.

As técnicas usadas para realizar a veloplastia também têm sido citadas como responsáveis pelos diferentes desfechos encontrados entre as amostras, relacionados não só ao crescimento da face mas também com a voz e fala ${ }^{89}$. A conduta proposta por Schweckendiek e $\operatorname{Doz}^{128}$ para fechamento do palato mole não previa incisões entre este e o palato duro e não realizava dissecções da musculatura do véu palatino, o que pode ter contribuído para os desfechos relatados - crescimento adequado da maxila e resultados fonarticulatórios pobres. Desde os trabalhos de Kriens ${ }^{143}$ e Braithwaite e Maurice ${ }^{144}$ que propuseram a liberação muscular do rebordo posterior do palato duro e sua transposição para a linha média, formando assim uma cinta muscular, aos trabalhos de Sommerlad ${ }^{145,146}$ e Dissaux et al. ${ }^{73}$ que a maior parte dos autores incorporaram essa conduta aos seus procedimentos de veloplastia. Para a concretização desse objetivo Rohrich et al. ${ }^{147}$ realizaram descolamentos submucosos, enquanto que outros escolheram realizar retalhos locais e/ ou incisões na transição entre o palato duro e mole $34,133,138,148-151$ para o reparo da mucosa nasal, sugeriram o uso de retalhos de vômer deslocados posteriormente. A presença de tecido cicatricial, notadamente quando subsequente ao desnudamento ósseo proposto em algumas destas técnicas poderá segundo Friede ${ }^{89}$, ser responsável pela deficiência maxilar, e 
eventualmente maior que as cicatrizes junto ao rebordo alveolar subsequentes a alguns procedimentos destinados ao fechamento do palato duro ${ }^{138}$. Alguns autores referem que, ao evitar o trauma cirúrgico precoce no palato duro, há uma redução da formação da fibrose cicatricial e do descolamento mucoperiostal - efeitos da palatoplastia que promovem os distúrbios dos centros de crescimento na região, restringindo o crescimento ósseo da maxila ${ }^{132,152}$.

Já as técnicas usadas para o fechamento do palato duro abrangem desde os procedimentos mais usados e clássicos usados, em palatoplastias completas, Veau $^{68,73,153,154}$, Wardhill ${ }^{153}$, Langenbeck ${ }^{155}$ e a outros procedimentos como retalhos do vômer ${ }^{139,147}$, retalhos bipediculados da fibromucosa palatina de $\operatorname{Bardach}^{156}$ ou mais estreitos, adjacentes a fissura, uni ou bilaterais evitando assim, grandes descolamentos.

Friede et al. ${ }^{157}$ advogam o uso de retalhos palatinos com amplo descolamento até à arcada dentaria evitando assim em muitos casos incisões liberadoras laterais e reportando maior facilidade no fechamento da camada nasal. Outros autores também observaram que a ocorrência de fistulas oronasais é menor neste procedimento que com o uso de retalhos vomerianos ${ }^{158,139,142,147}$.

Em 1984, Witzel et al. ${ }^{159}$ discordaram do fechamento do palato em dois tempos, afirmando que geralmente este fechamento tardio resultava em graves problemas de fala e que não havia resultados convincentes relativos a um melhor crescimento maxilar, decorrentes de avaliações a longo prazo em trabalhos bem controlados. O Oxford Cleft Palate Study ${ }^{135,147,160}$ chegou a conclusões semelhantes, levando a alteração do protocolo com antecipação do fechamento do palato duro entre os 15 e 18 meses de idade. Holland et al. ${ }^{141}$ em artigo comparando dois grupos 
estudados em Pittsburgh encontrou desfechos fonoarticulatórios notadamente piores naquele que fechava tardiamente o palato duro. Em contraponto, Van Demark et al. ${ }^{161}$ analisando os desfechos fonoarticulatórios do grupo de pacientes do centro de Zurich mostraram que após o tratamento com fechamento em dois tempos e palatoplastia anterior tardia apresentavam uma boa harmonia entre crescimento facial e desempenho fonoarticulatório.

Em 1994, foi iniciado em Gotemburgo um novo protocolo, com a palatoplastia posterior até seis a oito meses e a palatoplastia anterior, hoje em torno dos três anos, com o intuito de diminuir o prejuízo na fala, mas ainda é cedo para determinar o efeito a longo prazo nesta modificação de protocolo ${ }^{66,71}$, mas existem bons indícios que após tratamento fonoaudiológico adequado os desfechos obtidos sejam positivos $^{162}$.

Os resultados destes estudos vêm continuamente sendo analisados e indicam um bom crescimento do terço médio da face (mantida na idade adulta), com um discreto prejuízo na articulação de alguns fonemas, que são corrigidos com acompanhamento foniátrico após o fechamento definitivo da fissura do palato duro $^{71,85,90}$. Em trabalho publicado em 2011, por Lohmanderet al. ${ }^{163}$, os autores relataram uma alta prevalência (em torno de $87 \%$ ) de competência velofaríngea e ausência de distúrbios articulatórios nos pacientes, mesmo nos pacientes que em torno dos cinco anos de idade apresentavam algum distúrbio fonoarticulatório, o que se assemelhava aos desfechos relatados com o fechamento precoce do palato. A adesão aos tratamentos e procedimentos ancilares garantiram excelência aos desfechos obtidos por este grupo de sujeitos submetidos ao fechamento tardio do palato duro (FTPD). 
Vários autores afirmam que aos 48 meses a cirurgia de fechamento do palato duro pode ser realizada, sem promover sequelas sobre o crescimento facial e com menores prejuízos para a fala ${ }^{164}$. O fechamento mecânico e funcional do palato quando da idade de aprendizado da fala permite a articulação correta dos sons, evita o aparecimento de articulações compensatórias, mímicas faciais e escapes nasais, e favorece um desenvolvimento foniátrico normal ${ }^{69}$.

O estudo científico dos resultados obtidos nos pacientes com FLPU é dificultado pelo longo tempo de seguimento necessário e pela complexidade de fatores que interagem durante as fases de desenvolvimento e crescimento destas crianças até que atinjam a idade adulta ${ }^{66}$.

No IMIP - Recife-PE, o Centro de Atenção aos Defeitos da Face do IMIP (CADEFI) que é um centro de referência de alta complexidade para o tratamento de portadores de fissura pertencente à Rede de Referência no Tratamento de Deformidades Craniofaciais do Ministério da Saúde (RRTDCF). Entre 2002 e 2005 foram atendidos 584 novos pacientes -com fissura labiopalatina, sendo que cerca de $50 \%$ destes pacientes foram atendidos pela primeira vez antes do primeiro ano de vida ${ }^{35}$. Em 2007, foi realizada uma avaliação dos seus resultados para o crescimento maxilo-mandibular, usando o índice FYOI para um protocolo cirúrgico primário de palatoplastia em tempo único. Os resultados obtidos indicaram 44,4\% dos escores nos grupos 1 e 2, favoráveis ao crescimento maxilofacial e uma média geral entre os escores de2,62 $(\mathrm{dp}=0,98)^{58}$.

Na perspectiva de introduzir mudanças no protocolo cirúrgico da palatoplastia no CADEFI, esta pesquisa visa comparar os efeitos de dois protocolos cirúrgicos primários para palatoplastia, em um e em dois tempos cirúrgicos, sobre o complexo maxilo-mandibular de pacientes com fissura labiopalatina unilateral completa. 


\subsection{Justificativa}

O tratamento dos pacientes com fissura labiopalatina oferece desafios contínuos para a equipe multidisciplinar. A interação entre as diferentes especialidades tem como objetivo reabilitar e integrar o indivíduo com FLP no seu contexto social, proporcionando desenvolvimento saudável do ponto de vista físico e psíquico, sem disfunções auditivas ou de fala e que, do ponto de vista estético, se aproxime ao máximo da população não portadora de fissura.

A discrepância maxilo-mandibular é uma das sequelas mais indesejadas decorrentes do tratamento cirúrgico realizado em pacientes com FLPU, pois além de acarretar deformidade estética, causa problemas respiratórios e de oclusão dentária, exigindo tratamento ortodôntico prolongado e, necessitando muitas vezes, de osteotomias para avanço maxilar. A retrusão maxilar acentuada, decorrente da fibrose cicatricial, frequentemente limita os resultados cirúrgicos obtidos, tornandose causa de recidivas a longo prazo, neste tipo de procedimentos, sendo a palatoplastia um dos fatores mais importantes na sua ocorrência.

Considerando as consequências da palatoplastia primária para o crescimento maxilo-mandibular, a busca por protocolos cirúrgicos capazes de minimizar os seus efeitos negativos é de capital importância para a reabilitação do paciente com FLPU completa, diminuindo a complexidade e a duração do tratamento integral, o que justifica a realização do presente estudo. 


\subsection{Hipótese}

A palatoplastia realizada em dois tempos cirúrgicos, com a veloplastia realizada entre os seis e nove meses e o fechamento do palato duro entre 36 e 48 meses de vida, favorece uma melhor relação entre os arcos dentários maxilar e mandibular no estágio final da dentadura decídua, em crianças com FLPU completa. 
2 OBJetivos 


\subsection{Objetivo Geral}

Comparar os efeitos da palatoplastia primária sobre o complexo maxilomandibular dos pacientes com fissura labiopalatina unilateral completa, operados no CADEFI.

\subsection{Objetivo Específicos}

a) Comparar os efeitos de dois protocolos cirúrgicos para palatoplastia, um em tempo único e outro em dois tempos cirúrgicos, por meio da avaliação da relação entre os arcos dentários maxilar e mandibular, em modelos de estudo obtidos no final da dentadura decídua, utilizando-se o Índice FYOI.

b) Verificar se existe correlação entre a largura/amplitude da fissura não operada e o resultado das avaliações utilizando o índice FYOI em ambos os protocolos cirúrgicos.

c) Para cada protocolo cirúrgico, verificar se existe diferença significante entre as medidas transversas e longitudinais do palato das crianças no final da dentadura decídua.

d) Comparar a frequência de complicações pós-cirúrgicas que afetam a morfologia das estruturas envolvidas nos dois protocolos cirúrgicos. 
3 MÉtodos 


\subsection{Desenho do Estudo}

Trata-se de um estudo do tipo ensaio clínico randomizado, controlado e cego.

\subsection{Local do Estudo}

O estudo foi realizado no Instituto de Medicina Integral Prof. Fernando Figueira, hospital que atende pacientes do Sistema Único de Saúde (SUS), localizado na cidade de Recife, PE - Brasil. Os pacientes foram recrutados no Centro de Atenção aos Defeitos da Face do IMIP, que integra a Rede de Referência no Tratamento de Deformidades Craniofaciais do Ministério da Saúde do Brasil.

O CADEFI possui páginas na internet ${ }^{\ddagger}$. A intervenção foi realizada nos Blocos Cirúrgicos do Hospital Geral de Pediatria do IMIP e do Real Hospital Português de Recife e o acompanhamento ambulatorial dos pacientes nas instalações do CADEFI.

\subsection{Período do Estudo}

O estudo foi realizado no período compreendido entre janeiro de 2010 e outubro de 2016. A coleta de dados ocorreu no período compreendido entre janeiro de 2010 e junho de 2016.

* Disponíveis em: <http://www1.imip.org.br/imip/assistenciaesaude/diagnosticoeterapia/cadefi. html > e $<$ https://www.facebook.com/IMIP-Cadefi-389783491171630/>. 


\subsection{População do Estudo}

A população do estudo foi constituída por todos os pacientes com fissura labiopalatina unilateral completa, na idade pretendida pelo estudo, inscritos no CADEFI.

\subsection{Amostra}

\subsubsection{Amostragem}

Todos os responsáveis legais pelos pacientes que seriam submetidos às cirurgias primárias (queiloplastia e palatoplastia) no período de estudo foram convidados a participar do mesmo durante o atendimento ambulatorial. Todos os pacientes que preencheram os critérios de elegibilidade e cujos genitores concordaram em participar fizeram parte da amostra.

\subsubsection{Tamanho Amostral}

O cálculo do tamanho amostral foi realizado no programa Stata 12.1 considerando o poder do teste de $80 \%$, com uma significância de $5 \%$ e intervalo de confiança de $75 \%$ determinado com uma diferença de no mínimo $25 \%$ entre os dois grupos. A amostra foi calculada para a variável dependente comumente presente no paciente com fissura labiopalatina completa unilateral: a discrepância transversal e anteroposterior dos arcos dentários.

O resultado foi um tamanho amostral igual a 64 pacientes, 32 para o Grupo intervenção (GI) e 32 para o Grupo controle (GC). 


\subsection{Critérios e Procedimentos para Seleção dos Participantes}

Foram avaliados para inclusão todos os pacientes do CADEFI com indicação para tratamento da fissura labiopalatina unilateral completa durante o período do estudo até obtenção da amostra necessária.

Setenta e sete crianças foram avaliadas para elegibilidade, das quais sete foram excluídas por falta de cooperação e inobservância ao protocolo de tratamento, cinco abandonaram o tratamento e uma foi a óbito por razões não relacionadas à malformação em estudo. Foram então randomizados 64 para formar dois grupos de 32 participantes: GI e GC. Após a randomização, dois pacientes do GC abandonaram o tratamento.

\subsubsection{Critérios de inclusão}

- Presença de FLPU completa em Crianças matriculadas no CADEFI para a realização das cirurgias primárias (queiloplastia e palatoplastia) de forma sequencial.

- Crianças com idade inferior a seis meses quando do primeiro registro no CADEFI.

- Presença de queiloplastia realizada no CADEFI, pelo autor do estudo, em crianças com fissura labiopalatina completa e idade variando de três a seis meses.

\subsubsection{Critérios de exclusão}

- Presença de síndromes associadas que retardam o desenvolvimento neuropsicomotor e a fala.

- Pacientes sem condições clínicas para a realização da cronologia cirúrgica proposta. 
- Pacientes, cujos pais ou responsáveis não estejam de acordo com o TLC proposto pelo pesquisador.

- Pacientes que embora tenham sido eleitos para o tratamento cirúrgico da fissura labiopalatina, abandonaram o tratamento, após a queiloplastia e antes da randomização.

\subsection{Variáveis de Análise}

\subsubsection{Variáveis independentes estudadas}

- Palatoplastia em um tempo cirúrgico.

- Palatoplastia em dois tempos cirúrgicos.

\subsubsection{Variáveis dependentes}

- Ocorrência de fistula oronasal.

- Ocorrência de deiscência.

- Ocorrência de necrose.

- Distância intercaninos.

- Distância intermolares.

- Comprimento do arco dentário maxilar.

- Relação maxilo-mandibular na dentadura decídua. 


\subsubsection{Variáveis Confundidoras}

- Presença de Banda cutânea.

- Largura/amplitude inicial da fissura.

\subsection{Definição e Operacionalização dos Termos, Critérios e Variáveis}

As definições e operacionalização dos termos, critérios e variáveis encontramse nos Quadros de 1 a 5.

\section{Quadro 1 - Variáveis independentes}

\begin{tabular}{|c|c|c|}
\hline Variável & Definição operacional & Categorização \\
\hline $\begin{array}{l}\text { Palatoplastia em um } \\
\text { tempo cirúrgico }\end{array}$ & $\begin{array}{l}\text { Palatoplastia realizada em estágio único (palato duro e } \\
\text { mole) entre } 9 \text { e } 15 \text { meses de vida pela técnica de } \\
\text { Langenbeck/Kriens/Braithwaite, com as modificações } \\
\text { propostas por Sommerlad para o tratamento cirúrgico do } \\
\text { palato mole. }\end{array}$ & $\begin{array}{l}\text { Variável nominal dicotômica: } \\
\text { 1) Sim } \\
\text { 2) Não }\end{array}$ \\
\hline $\begin{array}{l}\text { Palatoplastia em dois } \\
\text { tempos cirúrgicos }\end{array}$ & $\begin{array}{l}\text { Palatoplastia realizada em dois estágios (baseado em } \\
\text { protocolo de palatoplastia modificado em dois estágios de } \\
\text { Göteborg): } \\
\text { - } \quad \text { Palatoplastia posterior (Veloplastia) realizada entre os } \\
6 \text { e } 9 \text { meses de idade, com o reposicionamento da } \\
\text { musculatura do véu palatino (veloplastia intravelar } \\
\text { estendida) } \\
\text { - Palatoplastia anterior (palato duro) realizada entre } 36 \text { e } \\
48 \text { meses de vida, pela técnica de simples adesão ou de } \\
\text { Langenbeck. }\end{array}$ & $\begin{array}{l}\text { Variável nominal dicotômica: } \\
\text { 1) Sim } \\
\text { 2) Não }\end{array}$ \\
\hline
\end{tabular}




\section{Quadro 2 - Variáveis dependentes}

\begin{tabular}{|c|c|c|}
\hline Variável & Definição operacional & Categorização \\
\hline $\begin{array}{l}\text { Presença de infecção } \\
\text { pós-operatória }\end{array}$ & $\begin{array}{l}\text { Ocorrência de processo infeccioso local ou sistêmico no } \\
\text { pós-operatório imediato }\end{array}$ & $\begin{array}{l}\text { Variável nominal dicotômica: } \\
\text { 1) Sim } \\
\text { 2) Não }\end{array}$ \\
\hline Fístula oronasal & $\begin{array}{l}\text { Presença de fístula oronasal tipo II, III ou IV da } \\
\text { classificação de Pittsburg }{ }^{165} \text { verificada no retorno pós- } \\
\text { operatório de } 1 \text { mês e por registro fotográfico. } \\
\begin{array}{|l}\text { Classificação de Pittsburg } \\
\text { Tipo I: Úvula } \\
\text { Tipo II: Palato mole } \\
\text { Tipo III: Junção de palato mole e duro } \\
\text { Tipo IV: Palato duro } \\
\text { Tipo V: Junção de palato primário e secundário } \\
\text { Tipo VI: Lingual-alveolar } \\
\text { Tipo VII: Lábio-alveolar }\end{array}\end{array}$ & $\begin{array}{l}\text { Variável nominal dicotômica: } \\
\text { 1) Sim } \\
\text { 2) Não }\end{array}$ \\
\hline \multicolumn{3}{|l|}{ Deiscência } \\
\hline \multicolumn{3}{|l|}{ Necrose } \\
\hline $\begin{array}{l}\text { Distância Intercanina } \\
\text { (DC) }\end{array}$ & $\begin{array}{l}\text { Corresponde à distância entre os pontos } \mathrm{C} \text { e C', localizados } \\
\text { no ápice das cúspides dos caninos decíduos, em ambos os } \\
\text { lados do arco dentário, aferida nos modelos de gesso } \\
\text { obtidos dos pacientes após palatoplastia, entre os } 48 \text { e } 60 \\
\text { meses de idade. }\end{array}$ & $\begin{array}{l}\text { Variável quantitativa continua } \\
\text { expressa em milímetros }\end{array}$ \\
\hline $\begin{array}{l}\text { Distância } \\
\text { intermolares (DM) }\end{array}$ & $\begin{array}{l}\text { Corresponde à distância entre os pontos M e M', } \\
\text { localizados no ápice das cúspides palatinas anteriores dos } \\
\text { segundos molares decíduos, aferida nos modelos de gesso } \\
\text { obtidos dos pacientes após palatoplastia, entre os } 48 \text { e } 60 \\
\text { meses de idade. }\end{array}$ & $\begin{array}{l}\text { Variável quantitativa continua } \\
\text { expressa em milímetros }\end{array}$ \\
\hline $\begin{array}{l}\text { Comprimento do arco } \\
\text { dentário maxilar (IP) }\end{array}$ & $\begin{array}{l}\text { Corresponde à distância entre o ponto I, localizado entre os } \\
\text { incisivos, ponto interincisivo, até uma linha tangente às } \\
\text { faces distais dos segundos molares decíduos superiores, } \\
\text { aferida nos modelos de gesso obtidos dos pacientes após } \\
\text { palatoplastia, entre os } 48 \text { e } 60 \text { meses de idade. }\end{array}$ & $\begin{array}{l}\text { Variável quantitativa continua } \\
\text { expressa em milímetros }\end{array}$ \\
\hline $\begin{array}{l}\text { Relação maxilo- } \\
\text { mandibular }\end{array}$ & $\begin{array}{l}\text { Avaliada em modelos de gesso digitalizado dos pacientes, } \\
\text { por meio da utilização do Five YearsOld Index (FYOI) } \\
\text { proposto por Atack et al. }{ }^{76} \text {. }\end{array}$ & $\begin{array}{l}\text { Variável categórica ordinal } \\
\text { Escore } 1 \text { - Relação Excelente } \\
\text { Escore } 2 \text { - Relação Boa } \\
\text { Escore } 3 \text { - Relação Regular } \\
\text { Escore } 4 \text { - Relação Ruim } \\
\text { Escore } 5 \text { - Relação Muito Ruim }\end{array}$ \\
\hline
\end{tabular}




\section{Quadro 3 - Variáveis confundidoras}

\begin{tabular}{|l|l|l|}
\hline \multicolumn{1}{|c|}{ Variável } & \multicolumn{1}{c|}{ Definição operacional } & \multicolumn{1}{c|}{ Categorização } \\
\hline Banda cutânea & $\begin{array}{l}\text { Presença de ponte cutaneomucosa unindo as duas bordas da } \\
\text { fissura labial. }\end{array}$ & $\begin{array}{c}\text { Variável nominal dicotômica: } \\
\text { Sim }\end{array}$ \\
$\begin{array}{l}\text { Largura anterior da } \\
\text { fissura }\end{array}$ & $\begin{array}{l}\text { Corresponde à distância entre o ponto G, localizado na } \\
\text { extremidade anterior da crista alveolar do segmento maior } \\
\text { do arco, e o ponto L, localizado na extremidade anterior da } \\
\text { crista alveolar do segmento menor do arco, aferida nos } \\
\text { modelos de gesso obtidos dos pacientes antes da } \\
\text { queiloplastia. }\end{array}$ & $\begin{array}{l}\text { Variável quantitativa continua } \\
\text { expressa em milímetros }\end{array}$ \\
$\begin{array}{l}\text { Largura posterior da } \\
\text { fissura }\end{array}$ & $\begin{array}{l}\text { Corresponde à distância entre os pontos A e A', localizados } \\
\text { em ambos os lados nas extremidades dos rebordos do } \\
\text { palato mole, na altura da linha T-T' (inter-tuberosidade), } \\
\text { aferida nos modelos de gesso obtidos dos pacientes antes } \\
\text { da queiloplastia. }\end{array}$ & $\begin{array}{l}\text { Variável quantitativa continua } \\
\text { expressa em milímetros }\end{array}$ \\
\hline
\end{tabular}

\section{Quadro 4 - Critérios de inclusão}

\begin{tabular}{|l|l|c|}
\hline \multicolumn{1}{|c|}{ Variável } & \multicolumn{1}{c|}{ Definição operacional } & \multicolumn{1}{c|}{ Categorização } \\
\hline $\begin{array}{l}\text { Presença de fissura } \\
\text { labiopalatina } \\
\text { unilateral completa }\end{array}$ & $\begin{array}{l}\text { Fissura congênita acometendo unilateralmente o lábio e } \\
\text { palato em toda a extensão. }\end{array}$ & $\begin{array}{c}\text { Variável nominal dicotômica: } \\
\text { Sim }\end{array}$ \\
$\begin{array}{l}\text { Presença de } \\
\text { queiloplastia } \\
\text { realizada pelo autor } \\
\text { do estudo }\end{array}$ & $\begin{array}{l}\text { Cirurgia de reconstituição da fissura labial, realizada pelo } \\
\text { autor do estudo, em crianças com FLPU completa, entre os } \\
\text { 3 e 6 meses de vida, utilizando a técnica de rotação e } \\
\text { avanço de Mohler }{ }^{166} \text {. }\end{array}$ & $\begin{array}{l}\text { Variável nominal dicotômica: } \\
\text { Sim }\end{array}$ \\
\hline
\end{tabular}

\section{Quadro 5 - Critérios de exclusão}

\begin{tabular}{|c|c|c|}
\hline Variável & Definição operacional & Categorização \\
\hline $\begin{array}{l}\text { Síndromes associados } \\
\text { à FLPU }\end{array}$ & $\begin{array}{l}\text { Presença de outras Malformações ou Síndromes que } \\
\text { comprometam o desenvolvimento neuropsicomotor ou fala }\end{array}$ & $\begin{array}{l}\text { Variável nominal dicotômica: } \\
\text { 1) Sim } \\
\text { 2) Não }\end{array}$ \\
\hline Condição clínica & $\begin{array}{l}\text { Presença de quadro clinico que comprometa a cronologia } \\
\text { cirúrgica objeto deste estudo }\end{array}$ & $\begin{array}{l}\text { Variável nominal dicotômica: } \\
\text { 1) Sim } \\
\text { 2) Não }\end{array}$ \\
\hline $\begin{array}{l}\text { Falta de adesão ao } \\
\text { tratamento }\end{array}$ & $\begin{array}{l}\text { Pacientes que abandonaram a cronologia cirúrgica em } \\
\text { função de condicionantes clinicas ou sociais antes do } \\
\text { processo de randomização }\end{array}$ & $\begin{array}{l}\text { Variável nominal dicotômica: } \\
\text { 1) Sim } \\
\text { 2) Não }\end{array}$ \\
\hline $\begin{array}{l}\text { Não autorização } \\
\text { prévia dos } \\
\text { representantes legais } \\
\text { das crianças }\end{array}$ & $\begin{array}{l}\text { Recusa dos pais ou representantes legais das crianças em } \\
\text { assinar o termo de consentimento livre e esclarecido } \\
\text { (TCLE) e permitir a participação das crianças no estudo }\end{array}$ & $\begin{array}{l}\text { Variável nominal dicotômica: } \\
\text { 1) Sim } \\
\text { 2) Não }\end{array}$ \\
\hline
\end{tabular}




\subsection{Procedimentos para Captação e Acompanhamento dos Participantes}

O recrutamento dos participantes foi realizado durante o atendimento ambulatorial no CADEFI no período do estudo. Os pacientes foram selecionados de forma sequencial e de acordo com os critérios de inclusão e exclusão contidos na lista de checagem (Anexo A).

Em seguida os representantes legais dos pacientes potencialmente elegíveis para o estudo foram convidados a participar do mesmo, após serem informados verbalmente sobre os objetivos, potenciais benefícios e riscos.

Após o consentimento verbal do seu representante legal da criança, foi apresentado o TCLE, em duas vias, que foram assinadas pelo representante legal da criança e pelo pesquisador (Anexo B).

No momento da primeira consulta foi agendada para os participantes a data do primeiro procedimento, a queiloplastia, realizada pelo autor do estudo, conforme o protocolo do CADEFI: queiloplastia primária realizada entre os três e seis meses de vida, pela técnica de rotação e avanço de Mohler ${ }^{166,167}$. Não foi realizado em nenhum paciente alveoloplastia, nem usados retalhos alveolares ou do septo nasal.

O processo de aleatorização foi realizado por um pesquisador não envolvido diretamente nas avaliações dos pacientes, com o auxílio do programa estatístico computadorizado, Random Allocation Software 1.0.

Utilizou-se envelopes selados e numerados sequencialmente, os quais continham a informação sobre o tipo de protocolo a ser adotado para a palatoplastia. Este procedimento permitiu que os componentes da amostra fossem separados, aleatoriamente, de modo a constituir dois grupos com características semelhantes: o GI e o GC. 
As crianças desses dois grupos receberiam então tratamentos cirúrgicos distintos. GI seriam submetidas à palatoplastia em dois tempos cirúrgicos para o fechamento do palato mole e duro, respectivamente, enquanto que as do grupo controle seriam submetidas à palatoplastia completa em tempo único.

Durante a consulta para avaliação pós-operatória de cada criança, realizada 30 dias após a queiloplastia, o envelope da randomização era aberto para que se pudesse programar a palatoplastia conforme o protocolo especificado no referido envelope: em tempo único ou em dois tempos cirúrgicos.

Todas as etapas do pré-operatório, internamento, intervenção cirúrgica e pósoperatórios foram cumpridas de acordo com o protocolo do CADEFI. Os pacientes foram avaliados para alta no dia seguinte ao procedimento, se as condições clínicas a permitissem. Caso contrário foram acompanhados pela equipe de cirurgia plástica, em frequência definida de acordo com o caso, até a alta hospitalar.

Os retornos para o acompanhamento ambulatorial foram realizados obedecendo à seguinte cronologia: no quinto, $10^{\circ}$ e $30^{\circ}$ dia pós-operatório, no segundo, terceiro e sexto mês e, posteriormente, no primeiro e segundo ano do pósoperatório. Os dados obtidos em todas as avaliações pós-operatórias foram registrados pelo residente de Cirurgia Plástica, em um formulário específico.

Os pacientes que não compareceram para a avaliação ambulatorial no período estabelecido foram contatados por telefone e convidados a comparecer ao serviço. 


\subsection{Procedimentos Técnicos}

\subsubsection{Procedimentos cirúrgicos}

Os procedimentos cirúrgicos foram realizados nos blocos cirúrgicos do IMIP ou RHP, conforme rotina do serviço, por um único cirurgião, o mesmo que já havia executado a queiloplastia nas crianças da amostra. A palatoplastia foi realizada de acordo com os protocolos objeto deste estudo, a saber:

- Palatoplastia em dois tempos cirúrgicos, baseado no protocolo de Göteborg palatoplastia posterior (palato mole) entre os seis e nove meses de idade, com o reposicionamento da musculatura do véu palatino (veloplastia intravelar estendida. Incisão nos bordos da fissura do palato mole e uma pequena incisão transversa na transição do palato duro e mole, sempre que necessária e não se prolongando além do terço medial do palato. Descolamento e transposição muscular como preconizado por Kriens, Braithwaite e Sommerlad.

- Palatoplastia anterior (palato duro) entre 36 e 48 meses de vida, pela técnica de simples adesão ou de Von Langenbeck, com fechamento primário após descolamento de retalhos da fibromucosa palatina. Fechamento do plano nasal com retalhos da mucosa nasal e em caso de necessidade, em virtude da amplitude da fissura residual com o uso de retalho de vômer. Sempre que foi imprescindível foram realizadas incisões liberadoras unilateral (preferencialmente no lado não fissurado) ou bilaterais.

- Palatoplastia em tempo único: palatoplastia completa (palato duro e mole) entre os nove e 15 meses de vida pela técnica de Von Langenbeck/ 
Kriens/Braitwaite, com as modificações propostas por Sommerlad para o tratamento cirúrgico do palato mole. Quando a fissura era de tal forma ampla que não permitia o fechamento do assoalho nasal com retalhos da mucosa nasal, foi realizada transposição de retalho de vômer. A Veloplastia foi executada como proposta por Kriens, Braithwaite e Sommerlad.

\subsubsection{Procedimentos para Avaliação da Largura da Fissura e das Dimensões Transversais e Anteroposteriores do Arco Dentário Maxilar}

\subsubsection{Obtenção dos modelos de estudo}

Foram confeccionados modelos de estudo dos arcos dentários dos pacientes de ambos os grupos, em diferentes fases do crescimento. Os arcos dentários foram moldados por um único odontopediatra, utilizando hidrocoloide irreversível de presa rápida (alginato) para obtenção dos moldes e, posteriormente, dos modelos em gesso pedra. Os dois grupos de pacientes foram moldados em dois tempos préestabelecidos:

- T1 - Moldagem inicial - entre um e 180 dias de nascido.

- T2 - Moldagem da dentadura decídua completa, entre os quatro e cinco anos de idade. A média de idade foi de 55,05 meses com desvio padrão de 9,14 meses no Grupo GI e 56,71 meses com desvio padrão de 10,33 no grupo GC.

Todos os modelos de gesso foram posteriormente escaneados em um aparelho R640 3Shape Desktop Study Model Scanner (3Shape A/S, Copenhagen, Denmark), com definição de imagem de 150dpi, no tamanho de $100 \%$ da imagem através do software visualizador de imagem 3Shape Viewing Software (3Shape A/S). O escaneamento foi realizado com os modelos nas seguintes posições: vista frontal, vistas bucais direita e 
esquerda e vistas oclusais superior e inferior. Após digitalização, os modelos foram ordenados de forma aleatória e em seguida foram numerados. Todas as imagens foram salvas em arquivo com extensão “.jpg”.

\subsubsection{Avaliação da largura da fissura do recém-nascido}

As larguras anterior e posterior da fissura foram avaliadas por meio de duas dimensões aferidas nos modelos de gesso obtidos em T1. A aferição foi feita utilizando-se um compasso digital (Digital Caliper MTX 0-150 mm). A unidade de medida empregadas foi o milímetro, aferindo-se até uma casa decimal. As aferições foram realizadas por um mesmo examinador calibrado, em dois momentos distintos, para possibilitar a avaliação da concordância intrexaminador. As dimensões aferidas foram as seguintes, segundo Mazaheri, Kramer, Seckel e Reiser (Figura 1):

- Largura Anterior da Fissura (G-L) - Corresponde à distância entre o ponto G, localizado na extremidade anterior da crista alveolar do segmento maior do arco, e o ponto L, localizado na extremidade anterior da crista alveolar do segmento menor do arco.

- Largura Posterior da Fissura (A-A' ) -Corresponde à distância entre os pontos A e A', localizados em ambos os lados nas extremidades dos rebordos do palato mole, na altura da linha T-T'(inter-tuberosidade). 


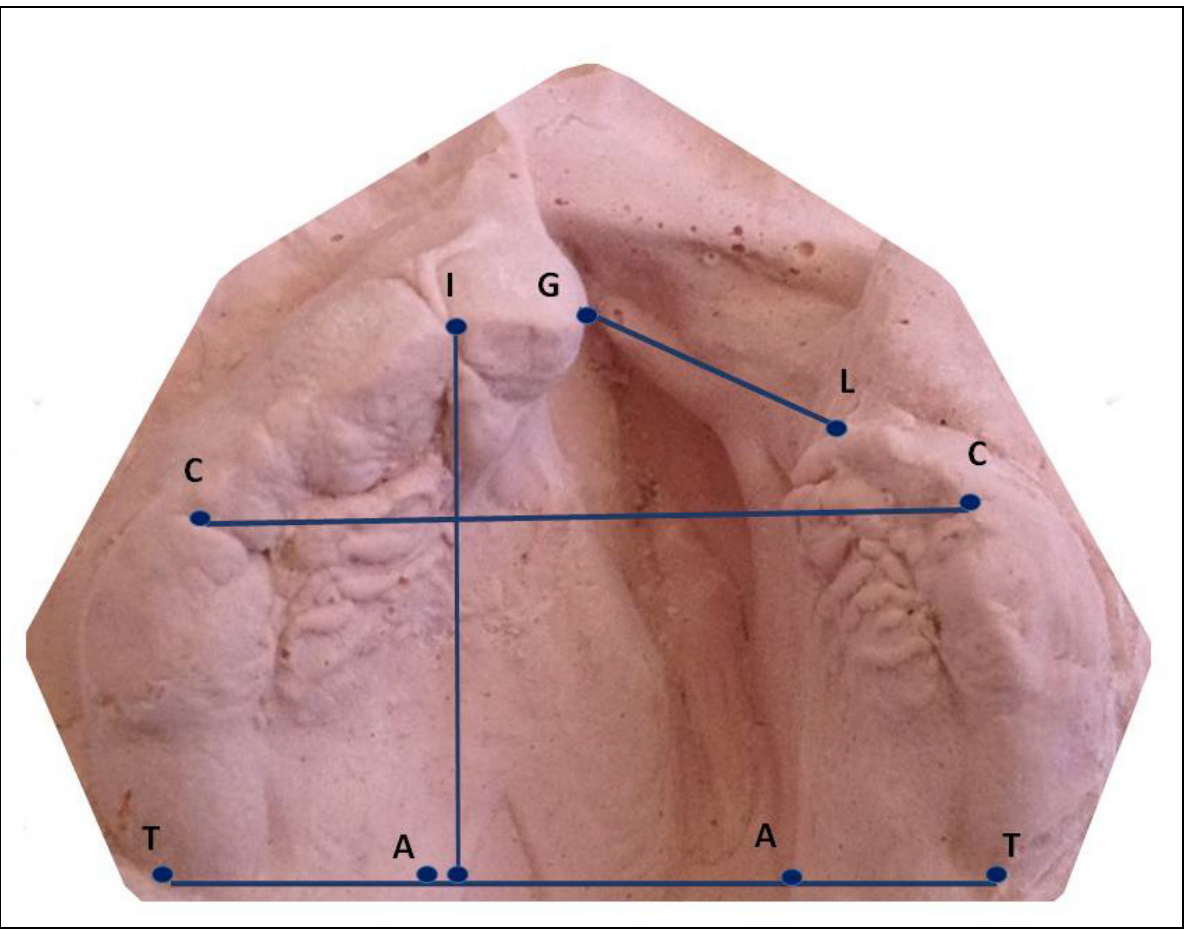

Figura 1 - Dimensões transversais e anteroposterior da maxila do recém-nascido [Fonte: Arquivo do CADEFI]

\subsubsection{Avaliação das dimensões transversais e anteroposterior da maxila do recém-nascido}

As dimensões transversais e anteroposterior da maxila do recém-nascido foram avaliadas por meio de três dimensões aferidas nos modelos de gesso utilizando a mesma metodologia empregada para aferir a largura da fissura do recém-nascido seguintes, segundo Mazaheri, Kramer, Seckel e Reiser (Figura 1):

- Largura anterior do arco alveolar (C-C') - Corresponde à distância entre os pontos C e C', localizados no ápice das cúspides dos caninos decíduos, em ambos os lados do arco dentário, aferida nos modelos de gesso obtidos dos pacientes em T1, antes da queiloplastia.

- Largura posterior do arco alveolar (T-T') - Corresponde à distância intertuberosidade na área da tuberosidade da maxila. Linha que liga um ponto $\mathrm{T}$ (cume da tuberosidade) de um lado a outro da maxila. 
- Comprimento do arco alveolar (I-TT') - Corresponde à distância entre o ponto I, localizado localizado na interseção da linha do freio labial com a papila incisiva na altura da crista alveolar,até a linha da distância intertuberosidade $\left(\mathrm{T}-\mathrm{T}^{\prime}\right)$.

\subsubsection{Avaliação das dimensões transversais e anteroposterior da maxila na dentadura decídua}

As dimensões transversais e anteroposterior da maxila das crianças na fase da dentadura decídua completa, entre os quatro e cinco anos de idade foram avaliadas por meio de três dimensões aferidas nos modelos de gesso digitalizados. As imagens digitais 3D dos modelos de referência foram obtidas utilizando o scanner R640 3Shape Desktop (Copenhagen, Dinamarca) e disponibilizados para download e visualização utilizando o software de visualização 3Shape Foram aferidas as seguintes dimensões segundo Moorees e DiBiase (Figura 2):

- Distância intercaninos (DC) - corresponde à distância entre os pontos C e C', localizados no ápice das cúspides dos caninos decíduos, em ambos os lados do arco dentário, aferida nos modelos de gesso obtidos dos pacientes após palatoplastia, entre os 48 e 72 meses de idade.

- Distância intermolares (DM) - corresponde à distância entre os pontos $\mathrm{M} \mathrm{e}$ M', localizados no ápice das cúspides palatinas anteriores dos segundos molares decíduos, aferida nos modelos de gesso obtidos dos pacientes após palatoplastia, entre os 48 e 72 meses de idade.

- Comprimento do arco alveolar maxilar (IP) - corresponde à distância entre o ponto I, localizado entre os incisivos, ponto interincisivo, até uma linha 
tangente às faces distais dos segundos molares decíduos superiores, aferida nos modelos de gesso obtidos dos pacientes após palatoplastia, entre os 48 e 72 meses de idade.

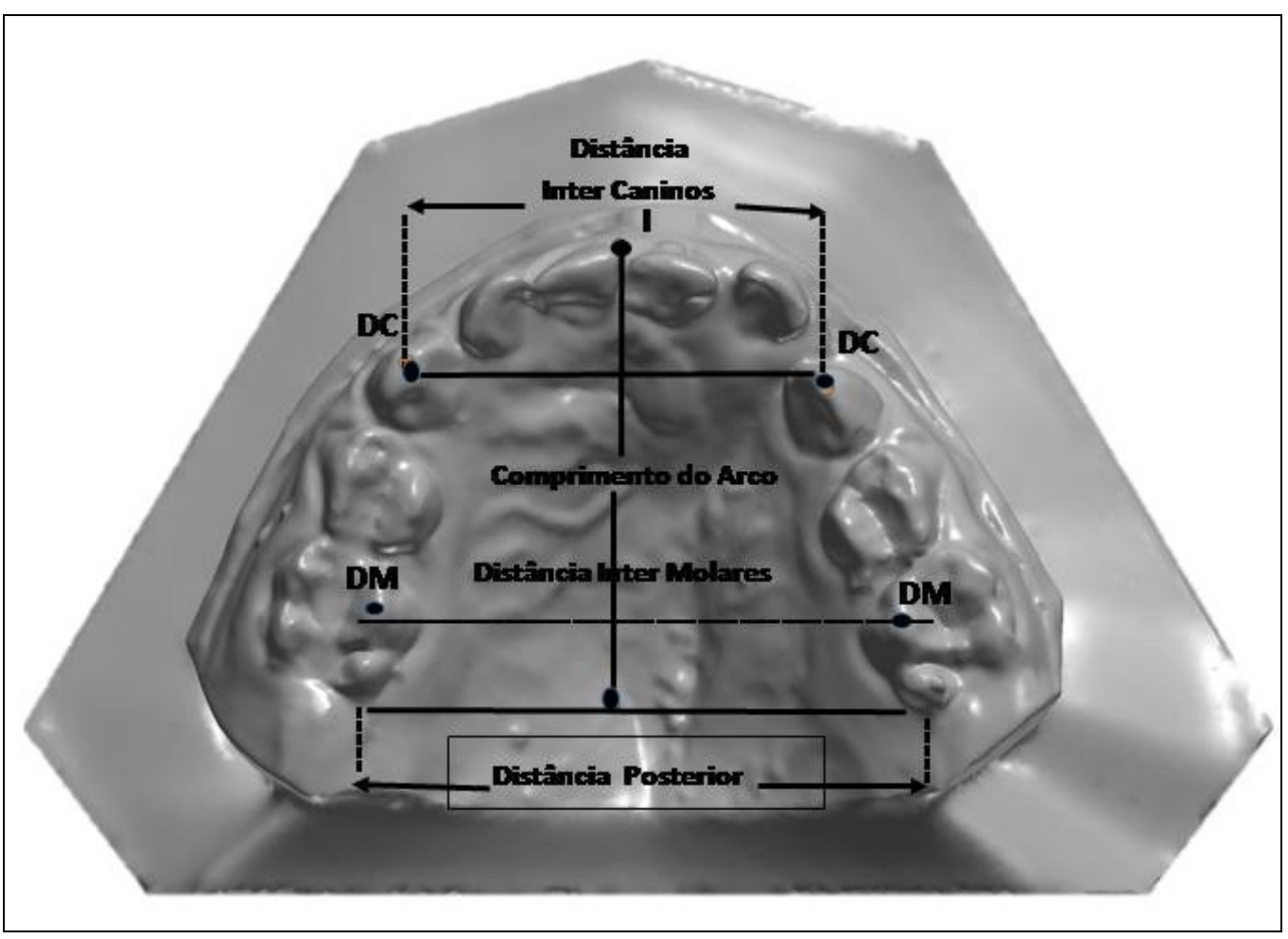

Figura 2 - Dimensões transversais e anteroposterior da maxila na dentadura decídua [Fonte: Arquivo do CADEFI]

\subsubsection{Avaliação da relação maxilo-mandibular na dentadura decídua}

A relação entre os arcos dentários maxilar e mandibular foi avaliada nos modelos de estudo digitalizados obtidos das crianças na fase da dentadura decídua completa, entre os quatro e cinco anos de idade, utilizando-se o FYOI proposto por $\operatorname{Atack}^{76}$. Trata-se de um índice oclusal para a avaliação da relação interarcos dos pacientes com fissura labiopalatina unilateral completa, composto por escores (graus da relação entre a maxila e a mandíbula) que variam de um a cinco. Quanto maior o escore pior é a relação maxilomandibuilar, conforme descrito no Quadro 6. 


\section{Quadro 6 -Classificação das características oclusais pelo índice FYOI}

\begin{tabular}{|c|c|}
\hline Índice & Características \\
\hline Índice 1 & $\begin{array}{l}\text { Há trespasse horizontal positivo, inclinação dos incisivos superiores para } \\
\text { palatino ou normal, ausência de mordida cruzada e aberta e morfologia da } \\
\text { arcada dentária superior satisfatória, caracterizando um excelente prognóstico a } \\
\text { longo prazo. }\end{array}$ \\
\hline Índice 2 & $\begin{array}{l}\text { Apresenta trespasse horizontal positivo, inclinações dos incisivos para } \\
\text { vestibular ou normal, presença de mordida cruzada posterior uni ou bilateral, } \\
\text { caracterizando um bom prognóstico. }\end{array}$ \\
\hline Índice 3 & $\begin{array}{l}\text { Apresenta mordida topo a topo interior, inclinação dos incisivos para vestibular } \\
\text { ou trespasse horizontal com incisivos inclinados para palatino, tendência à } \\
\text { mordida aberta adjacente à fissura, caracterizando um prognóstico regular. }\end{array}$ \\
\hline Índice 4 & $\begin{array}{l}\text { Trespasse horizontal negativo, inclinação dos incisivos superiores para } \\
\text { vestibular ou normal, tendência à mordida aberta adjacente à fissura e mordida } \\
\text { cruzada posterior unilateral ou bilateral, caracterizando um prognóstico ruim }\end{array}$ \\
\hline Índice 5 & $\begin{array}{l}\text { Traspasse horizontal negativo, inclinação dos incisivos para vestibular, mordida } \\
\text { cruzada posterior bilateral e morfologia da arcada dentária superior muito } \\
\text { alterada, caracterizando um prognóstico muito ruim dos resultados terapêuticos } \\
\text { dos resultados. }\end{array}$ \\
\hline Fonte: $\mathrm{O}$ & \\
\hline
\end{tabular}

Três ortodontistas, externos ao CADEFI, com prévio e extenso treinamento na utilização do referido índice, procederam de forma cega à avaliação dos 62 pares de modelos de gesso. $\mathrm{Na}$ mesma ocasião, $40 \%$ desses modelos, escolhidos aleatoriamente, foram reavaliados por cada um dos examinadores, para que se pudesse calcular a concordância intraexaminador no exame da relação maxilomandibular. Os modelos numerados de forma aleatória foram expostos sem referência alguma à identidade dos pacientes ou ao tipo de protocolo a que foram submetidos (Figura 3) 


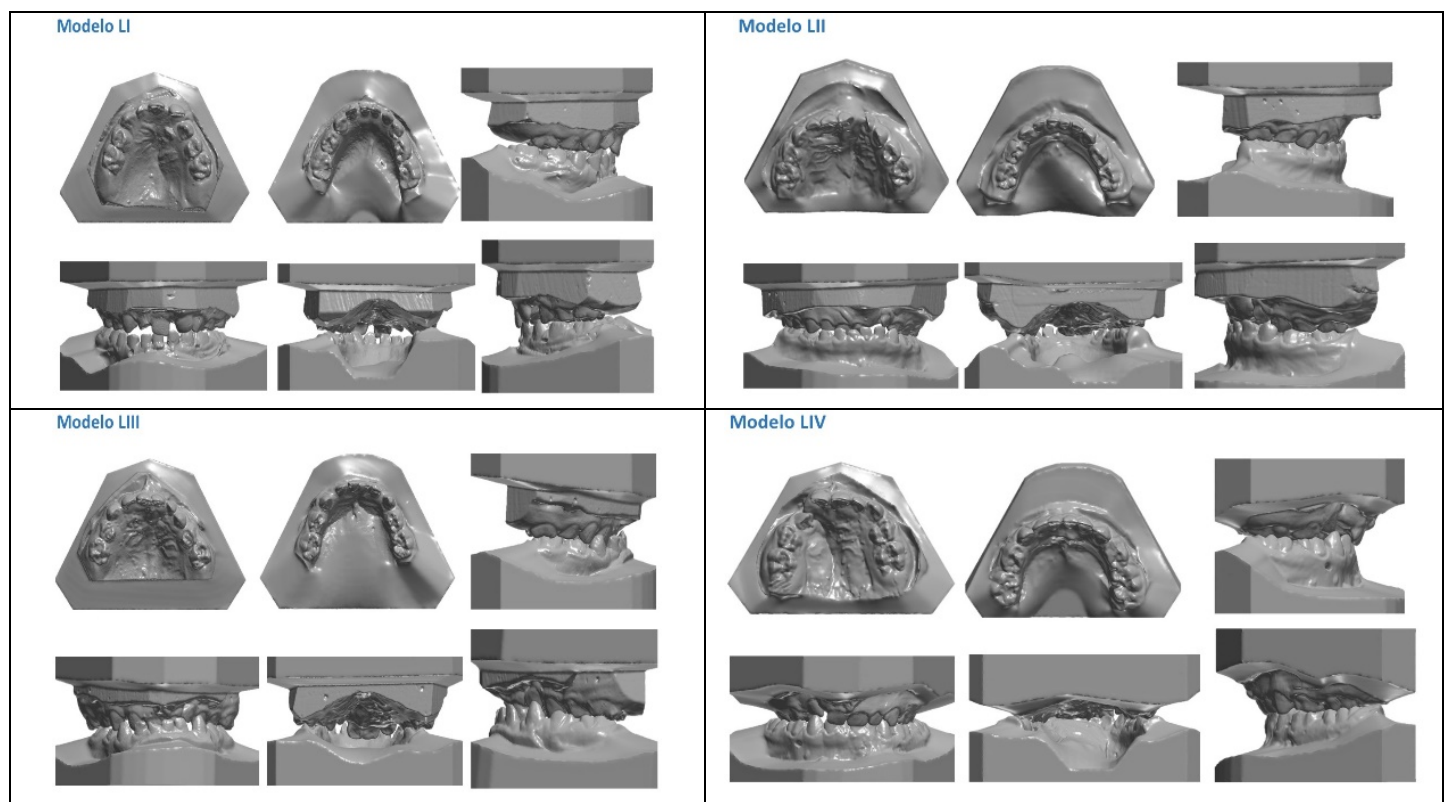

Figura 3 - Modelos dos arcos dentários superior e inferior em oclusão para avaliação do índice FYOI [Fonte: Arquivo do CADEFI]

\subsection{Instrumento para Coleta dos Dados}

Os dados de identificação dos pacientes, o número do envelope da randomização, os dados transoperatórios e pós-operatórios da queiloplastia e palatoplastia foram registrados em ficha clínica elaborada para tal finalidade (Anexo A). Os dados foram registrados pelo Residente de Cirurgia Plástica.

\subsection{Processamento e Análise dos Dados}

\subsubsection{Processamento dos dados}

Ao final da realização de todos os procedimentos técnicos as fichas clínicas foram separadas conforme o grupo a que pertenciam, GI ou GC, e, em seguida, ordenadas e numeradas.

As informações contidas nas fichas foram digitadas em planilha Excel, por um único digitador, em duas ocasiões distintas, para que os erros de digitação fossem identificados e eliminados, garantindo a confiabilidade da digitação. 
Os dados referentes aos sujeitos recrutados originalmente para o estudo e que foram excluídos antes da randomização, por não terem cumprido integralmente com os critérios de inclusão, foram transferidos para uma planilha auxiliar com o registro do ocorrido.

\subsubsection{Análise dos dados}

Os dados foram analisados descritivamente através de frequências absolutas e percentuais para a variável sexo e das estatísticas: média, desvio padrão, mediana e amplitude entre quartis para as medidas numéricas e foram analisados inferencialmente através dos testes: na comparação entre os grupos ou no estudo de associação de variáveis categóricas foi utilizado teste Qui-quadrado de Pearson ou Exato de Fisher nas situações que o Qui-quadrado não foi um teste valido; na comparação entre grupos ou entre duas categorias de variáveis categóricas em relação às variáveis numéricas foi utilizado teste t-Student ou Mann-Whitney. Para avaliar o grau de concordância entre avaliadores foi obtido o kappa e um intervalo para o respectivo parâmetro e foi utilizado o teste t-Student específico para a hipótese de correlação nula.

Destaca-se que a escolha do teste t-Student ocorreu no caso da verificação da hipótese de normalidade dos dados e o teste de Mann-Whitney e correlação de Spearman foi devido a rejeição da hipótese de normalidade. A verificação da normalidade foi realizada através do teste de Shapiro-Wilks e a de igualdade de variâncias através do teste $\mathrm{F}$ de Levene.

A margem de erro utilizada nas decisões dos testes estatísticos foi de $5 \%$ e os intervalos foram obtidos com confiabilidade de $95 \%$. Os dados foram digitados na 
planilha EXCEL e o programa utilizado na obtenção dos cálculos estatísticos foi o SPSS (Statistical Package for the Social Sciences) na versão 23.

\subsection{Captação e Acompanhamento dos Participantes}

Foi preenchido fluxograma com o perfil do ensaio clínico (Figura 4).

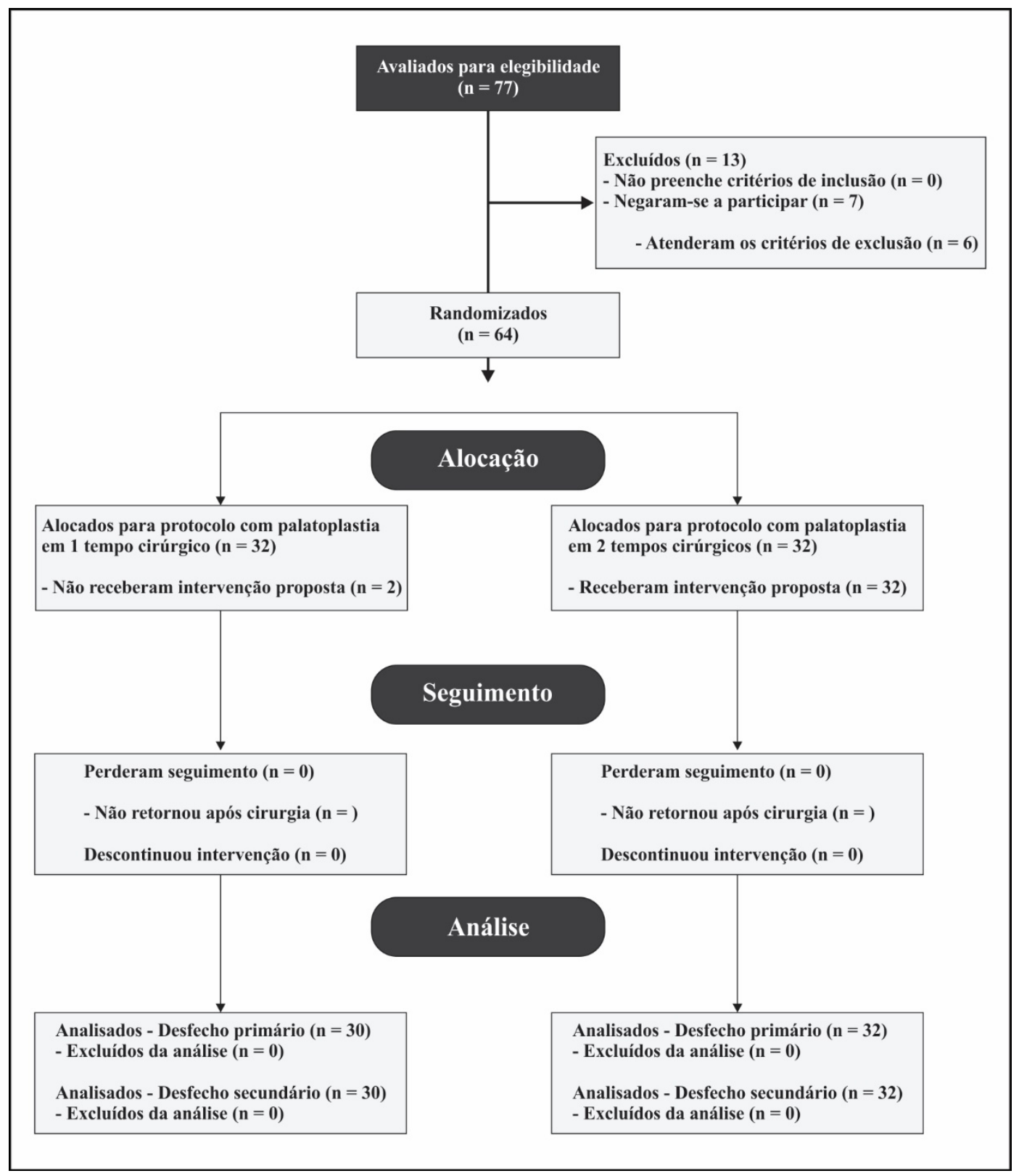

Figura 4 - Fluxograma de captação e acompanhamento dos pacientes [Fonte: CONSORT ${ }^{169}$ ] 


\subsection{Aspectos Éticos}

A escolha dos protocolos cirúrgicos adotados no estudo se encontra respaldada na literatura mostrando sua segurança em contextos clínicos amplamente descritos e que sintetizam a principal preocupação de todos aqueles envolvidos no tratamento dos pacientes com fissura labiopalatina, a oportunidade e idade da execução da cirurgia do palato.

O fato destes protocolos já terem sido objeto de estudos observacionais anteriores e tendo sido observado o baixo potencial de risco relacionado ao crescimento facial e desenvolvimento da fala e linguagem aliado aos benefícios que um estudo prospetivo e randomizado poderia trazer para a avaliação destes desempenhos aos sujeitos da pesquisa formaram a base ética deste estudo.

Em virtude do serviço ter um protocolo de tratamento destas malformações, já conhecido e para garantir o princípio da justiça e autonomia nestes casos, foi assegurado para os pacientes e seus representantes legais que não aceitassem participar do estudo, o tratamento usual do serviço, sem qualquer prejuízo para os mesmos. A participação foi condicionada à concordância verbal e escrita do TCLE.

A qualquer momento o paciente e seu representante tiveram a autonomia de retirar sua autorização para participação no estudo sem qualquer prejuízo para o seu tratamento. O pesquisador responsável pela pesquisa esteve permanentemente disponível para responder questões referentes ao estudo. Todos os pacientes e/ou representantes tiveram o número para contato telefônico e o endereço para poderem se comunicar com o pesquisador responsável e com o Comitê de Ética responsável pela aprovação do projeto. 
Todo e qualquer dano ao paciente, que pudesse eventualmente decorrer desta pesquisa, seria avaliado e apropriadamente tratado de forma gratuita no IMIP, que realiza atendimentos na rede do SUS.

Foi realizada previamente e para a auditoria do andamento do ensaio clinico, avaliação preliminar dos modelos dentários bimaxilares em 29 pacientes por um painel de avaliadores do serviço, que foram previamente capacitadas e calibradas pelas Dras. Terumi Ozawa e Gunvor Semb, em duas oportunidades (Recife em outubro de 2012 e Bauru em 2014), sendo esta última em conjunto com outros profissionais dentro da iniciativa "Brasil Cleft". Não foi verificado nenhum indicio que qualquer um dos procedimentos tenha tido desempenho deletério que obrigasse à suspensão do estudo.

As informações dos pacientes foram mantidas em sigilo. Para a análise das informações e posterior publicação de resultados os pacientes foram identificados apenas pelo número de randomização. As identidades correspondentes aos números foram verificadas apenas pelo pesquisador após o final da avaliação realizada pelos especialistas e sua impressão exarada em planilha definitiva.

A presente pesquisa teve seu projeto aprovado pelo Comité de Ética em Pesquisa em Seres Humanos do Instituto de Medicina Integral Prof. Fernando Figueira sob o número 1282 em 13 de novembro de 2008, e também pelo Comité de Ética em Pesquisa em Seres Humanos da Faculdade de Medicina da Universidade de São Paulo no 269/12 em 8 de novembro de 2012 (Anexo C).

Também se encontra registrado no Clinical Trials Database sob o número NCT02329509 (Anexo C). 


\subsubsection{Termo de Consentimento Livre e Esclarecido}

O Termo de Consentimento Livre e Esclarecido foi lido pelo responsável legal do paciente momento de sua avaliação inicial para elegibilidade e assinado em duas vias. Uma das vias permaneceu em posse do responsável legal do paciente e a outra ficou aos cuidados do pesquisador responsável. O termo de consentimento completo encontra-se no Anexo B.

\subsubsection{Conflito de interesses}

Declaro não ter havido conflitos de interesse. O financiamento dos custos necessários à realização desta pesquisa foi operado pelo próprio pesquisador, com o apoio do CADEFI-IMIP. Nenhum dos envolvidos tinha qualquer relação com os fabricantes ou vendedores dos produtos, instrumentais e serviços utilizados neste estudo. 
4 RESULTADOS 
Setenta e sete sujeitos foram relacionados para o estudo dos quais treze não cumpriram os critérios de inclusão. Foram então randomizados 64 para formar dois grupos de 32 participantes: GI e GC. Após a randomização, dois pacientes do GC perderam o seguimento do tratamento.

Do total da amostra, 41 eram do sexo masculino (64,06 \%) e 23 do sexo feminino (35,94\%). Quinze apresentavam fissura do lado direito e 49 do lado esquerdo, o que corresponde a, respectivamente, $21,9 \%$ e $78,1 \%$ do grupo amostral (Tabela 1). Para a margem de erro fixada não foram registradas diferenças significativas entre os grupos relacionada à composição relativa ao gênero ou lateralidade da fissura $(\mathrm{p}>0,05)$.

Tabela 1 - Características da amostra pesquisada segundo o grupo

\begin{tabular}{|c|c|c|c|c|c|}
\hline \multirow{3}{*}{ Variável } & \multicolumn{4}{|c|}{ Grupo } & \multirow{3}{*}{ Valor de $\mathbf{p}$} \\
\hline & \multicolumn{2}{|c|}{ GI $(n=32)$} & \multicolumn{2}{|c|}{$G C(n=32)$} & \\
\hline & $\mathbf{n}$ & $\%$ & $\bar{n}$ & $\%$ & \\
\hline \multicolumn{6}{|l|}{ Sexo } \\
\hline Masculino & 21 & 65,6 & 20 & 62,5 & \multirow[t]{2}{*}{$\mathrm{p}^{(1)}=0,794$} \\
\hline Feminino & 11 & 34,4 & 12 & 37,5 & \\
\hline \multicolumn{6}{|c|}{ Lateralidade da fissura } \\
\hline Direita & 8 & 25,0 & 7 & 21,9 & \multirow[t]{2}{*}{$\mathrm{p}^{(1)}=0,768$} \\
\hline Esquerda & 24 & 75,0 & 25 & 78,1 & \\
\hline
\end{tabular}

(1) Através do teste Qui-quadrado de Pearson. 
Dos sujeitos incluídos na pesquisa, 16 (25,80\%)apresentavam banda cutânea labial, sendo 6 (18,7\%) no grupo GI e $10(33,3 \%)$ no grupo GC, distribuição esta que não apresentou diferença estatisticamente significante entre os grupos (Tabela 2).

Tabela 2 - Avaliação da presença da banda cutânea segundo o grupo

\begin{tabular}{|c|c|c|c|c|c|}
\hline \multirow{3}{*}{ Banda Cutânea Labial } & \multicolumn{4}{|c|}{ Grupo } & \multirow{3}{*}{ Valor de p } \\
\hline & \multicolumn{2}{|c|}{ GI $(n=32)$} & \multicolumn{2}{|c|}{$\mathrm{GC}(n=30)$} & \\
\hline & $n$ & $\%$ & $\mathrm{n}$ & $\%$ & \\
\hline Presente & 6 & 18,7 & 10 & 33,3 & $\mathrm{p}^{(1)}=0,190$ \\
\hline Ausente & 26 & 81,2 & 20 & 66,7 & \\
\hline
\end{tabular}

(1) Através do teste Qui-quadrado de Pearson.

Nos modelos de estudo obtidos dos pacientes antes das intervenções cirúrgicas (em T1) foram medidas as larguras anterior e posterior do arco alveolar (C-C' e T-T') além das larguras anterior e posterior da fissura (G-L e A-A') e não foram encontradas diferenças estatisticamente significantes entre as médias das medidas nos dois grupos amostrais (Tabelas 3 e 4).Na tabela 3 em ambos os grupos, verifica-se uma diminuição das dimensões transversais intercaninos, medidas nos modelos obtidos após todos os procedimentos cirúrgicos de palatoplastia (em T2) quando comparados com aquelas obtidas em T1 (DC x C-C'). 
Tabela 3 - Média e desvio padrão das dimensões transversais e anteroposteriores da maxila: largura anterior do arco alveolar (C-C'), largura posterior do arco alveolar (T-T', distância intercaninos pós tratamento (DC), distância intermolares pós-tratamento (DM) e comprimento do arco maxilar pós tratamento (IP) segundo o grupo

\begin{tabular}{|c|c|c|c|c|c|}
\hline \multirow{3}{*}{ Variável } & \multicolumn{4}{|c|}{ Grupo } & \multirow{3}{*}{ Valor de p } \\
\hline & \multicolumn{2}{|c|}{ GI $(n=32)$} & \multicolumn{2}{|c|}{$\mathrm{GC}(\mathrm{n}=30)$} & \\
\hline & Média & Desvio Padrão & Média & Desvio Padrão & \\
\hline C-C' & 29,81 & 3,16 & 29,70 & 2,48 & $\mathrm{p}^{(1)}=0,875$ \\
\hline T-T & 30,43 & 2,95 & 30,81 & 2,54 & $\mathrm{p}^{(1)}=0,592$ \\
\hline DC-DC' & 27,10 & 3,56 & 25,54 & 2,91 & $\mathrm{p}^{(1)}=0,063$ \\
\hline DM-DM' & 34,28 & 3,03 & 34,40 & 2,40 & $\mathrm{p}^{(1)}=0,865$ \\
\hline IP & 27,83 & 2,63 & 27,76 & 2,23 & $\mathrm{p}^{(1)}=0,900$ \\
\hline
\end{tabular}

(1) Através do teste t-Student com variâncias iguais.

Tabela 4 - Média e desvio padrão das medidas da largura anterior da fissura (G-L) e da largura posterior da fissura (A-A') segundo o grupo

\begin{tabular}{lccccc} 
& \multicolumn{4}{c}{ Grupo } & \multirow{2}{*}{ Valor de $\mathbf{p}$} \\
\cline { 2 - 5 } Variável & \multicolumn{2}{c}{$\mathbf{G I}(\mathbf{n}=\mathbf{3 2})$} & \multicolumn{2}{c}{$\mathbf{G C}(\mathbf{n}=\mathbf{3 0})$} & \\
\cline { 2 - 5 } & Média & Desvio Padrão & Média & Desvio Padrão & \\
G-L & 11,26 & 3,58 & 10,28 & 3,40 & $\mathrm{p}^{(1)}=0,278$ \\
A-A & 12,62 & 2,10 & 12,27 & 2,00 & $\mathrm{p}^{(1)}=0,513$ \\
\hline
\end{tabular}

(1) Através do teste t-Student com variâncias iguais.

Em estágio inicial (T1) as dimensões medias, anteriores e posteriores da fissura não apresentaram diferenças estatisticamente significantes entre os dois grupos amostrais, e também não foram detectadas diferenças intra e intergrupos relacionadas à presença/ausência de banda cutânea labial (Tabela 5). 
Tabela 5 - Média e desvio padrão das medidas: distâncias C-C' e T-T' a ocorrência de Banda Cutânea por grupo

\begin{tabular}{|c|c|c|c|c|c|}
\hline \multirow{3}{*}{ Variável } & \multirow{3}{*}{$\begin{array}{c}\text { Banda } \\
\text { Cutânea }\end{array}$} & \multicolumn{4}{|c|}{ Grupo } \\
\hline & & \multicolumn{2}{|c|}{$A(n=32 ; \operatorname{Sim}=6 ; N a ̃ 0=26)$} & \multicolumn{2}{|c|}{ B $(n=30 ; \operatorname{Sim}=10 ;$ Não=20) } \\
\hline & & Média & Desvio Padrão & Média & Desvio Padrão \\
\hline \multirow[t]{2}{*}{ C-C } & Sim & 31,51 & 4,17 & 28,84 & 1,46 \\
\hline & Não & 29,42 & 2,84 & 30,13 & 2,79 \\
\hline Valor de p & & $\mathrm{p}^{(1)}=0,148$ & & $\mathrm{p}^{(1)}=0,18$ & \\
\hline \multirow[t]{2}{*}{ T-T } & Sim & 36,02 & 2,15 & 36,25 & 2,47 \\
\hline & Não & 36,05 & 3,10 & 36,35 & 2,18 \\
\hline Valor de $p$ & & $\mathrm{p}^{(1)}=0,960$ & & $\mathrm{p}^{(2)}=0,79$ & \\
\hline
\end{tabular}

(1) Através do teste t-Student com variâncias iguais.

(2) Através do teste t-Student p;/ diferença entre as distancias.

Os pacientes do grupo GI foram submetidos a veloplastia com idade média de 10,62 meses e desvio padrão de 3,06eo fechamento do palato duro em torno dos 38,92 meses com desvio padrão de 4,76 meses. Os pacientes do Grupo GC foram operados de palatoplastia em tempo único com a média de idade de 11,84 meses com desvio padrão de 2,58(Tabela 6).

Tabela 6 - Média e desvio padrão da idade nas datas das cirurgias e na obtenção do modelo segundo o grupo

\begin{tabular}{lccccc}
\multirow{2}{*}{\begin{tabular}{c}
\multirow{2}{*}{$\begin{array}{c}\text { Idade } \\
\text { (meses) }\end{array}$} \\
\cline { 2 - 5 }
\end{tabular}} & \multicolumn{4}{c}{ GI $(\mathbf{n}=\mathbf{3 2})$} & \multicolumn{2}{c}{ GC $(\mathbf{n}=\mathbf{3 0})$} & \multirow{2}{*}{ Valor de $\mathbf{p}$} \\
\cline { 2 - 5 } & Média & Desvio Padrão & Média & Desvio Padrãon & \\
\hline Cirurgia 1 & 10,62 & 3,06 & 11,84 & 2,58 & $\mathrm{p}^{(1)}=0,096$ \\
Cirurgia 2 & 38,89 & 4,69 & & & \\
Obtenção do modelo & 55,05 & 9,14 & 56,71 & 10,33 & $\mathrm{p}^{(1)}=0,517$ \\
\hline
\end{tabular}

(1) Através do teste t-Student com variâncias iguais.

Embora as técnicas usadas tivessem sido realizadas conforme os protocolos já descritos, em casos que o cirurgião constatou que não havia a necessidade de incisões liberadoras laterais, esse procedimento não foi realizado. No grupo GI, em $37,5 \%$ dos pacientes foi realizado o fechamento do palato duro com o uso de incisões 
liberadoras laterais sendo que em $15,6 \%$ foi realizado bilateralmente. No grupo GC a palatoplastia completa foi realizada tendo usado a incisão liberadora $36,7 \%$ dos pacientes, sendo usado de forma unilateral em $16,7 \%$ dos casos, e não se verifica diferença significativa entre os grupos para a variável analisada $(p>0,05)$.

\section{Tabela 7 - Características da técnica cirúrgica (incisões laterais)}

\begin{tabular}{|c|c|c|c|c|c|}
\hline \multirow{3}{*}{ Incisão lateral } & \multicolumn{4}{|c|}{ Grupo } & \multirow[t]{3}{*}{ Valor de p } \\
\hline & \multicolumn{2}{|c|}{ GI $(n=32)$} & \multicolumn{2}{|c|}{ GC $(n=30)$} & \\
\hline & $\mathrm{n}$ & $\%$ & $\mathrm{n}$ & $\%$ & \\
\hline Sem incisão & 20 & 62,5 & 19 & 63,3 & $\mathrm{p}^{(1)}=0,825$ \\
\hline Unilateral & 7 & 21,9 & 5 & 16,7 & \\
\hline Bilateral & 5 & 15,6 & 6 & 20,0 & \\
\hline
\end{tabular}

(1) Através do teste Qui-quadrado de Pearson.

A Tabela 8 mostra que não houve ocorrência de complicações pós-cirúrgicas na veloplastia. A prevalência de fistulas foi relativamente baixa, 9,4\% e $6,7 \%$ respetivamente nos grupos GI e GC, todas, na classificação de Pittsburgh, tipos 3 e 4 sem diferenças estatisticamente significantes $(p>0,05)$ entre os dois grupos. Também, conforme as Tabelas 9 e 10, a opção técnica de não usar incisões liberadoras laterais no palato duro não comprova associação significativa com a ocorrência de fistulas oronasais. 
Tabela 8 - Avaliação das complicações segundo o grupo

\begin{tabular}{|c|c|c|c|c|c|}
\hline \multirow{3}{*}{ Complicação } & \multicolumn{4}{|c|}{ Grupo } & \multirow{3}{*}{ Valor de p } \\
\hline & \multicolumn{2}{|c|}{ GI $(n=32)$} & \multicolumn{2}{|c|}{ GC $(n=30)$} & \\
\hline & n & $\%$ & n & $\%$ & \\
\hline \multicolumn{6}{|c|}{ Complicação da queiloplastia } \\
\hline Presente & - & - & - & - & $*$ \\
\hline Ausente & 32 & 100,0 & 30 & 100,0 & \\
\hline \multicolumn{6}{|c|}{ Complicação Veloplastia } \\
\hline Presente & - & & - & - & $*$ \\
\hline Ausente & 32 & 100,0 & NA & NA & \\
\hline \multicolumn{6}{|c|}{ Complicação palatopastia completa (Fístula) } \\
\hline Presente & - & - & 2 & 6,7 & $\mathrm{p}^{(1)}=0,230$ \\
\hline Ausente & 32 & 100,0 & 28 & 93,3 & \\
\hline \multicolumn{5}{|c|}{ Complicação palatoplastia anterior (palato duro) (Fístula) } & \\
\hline Presente & 3 & 9,4 & & & $*$ \\
\hline Ausente & 29 & 90,6 & & & \\
\hline
\end{tabular}

(*) Não foi determinado devido à ocorrência de uma única categoria ou único grupo.

(1) Através do teste Exato de Fisher.

Tabela 9 - Presença de complicação (fistula) após Palatoplastia Completa com a execução ou não de incisão liberadora no grupo GC

\begin{tabular}{|c|c|c|c|c|c|}
\hline \multirow{3}{*}{ Incisão liberadora } & \multicolumn{4}{|c|}{ Complicação palatoplastia completa } & \multirow{3}{*}{ Valor de p } \\
\hline & \multicolumn{2}{|c|}{ Sim } & \multicolumn{2}{|c|}{ Não } & \\
\hline & n & $\%$ & n & $\%$ & \\
\hline $\operatorname{Sim}(n=11)$ & 1 & 9,1 & 10 & 90,9 & $\mathrm{p}^{(1)}=1,000$ \\
\hline Não (n=19) & 1 & 5,3 & 18 & 94,7 & \\
\hline
\end{tabular}

(1) Através do teste Exato de Fisher.

Tabela 10 - Presença de complicação (fístula) após a palatoplastia anterior com a execução ou não de incisão liberadora no grupo GI

\begin{tabular}{|c|c|c|c|c|c|}
\hline \multirow{3}{*}{ Incisão lateral } & \multicolumn{4}{|c|}{ Complicação no palato completo } & \multirow{3}{*}{ Valor de p } \\
\hline & \multicolumn{2}{|c|}{ Sim } & \multicolumn{2}{|c|}{ Não } & \\
\hline & $\mathrm{n}$ & $\%$ & n & $\%$ & \\
\hline $\operatorname{Sim}(n=12)$ & 2 & 16,7 & 10 & 83,3 & $\mathrm{p}^{(1)}=0,540$ \\
\hline Não $(n=20)$ & 1 & 5,0 & 19 & 95,0 & \\
\hline
\end{tabular}

(1) Através do teste Exato de Fisher.

Os modelos de estudo foram obtidos no Grupo GI aos 55,05 meses e no GC aos 56,71 meses (Tabela 3), não se encontrando diferença entre os dois grupos. 
A Tabela 11 mostra um grau de concordância elevada intra e entre examinadores. A concordância intra-examinadores variou de boa $(0,67)$ a excelente $(0,87)$ e a concordância entre examinadores variou de 0,76 (boa) a 0,90 (excelente).

Tabela 11 - Avaliação da concordância entre e intra avaliadores em relação ao escore ATTACK

\begin{tabular}{lccc}
\multirow{2}{*}{ Examinador } & E1 & E2 & E3 \\
\cline { 2 - 4 } & K (IC 95\%) & K (IC 95\%) & K (IC 95\%) \\
\hline E1 & $0,87(0,70$ a 1,00$)$ & & \\
E2 & $0,90(0,83$ a 0,97$)$ & $0,80(0,65$ a 0,96$)$ & \\
E3 & $0,83(0,71$ a 0,94$)$ & $0,76(0,64$ a 0,88$)$ & $0,67(0,46$ a 0,87$)$ \\
\hline
\end{tabular}

(1) Kappa intra e xaminador

(2) Kappa entre examinadores.

O valor do kappa geral entre avaliadores $0,83(0,73$ a 0,93$)$ e o kappa intraavaliador $0,78(0,60$ a 0,94$)$ indicando que a concordância foi excelente $(0,81$ a 1,00$)$ entre os examinadores e boa (de 0,61 a 0,80$)$ intra-examinadores.

\subsection{Avaliação dos resultados intergrupos por meio dos scores do índice FYOI atribuídos pelos examinadores}

A Tabela 12 apresenta a média, desvio padrão, mediana e amplitude entre quartis dos escores medianos do Índice FYOI por grupo, onde se destaca que a média e a mediana foram correspondentemente mais elevadas no grupo GC do que no GI (médias de 2,76 x 2,08 e medianas de 2,00 x 2,33). A diferença avaliada pelo teste de Mann-Whitney é significativa $(\mathrm{p}<0,05)$. 
Tabela 12 - Média, desvio padrão e mediana dos escores do Índice FYOI segundo o grupo

\begin{tabular}{lccc}
\multicolumn{1}{c}{ Estatística } & Grupo GI $(\mathbf{n}=\mathbf{3 2})$ & Grupo GC $(\mathbf{n}=\mathbf{3 0})$ & Valor de $\mathbf{p}$ \\
\hline Média & 2,08 & 2,76 & $\mathrm{p}^{(1)}=0,007^{*}$ \\
Desvio padrão & 0,96 & 0,93 & \\
Mediana & 2,00 & 2,33 & \\
Q1 - Q3 & 1,92 & 1,67 & \\
\hline
\end{tabular}

(*) Diferença significativa a $5 \%$

(1) Através do teste de Mann-Whitney.

Quando se analisa os resultados do índice FYOI referente a todas 186 avaliações realizadas pelos três examinadores, é possível ressaltar que: as maiores frequências corresponderam ao escore 2 (42,7\% no grupo GI e 48,9\% no grupo GC), seguido do escore 1 do grupo GI (31,2\%), escore 4 do grupo GC (26,7\%) e escore 3 do grupo GC $(18,9 \%$, conforme ilustrado no Gráfico 1. As maiores diferenças percentuais entre os dois grupos ocorreram no escore 1, com percentual mais elevado no grupo GI $(31,2 \%$ x 3,3\%) diferença que se mostra significativa $(\mathrm{p}<0,001)$ e no escore 4, mais elevado no grupo GC (26,7\% x 11,5\%) (Tabela 13$)$.

Gráfico 1 - Resultado da avaliação de 62 pacientes, realizada por três examinadores, utilizando o Índice FYOI nos grupos GI e GC

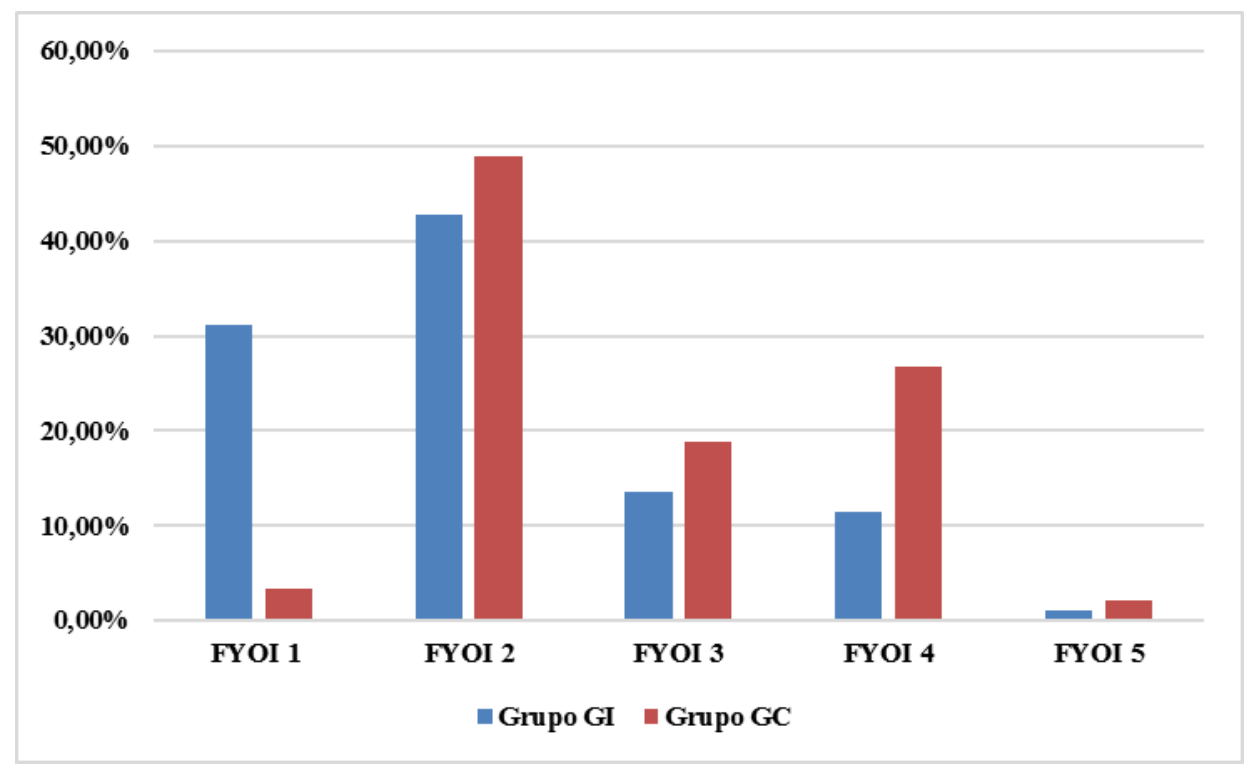


Tabela 13 - Resultados de todas as avaliações do Índice FYOI segundo o grupo

\begin{tabular}{|c|c|c|c|c|c|}
\hline \multirow{3}{*}{$\begin{array}{l}\text { Escore do FYOI } \\
\text { /ATTACK }\end{array}$} & \multicolumn{4}{|c|}{ Grupo } & \multirow{3}{*}{ Valor de $p$} \\
\hline & \multicolumn{2}{|c|}{ GI $(n=96)$} & \multicolumn{2}{|c|}{ GC $(n=90)$} & \\
\hline & $\mathrm{n}$ & $\%$ & $\mathrm{n}$ & $\%$ & \\
\hline 1 & 30 & 31,2 & 3 & 3,3 & $\mathrm{p}^{(1)}<0,001^{*}$ \\
\hline 2 & 41 & 42,7 & 44 & 48,9 & \\
\hline 3 & 13 & 13,5 & 17 & 18,9 & \\
\hline 4 & 11 & 11,5 & 24 & 26,7 & \\
\hline 5 & 1 & 1,0 & 2 & 2,2 & \\
\hline
\end{tabular}

(*) Diferença significativa a $5 \%$

(1) Através do teste Qui-quadrado de Pearson.

Quando os scores foram agrupados em três categorias, bom (scores 1 e 2), regular (score 3 ) e ruim (scores 4 e 5) verificou-se diferença significativa $(p<0,006)$ na categoria bom (scores 1 e 2) nos grupos GI e GC (Tabela 14, Gráfico 2).

Tabela 14 - Resultados de todas as avaliações categorizadas do Índice FYOI segundo o grupo

\begin{tabular}{|c|c|c|c|c|c|}
\hline \multirow{3}{*}{$\begin{array}{c}\text { Categoria do } \\
\text { FYOI }\end{array}$} & \multicolumn{4}{|c|}{ Grupo } & \multirow{3}{*}{ Valor de p } \\
\hline & \multicolumn{2}{|c|}{ GI $(n=96)$} & \multicolumn{2}{|c|}{ GC $(n=90)$} & \\
\hline & n & $\%$ & $\bar{n}$ & $\%$ & \\
\hline 1 e 2 (Bom) & 71 & 74,0 & 47 & 52,2 & $\mathrm{p}^{(1)}=0,006^{*}$ \\
\hline 3 (Regular) & 13 & 13,5 & 17 & 18,9 & \\
\hline 4 e 5 (Ruim) & 12 & 12,5 & 26 & 28,9 & \\
\hline
\end{tabular}

(*) Diferença significativa a $5 \%$.

(1) Através do teste Qui-quadrado de Pearson. 
Gráfico 2 - Resultado da avaliação de 62 pacientes, realizada por três examinadores, utilizando o Índice FYOI, agrupadas em três categorias, nos grupos GI e GC

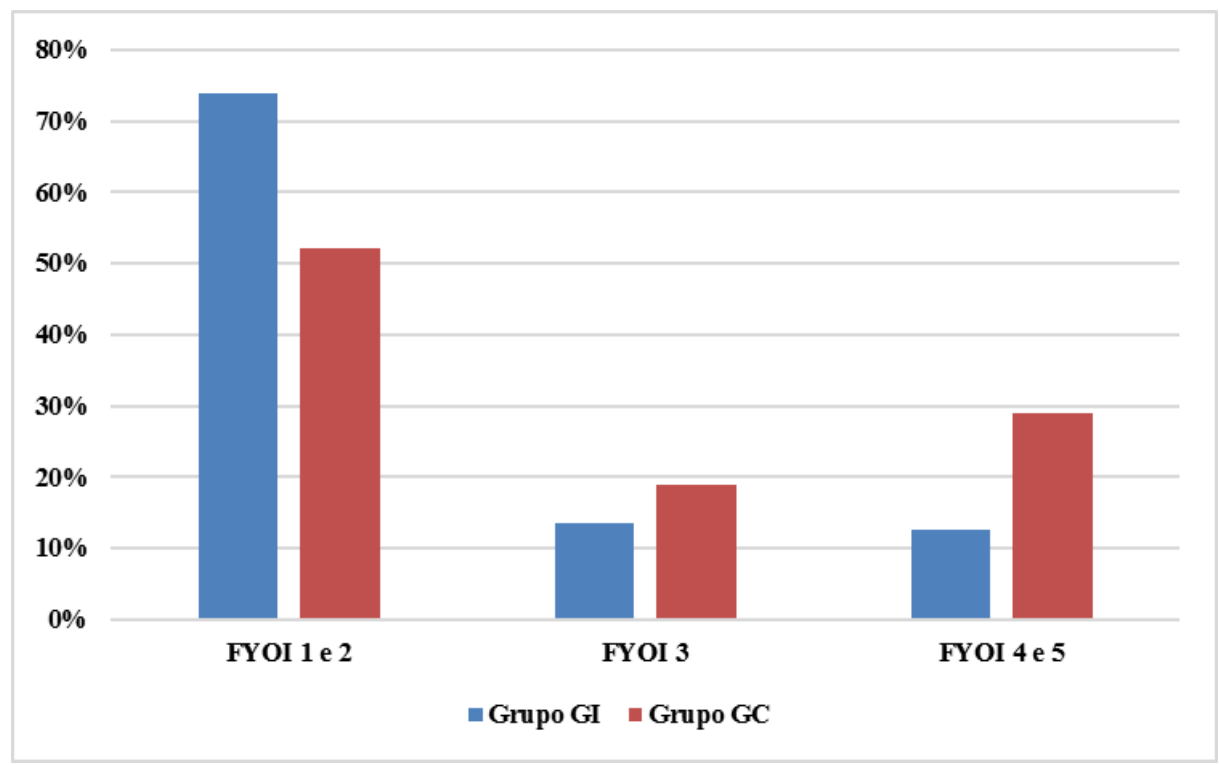

Os resultados contidos nas Tabelas 15 e 16 são relativos a moda ou, a mediana no caso de três escores distintos que foram obtidas para cada criança a partir das avaliações dos três examinadores, sendo duas tabelas com todas as medianas: a Tabela 15 sem agrupamento dos escores e a Tabela 16 com escores agrupados.

Tabela 15 - Resultados das medianas entre avaliadores do escore Índice FYOI segundo o grupo

\begin{tabular}{|c|c|c|c|c|c|}
\hline \multirow{3}{*}{$\begin{array}{c}\text { Mediana dos } \\
\text { escores }\end{array}$} & \multicolumn{4}{|c|}{ Grupo } & \multirow{3}{*}{ Valor de p } \\
\hline & \multicolumn{2}{|c|}{ GI $(n=32)$} & \multicolumn{2}{|c|}{$G C(n=30)$} & \\
\hline & $\mathbf{n}$ & $\%$ & $\mathbf{n}$ & $\%$ & \\
\hline 1 & 10 & 31,2 & 1 & 3,3 & $\mathrm{p}^{(1)}=0,024^{*}$ \\
\hline 2 & 14 & 43,8 & 14 & 46,7 & \\
\hline 3 & 4 & 12,5 & 7 & 23,3 & \\
\hline 4 & 4 & 12,5 & 8 & 26,7 & \\
\hline
\end{tabular}

(1) Através do teste Qui-quadrado de Pearson. 
Tabela 16 - Resultados das categorias das medianas entre avaliadores do escore Índice FYOI segundo o grupo

\begin{tabular}{|c|c|c|c|c|c|}
\hline \multirow{3}{*}{$\begin{array}{l}\text { Categoria da } \\
\text { mediana } \\
\text { do escore }\end{array}$} & \multicolumn{4}{|c|}{ Grupo } & \multirow{3}{*}{ Valor de p } \\
\hline & \multicolumn{2}{|c|}{ GI $(n=32)$} & \multicolumn{2}{|c|}{$G C(n=30)$} & \\
\hline & $\mathrm{n}$ & $\%$ & $\mathrm{n}$ & $\%$ & \\
\hline 1 e 2 (Bom) & 24 & 75,0 & 15 & 50,0 & $\mathrm{p}^{(1)}=0,124$ \\
\hline 3 (Regular) & 4 & 12,5 & 7 & 23,3 & \\
\hline 4 (Ruim) & 4 & 12,5 & 8 & 26,7 & \\
\hline
\end{tabular}

(1) Através do teste Qui-quadrado de Pearson.

A Tabela 16 mostra que as maiores frequências corresponderam ao escore mediano igual a $2(46,7 \%$ no grupo GC e $43,8 \%$ no grupo GI), seguido do escore 1 com $31,2 \%$ no grupo GI e dos escores 4 e 3 do grupo GC, com percentuais iguais a $26,7 \%$ e 23,3\%, respectivamente. A diferença entre os grupos é significativa $(\mathrm{p}<0,05)$.

Utilizando esta opção de relatório não se encontram mais alocações no escore 5 e também altera a distribuição entre os outros escores ressaltando-se aqui a diminuição do escore com pior prognostico no grupo GC.

Dos escores medianos agrupados tabela 16, a maior frequência correspondeu a categoria Bom, com percentual mais elevado no grupo GI $(75,0 \%$ x 50,0\%), entretanto sem diferença significativa $(p>0,05)$.

Dos valores da Tabela 17 o risco relativo (RR) de um paciente com FLPU completa alcançar os escores 4 e 5 (categoria ruim) em relação aos escores 1 e 2 (categoria bom) foi igual a 2,43 , intervalo de confiança $(0,84$ a 7,07$)$ do grupo GC em relação ao grupo GI. Como associação não foi significativa embora que o valor do risco é 2,43, entretanto o intervalo para o RR contém o valor 1,00. A associação não foi significativa, pois embora o valor do risco tenha sido 2,43 , o intervalo de confiança para o RR contém o valor 1,00. 
Tabela 17 - Resultados das categorias das medianas entre avaliadores dos escores 1 e 2 (Boa) e 4 (Ruim) do ATTACK segundo o grupo

\begin{tabular}{|c|c|c|c|c|c|}
\hline \multirow{3}{*}{$\begin{array}{c}\text { Categoria } \\
\text { mediana } \\
\text { Categorizada }\end{array}$} & \multicolumn{4}{|c|}{ Grupo } & \multirow{3}{*}{ Valor de p } \\
\hline & \multicolumn{2}{|c|}{ GI $(n=28)$} & \multicolumn{2}{|c|}{$G C(n=23)$} & \\
\hline & $\mathbf{n}$ & $\%$ & $\mathbf{n}$ & $\%$ & \\
\hline 1 e 2 (Boa) & 24 & 85,7 & 15 & 65,2 & $\mathrm{p}^{(1)}=0,086$ \\
\hline 4 (Ruim) & 4 & 14,3 & 8 & 34,8 & \\
\hline
\end{tabular}

\subsection{Avaliação dos Resultados Intergrupos Relacionados à Largura/Amplitude da Fissura}

A largura/amplitude da fissura avaliada pela dimensão média de G-L e A-A' aferidas em T1 apresentou distribuição semelhante nos dois grupos (Tabela 4). A correlação entre a largura/amplitude da fissura assim avaliada e a relação maxilomandibular avaliado pelo FYOI não foi evidenciada pelo método de Spearman (Tabela 18).

Tabela 18 - Correlação de Spearman com a mediana dos escores com cada uma das medidas G-L e A-A'

\begin{tabular}{ccc}
\multirow{2}{*}{ Variável } & \multicolumn{2}{c}{ Grupo } \\
\cline { 2 - 3 } & $\mathbf{G I}(\mathbf{n}=\mathbf{3 2})$ & $\mathbf{G C}(\mathbf{n}=\mathbf{3 0})$ \\
\cline { 2 - 3 } G-L & $\mathbf{r}(\mathbf{p})$ & $-0,148(0,434)$ \\
A-A & $0,083(0,651)$ & $0,008(0,966)$ \\
\hline
\end{tabular}

$(*)$ Estatisticamente diferente de zero. 


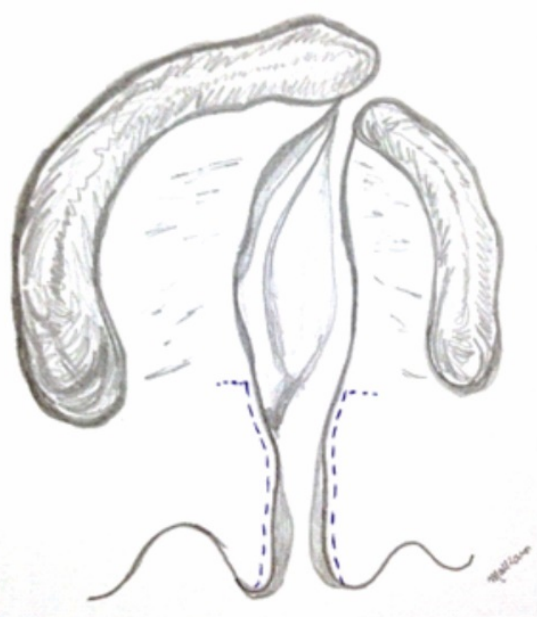

A

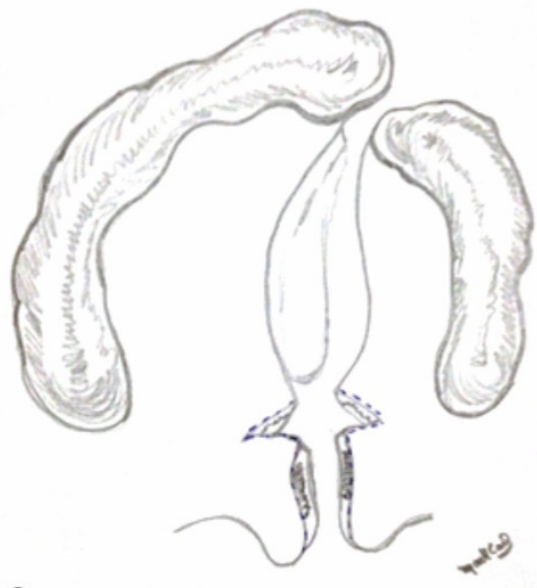

C

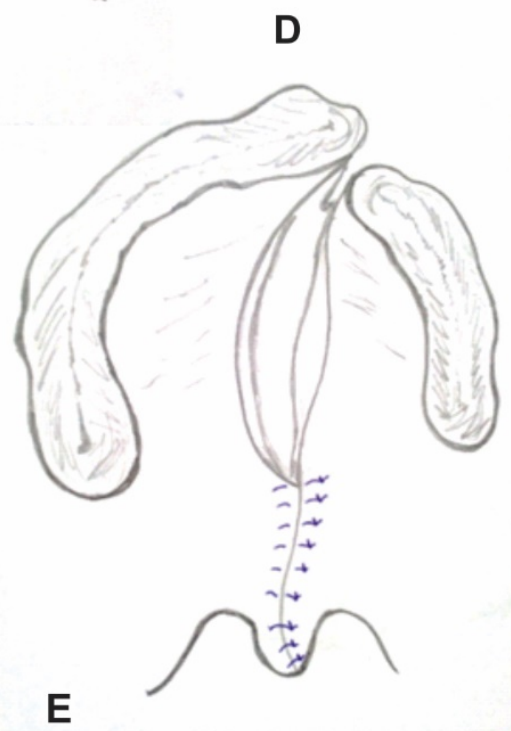

B

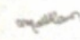

B
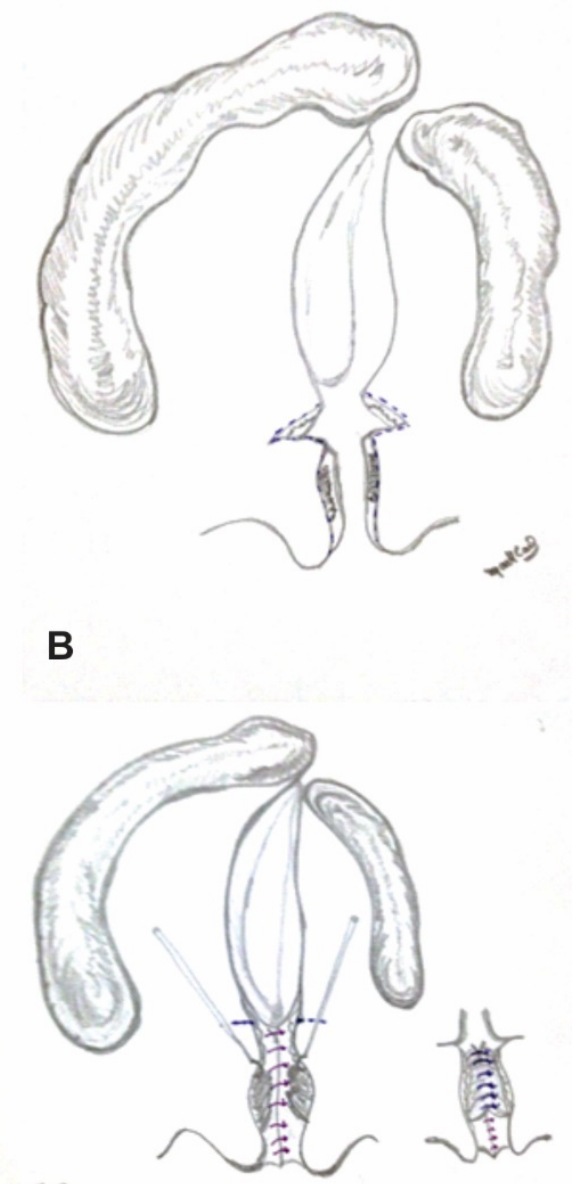


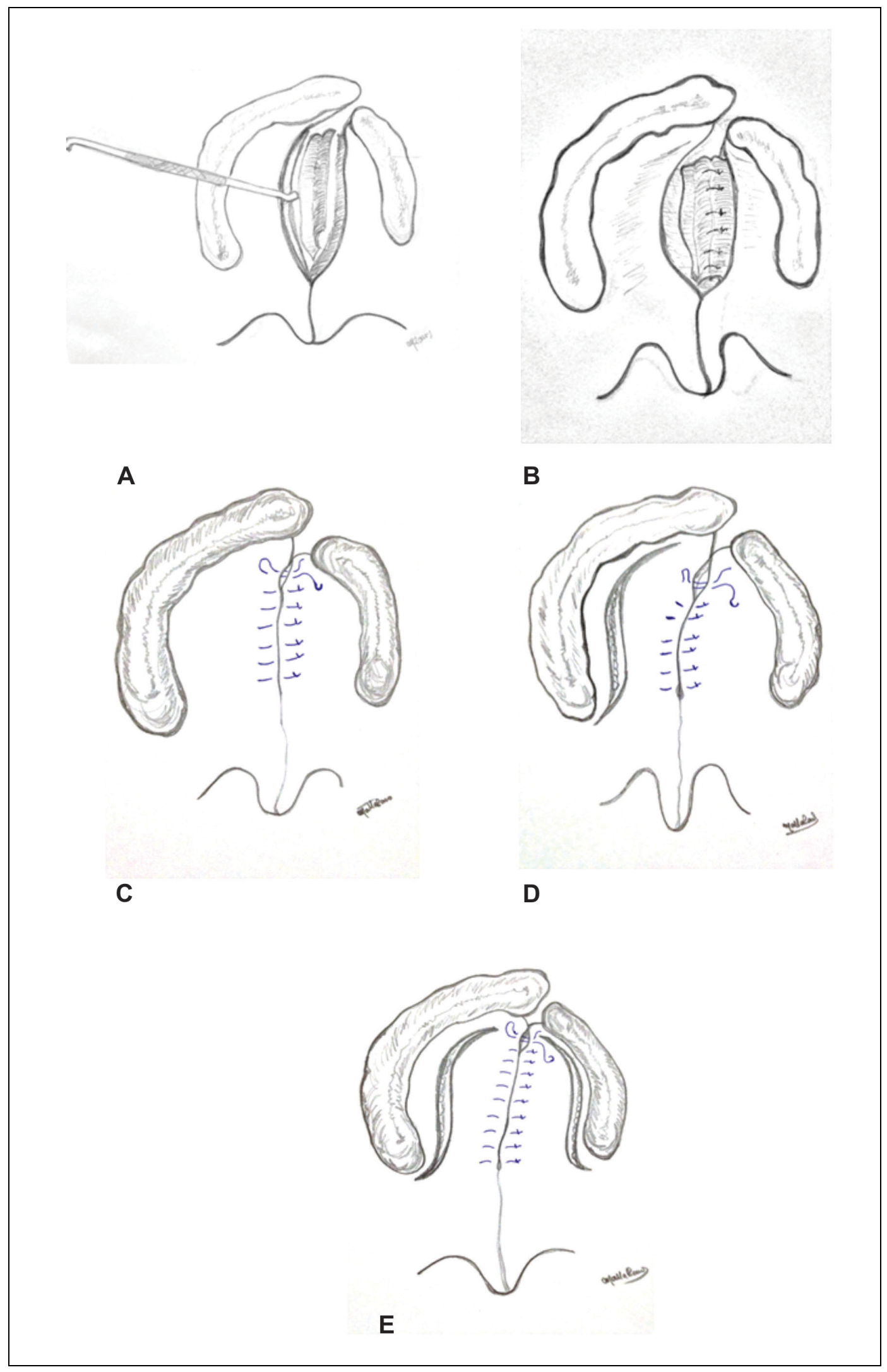

Figura 6 - $2^{\circ}$ Tempo - Fechamento do palato duro (Langenbeck modificada) 


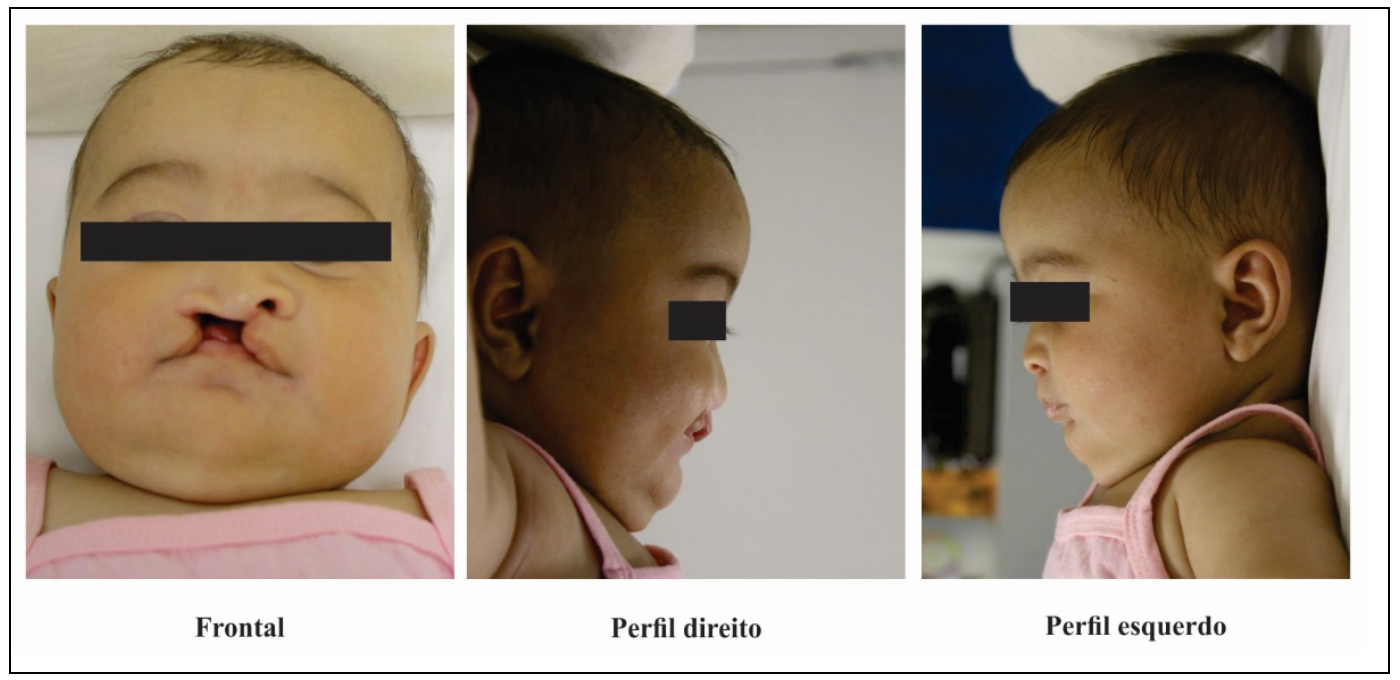

Figura 7 - Grupo GI - Admissão (Paciente: D. T. N.)

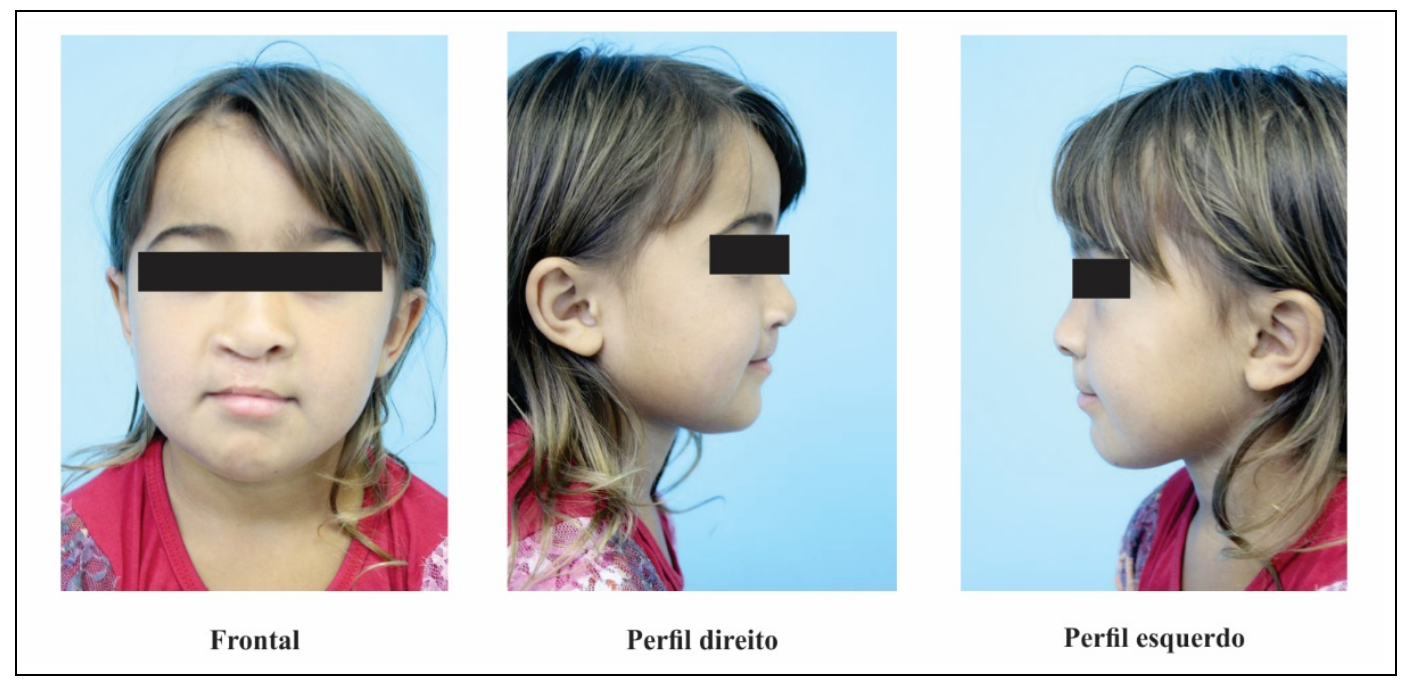

Figura 8 - Grupo GI - FYOI 1 (Paciente: D. T. N. - 5a 5m)

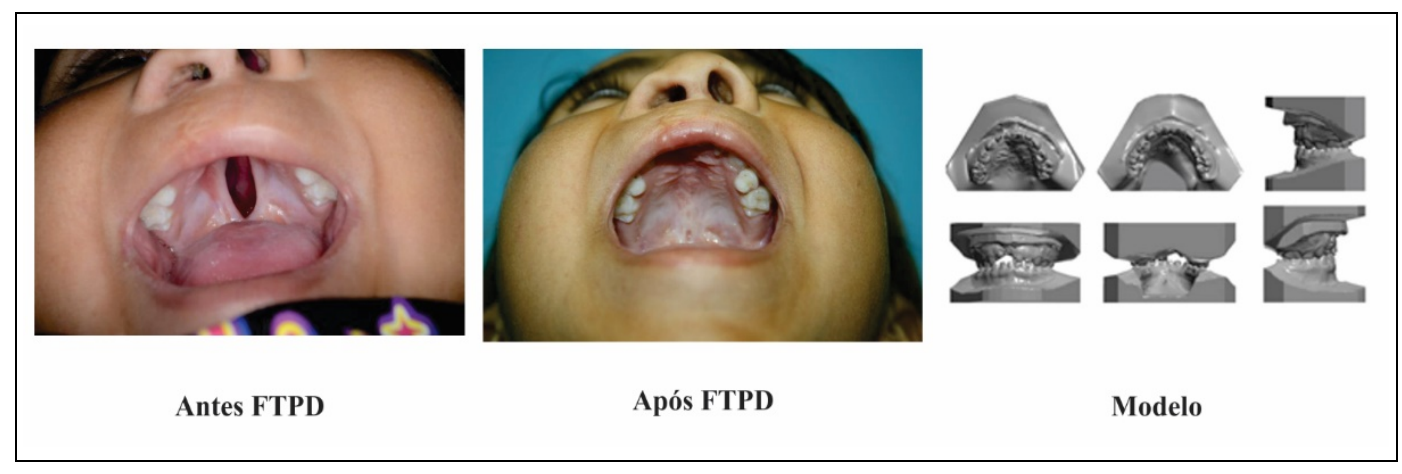

Figura 9 - Grupo GI - FTPD - Modelo FYOI 1 (Paciente: D. T. N.) 


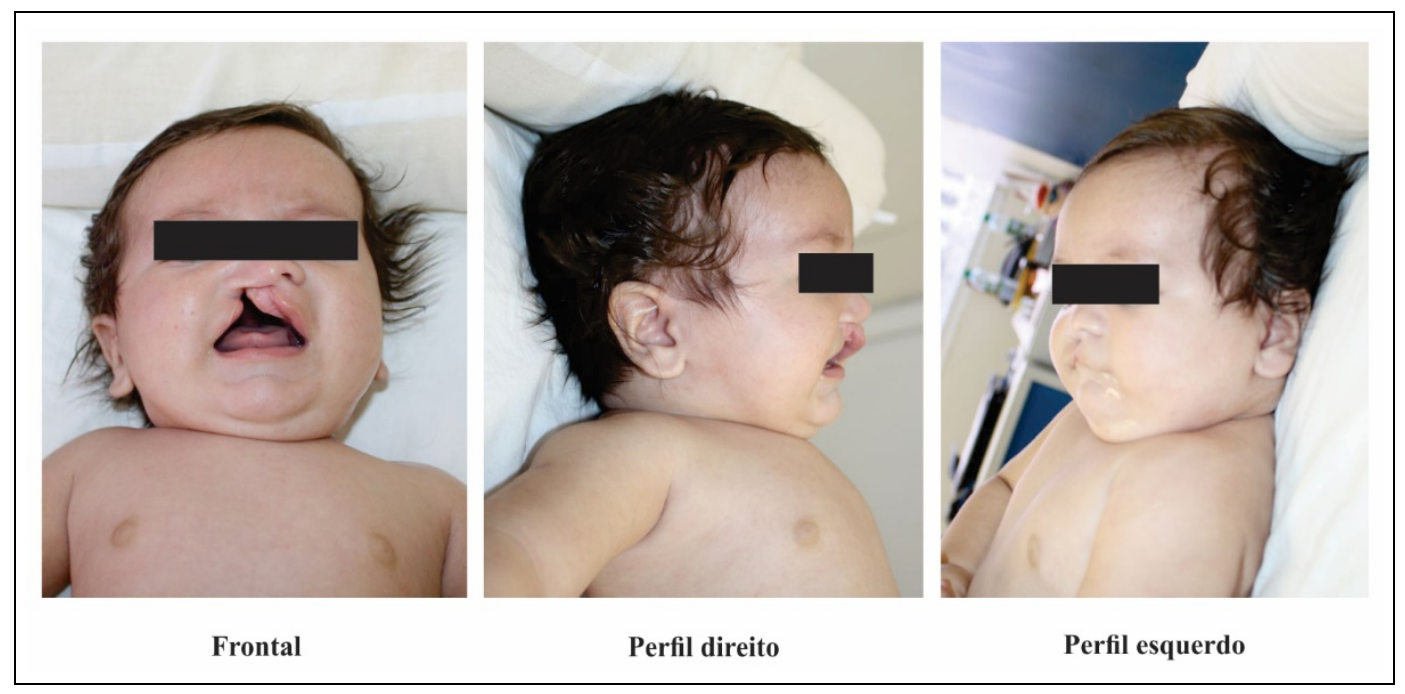

Figura 10 - Grupo GI - Admissão (Paciente: L. L. F. N.)

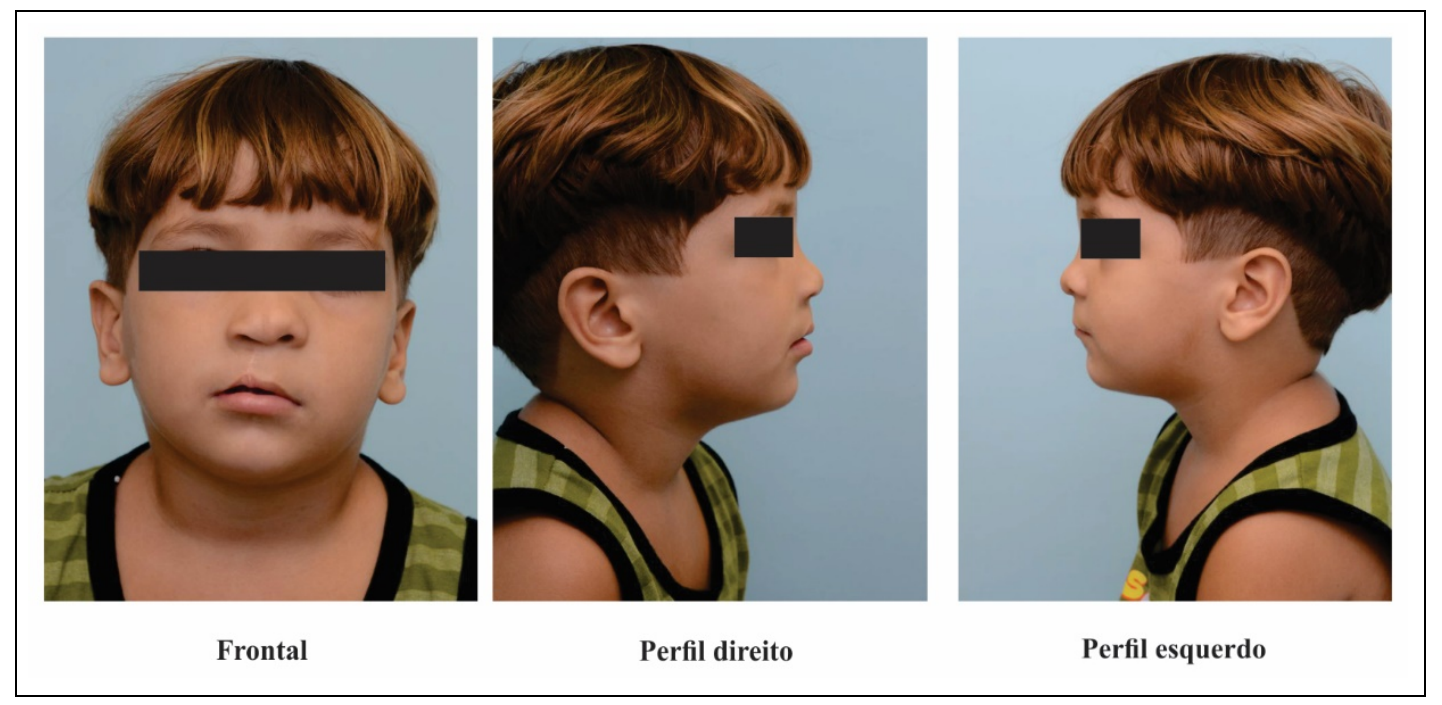

Figura 11 - Grupo GI - FYOI 4 (Paciente: L. L. F. N. - 5a 2m)

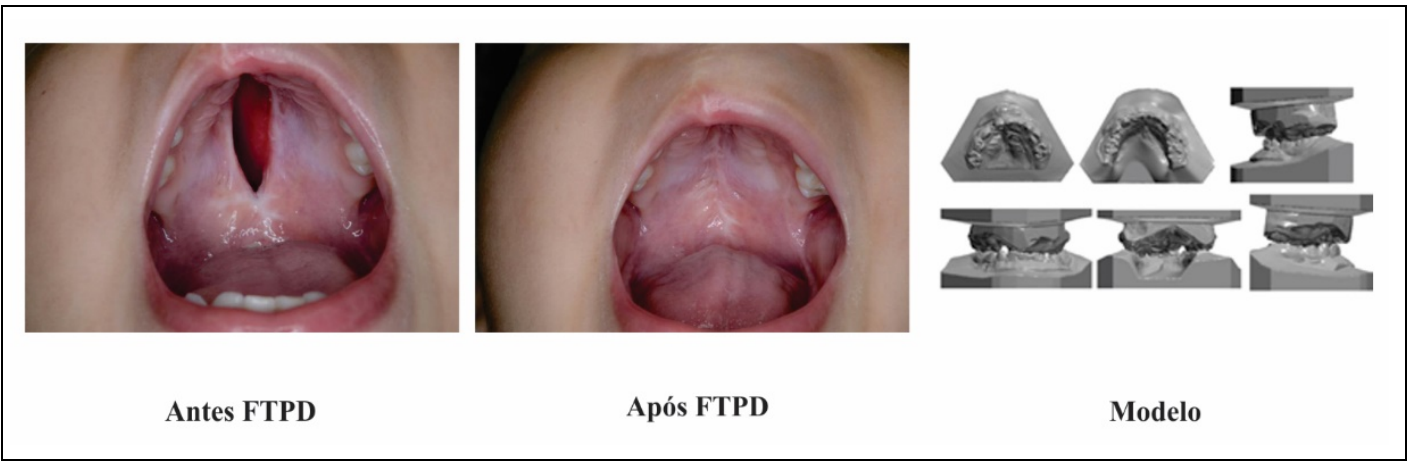

Figura 12 - Grupo GI - FTPD - Modelo FYOI 4 (Paciente: L. L. F. N.) 


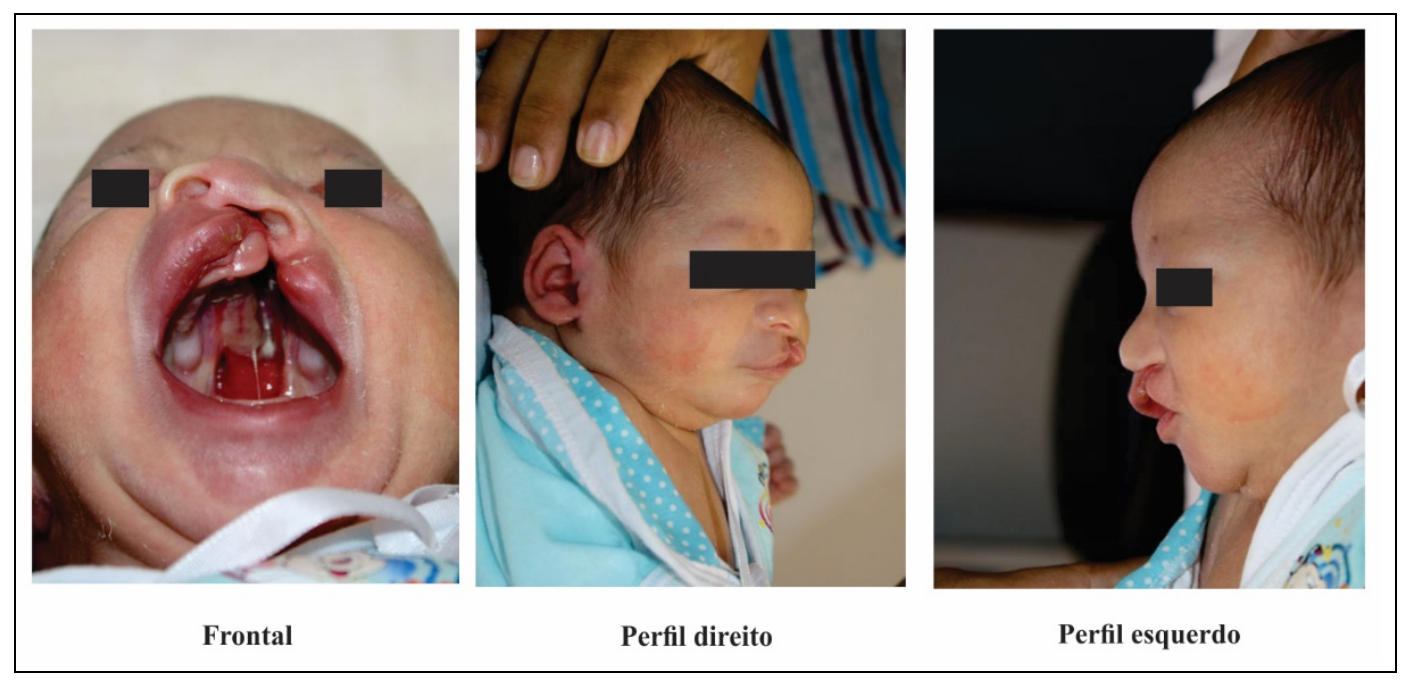

Figura 13 - Grupo GC - Admissão (Paciente: L. G. O.)

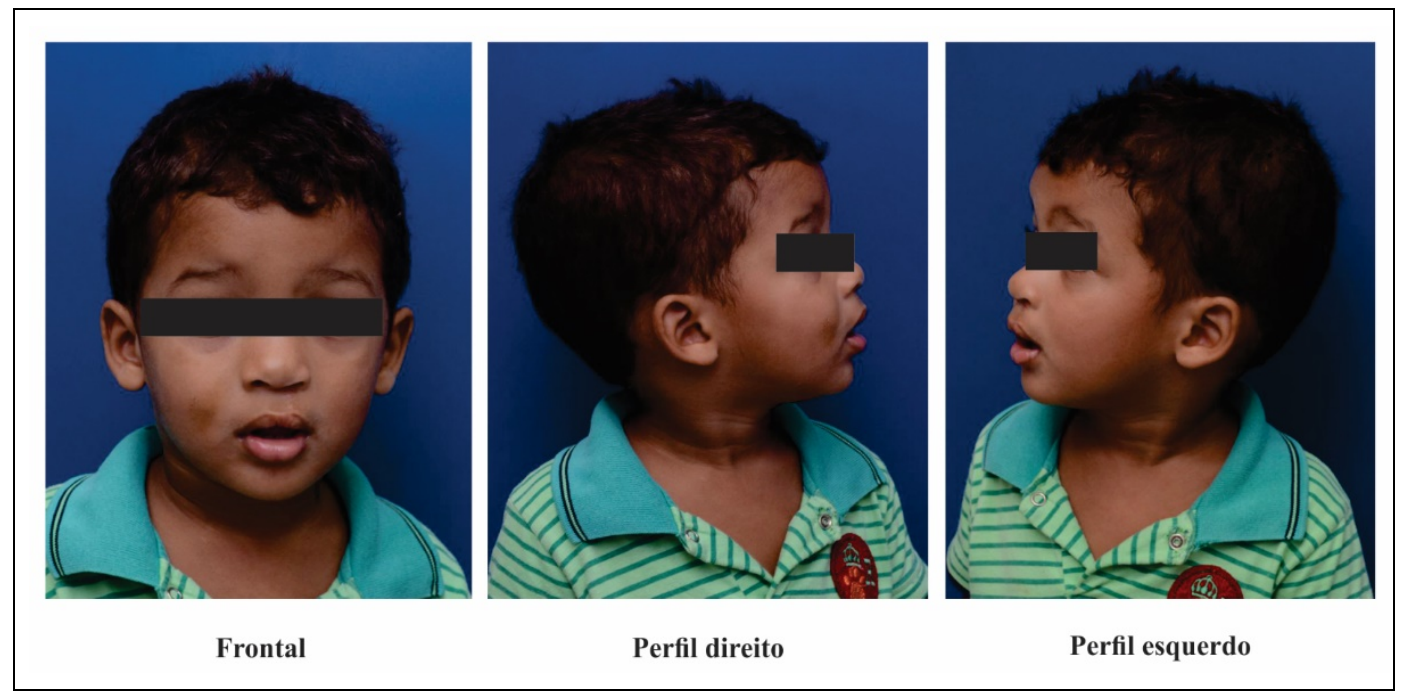

Figura 14 - Grupo GC - FYOI 2 (Paciente: L. G. O. L. - 4a 2m)

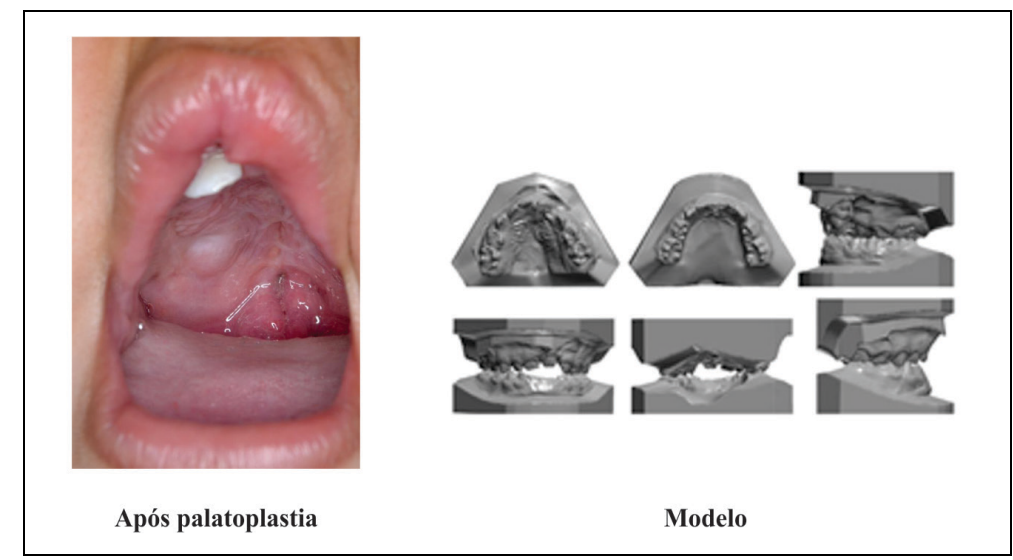

Figura 15 - Grupo GC - FYOI 2 após palatoplastia (Paciente: L. G. O. L.) 


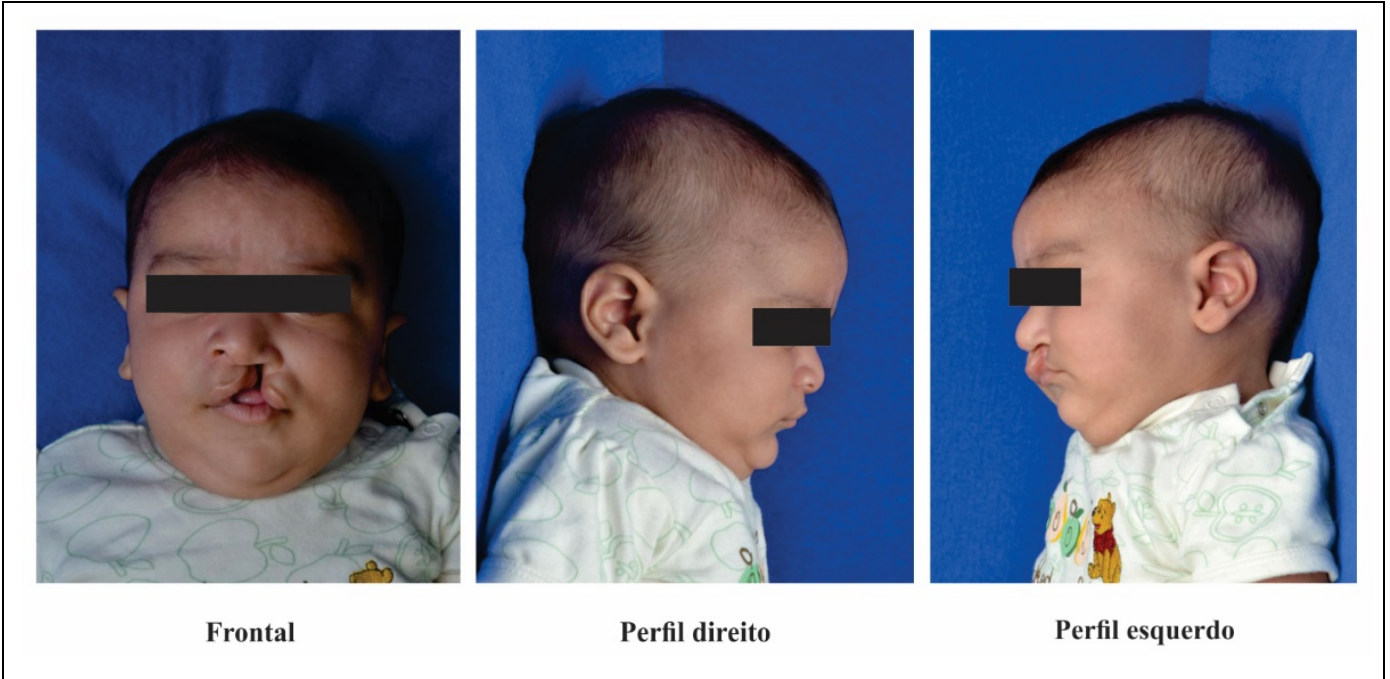

Figura 16 - Grupo GC - Admissão (Paciente: P. J. O. F.)

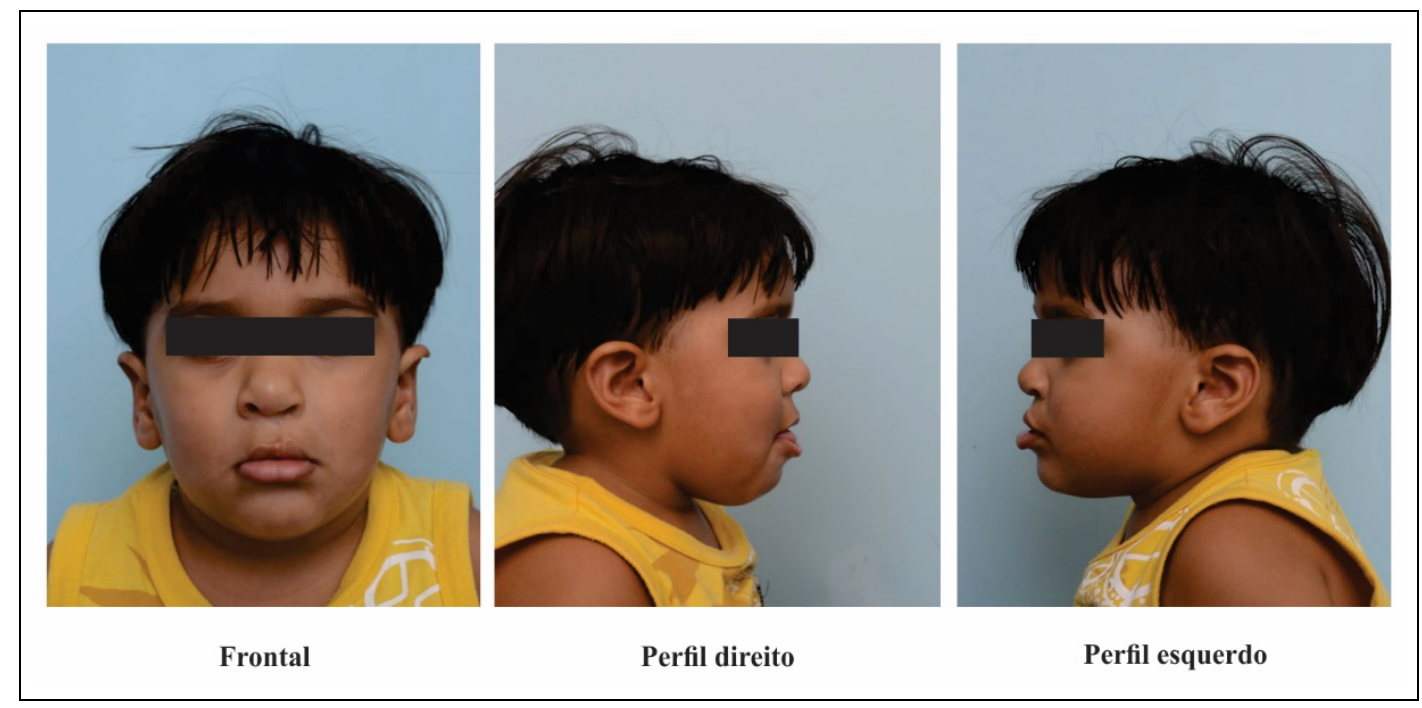

Figura 17 - Grupo GC - FYOI 4 (Paciente: P. J. O. F. - 3a 7m)

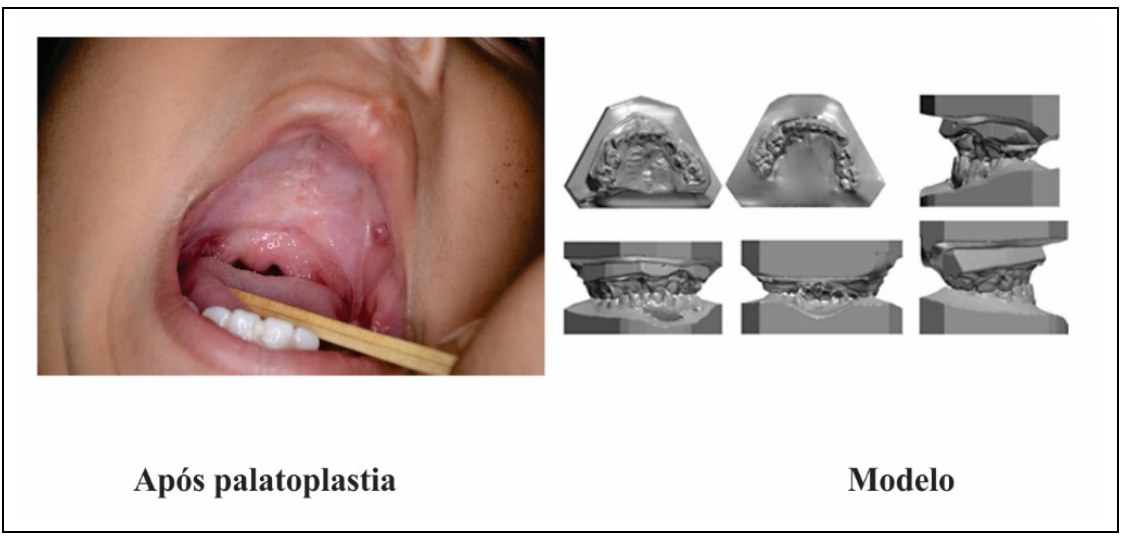

Figura 18 - Grupo GC - FYOI 4 (Paciente: P. J. O. F.) 
5 DISCUSSÃO 
A importância do tratamento da fissura labiopalatina de prover uma função palatina adequada para desenvolvimento da fala normal sem interferir significativamente no crescimento maxilofacial, é um conceito amplamente aceite por todos os que trabalham nesta atividade multidisciplinar delineando assim a primazia da função fonarticulatória, sem no entanto, menosprezar a importância que um adequado desenvolvimento do esqueleto facial tem nela e em outras funções também importantes com a mastigatória, auditiva, e claro que também a repercussão que gera sobre a imagem e consequente integração socioafetiva.

Além da multiplicidade de fatores que influenciam o resultado final dos tratamentos a que estes pacientes se submetem e que dificultam uma análise objetiva e sem vieses do papel de cada um, nesses desfechos, há também a necessidade de detectar o mais precocemente possível a evolução dos tratamentos e seus resultados, não só do ponto de vista do tratamento individual, mas também a de permitir auditorias, para que um centro possa em caso de claras evidencias deletérias alterar seus protocolos $39,170-173$.

Inúmeros estudos têm sido publicados sobre estes temas, pois além da própria limitação ocasionada pelos desenhos de pesquisa escolhidos, a falta de homogeneidade dos instrumentos de analise ou uniformidade conceptual das variáveis estudadas, dificulta a comparação entre os desfechos alcançados, e relativiza de forma impactante o alcance das conclusões obtidas ${ }^{127,170}$. O longo tempo de coleta de dados, as transformações que ocorrem durante o processo ${ }^{33,103,174,175}$ comum progressivo déficit de 
crescimento facial, os procedimentos requeridos para tratamento desta malformação ${ }^{33,176}$, poderão levar a diferentes leituras dos desfechos obtidos. Também o tempo de acompanhamento a que uma avaliação isenta e precisa obriga, abandonos e falta de adesão a tratamentos e avaliações, diminuindo muitas vezes o número de sujeitos analisados e assim também o impacto dos seus achados, são alguns dos fatores que mais intervêm e alteram as possíveis leituras dos desfechos alcançados.

Já há algumas décadas, Spriestersbach et al. ${ }^{177}$ apontavam a necessidade de serem realizadas pesquisas mais consistentes sobre este tema e desde os trabalhos de Roberts et $a{ }^{28}$ a alternativa dos ensaios clínicos, se tornava o caminho mais desejado para esclarecer as dúvidas relacionadas aos tratamentos dos pacientes com fissura, determinação esta que se consolidou pelas conclusões do projeto Eurocleft e subsequentemente se tornou diretriz da OMS.

Conforme constatado por inúmeros autores ${ }^{28,39,89,178,179}$, amostras heterogêneas, amostras de tamanho inadequado, participantes em várias faixas etárias, amostras comparando diferentes tipos de fissura, e grupos controle inadequados são frequentes na grande maioria dos artigos publicados, sobre este tema. Também problemas relacionados com o seguimento dos pacientes por longos períodos, estudos predominantemente retrospectivos e a inclusão de variáveis não controladas, são lembrados como limitantes e que interferem nas conclusões alcançadas ${ }^{89}$. Ainda assim, os estudos observacionais têm sido de fundamental importância para diagnosticar situações e apontar caminhos, de uma forma mais rápida e com menos riscos. Outro desenho de estudo apontado como padrão-ouro na busca de evidencias, a revisão sistemática com análise estatística mesmo com vários desenhos de pesquisa, inclusive observacionais, poderá fornecer informações equivalentes às de um ensaio clinico randomizado. conforme o encontrado por Nollet et 
$a l .{ }^{180}$. No entanto, os autores embora tenham chegado a conclusões importantes sobre fatores que interveem no crescimento facial concluem que há necessidade de serem realizados ensaios clínicos randomizados para a aprofundamento dessa questão.

O desenho do presente estudo, de um ensaio clínico randomizado (Randomized Clinical Trial [RCT]) diminui o risco de vieses, embora estes possam ocorrer em função, principalmente de erros na geração da sequência de alocação (randomização). Isso foi minimizado, por meio de um processo totalmente informatizado e somente realizada depois da cirurgia para tratamento da fissura labial, no decorrer do atendimento pósoperatório de rotina. Isso é evidenciado pela homogeneidade dos grupos amostrais, entre eles e com dados epidemiológicos, relativamente ao gênero, lateralidade e características morfológicas. Em relação aos vieses de seleção estes foram minimizados, garantindo-se a participação de forma continuada a todos os pacientes que de forma sequencial e dentro dos critérios de inclusão, deram entrada no CADEFI. A escolha do momento da randomização, somente após a queiloplastia, destinou-se a evitar contabilizar o abandono de tratamento, que é relativamente frequente após a correção da malformação labial em nosso Centro, conforme relatado em apresentação oral por este autor no $12^{\text {th }}$ International Congress on Cleft Lip/Palate and Related Craniofacial Anomalies, em 2013, realizado em Orlando, EUA ${ }^{181}$, sendo importante realçar que era o protocolo para a palatoplastia, o que seria avaliado.

Para evitar os vieses de performance referentes ao cegamento e independência dos avaliadores dos desfechos, optou-se por selecionar um painel de julgadores externo ao Centro, atuando de forma independente e autónoma ${ }^{163}$ além de serem portadores de expertise comprovada através de seguidos treinamentos, que avaliaram os modelos de estudo de forma totalmente randomizada e cega em relação ao 
protocolo adotado. A escolha dos examinadores, especialistas em ortodontia, consubstancia o publicado por Ozawa ${ }^{168}$ que encontrou nas avaliações publicadas na sua tese de doutorado, um maior rigor e melhor concordância inter e intraexaminadores, quando realizaram a avaliação das relações intermaxilares em modelos de estudo. Os valores encontrados neste estudo inserem-se nessa linha, tendo encontrado muito boa ou boa concordância intra e interexaminadores conferindo boa credibilidade aos seus achados (Tabela 11).

A descontinuação por abandono do tratamento pode afetar a credibilidade das conclusões $^{182}$. Objetivando evitar os vieses de seguimento (diferenças sistemáticas entre os grupos nas perdas e abandonos) e vieses de detecção (diferenças sistemáticas entre os grupos em como foram determinados os desfechos) foi realizada uma abordagem multidisciplinar com a participação de vários setores do Centro na tarefa de evitar o abandono do tratamento, ou no caso de tratamentos ancilares, como tratamentos odontológicos e fonoaudiológicos para o acompanhamento dos processos de amamentação, balbucio, otimização do sistema sensório-motor-oral e aquisição de linguagem. Apenas dois pacientes abandonaram o presente estudo antes de receberem a intervenção cirúrgica, o que representa uma perda de 3,12\%, entretanto não foi distribuída igualmente entre os grupos, uma vez que ambos os pacientes haviam sido randomizados para participar do grupo controle além de que a necessidade da palatoplastia para a recuperação do paciente é fato unanimemente compreendido e aceite pelas famílias e pacientes. Encontramos alguns problemas para a obtenção dos modelos e das avaliações fonoarticulatorias, que foram ocasionados pela dificuldade no contato com os pacientes, em que a inconsistência dos registros pessoais foi o principal óbice, como o que foi constatado também por 
Gundlach et al. ${ }^{183}$, e o mesmo acontecendo em regiões com melhor desenvolvimento socioeconômico e ampla cobertura sanitária ${ }^{163,184,185}$.

O desenho do presente estudo apresenta maior credibilidade, afastando inicialmente variáveis não controladas, multiplicidade das mesmas, amostras insuficientes, grupos com caraterísticas indefinidas, e de seguimentos diferentes com múltiplos instrumentos de análise, muitas vezes aplicados de formas diversas. Em relação ao tamanho da amostra embora não tivesse sido seguido de forma estrita o postulado por Shaw et al..$^{39}$, Flynn et al. ${ }^{186}$ e Richard et al. ${ }^{187}$, o cálculo se enquadra dentro dos números que esses autores apontam. Assim meio ponto na escala de Goslon era a amplitude da diferença entre os centros que se colocavam entre o topo e o meio da classificação e entre os centros classificados entre o meio e a parte inferior da tabela na coorte, avaliada aos nove anos de idade, no estudo publicado em $1992^{31,38}$. Isso equivalia a uma diferença de $20 \%$ na taxa de osteotomia da maxila, entre esses centros. Com $5 \%$ de probabilidade e poder de $80 \%$, a detecção da diferença de 0,5pontos na escala de GOSLON intercentros na idade de nove anos, segundo Shaw et al. ${ }^{188}$ requer amostras com as seguintes dimensões: 42 casos de FLPU necessários em uma comparação de dois grupos, 63 necessários em uma comparação de um grupo de cinco em relação a uma referência, e 77 exigido em um grupo de seis para comparação mútua. Richard et al. ${ }^{187}$ chegavam a números menores de sujeitos, 19 em cada grupo amostral quando procuravam uma diferença sistemática de 0,75 dum ponto na escala de Goslon. O grupo do Scandcleft optou por um cálculo diferente em virtude de ser um estudo multicêntrico, avaliando quatro protocolos diferentes e com 10 centros diferentes envolvidos ${ }^{185}$. 
Richard et al. ${ }^{187}$ publicaram os resultados de ensaio clinico randomizado comparando dois protocolos cirúrgicos um com fechamento do palato duro três meses após a queiloplastia e veloplastia e o outro com a veloplastia realizada também três meses após a queiloplastia e fechamento do palato duro, não tendo encontrado diferenças nos desfechos avaliados através de um sistema de avaliação pouco usual, overjet dos incisivos medido em modelos de estudo e que teria segundo os autores uma relação com o Goslon Yardstick. O processo de randomização inadequado e as faixas etárias em que foram realizadas as intervenções são também outros óbices encontrados neste artigo. Em 2015 um grupo liderado por Ganesh et al. ${ }^{189}$ que publicaram estudo relatando os resultados de um ensaio clínico randomizado comparando protocolos diferentes do proposto pelo presente estudo, e que apresentou uma elevada taxa de abandono e com um número também importante de desfechos não avaliados, embora tenha optado por um tamanho amostral acima dos parâmetros estatísticos adotados em outros ensaios clínicos. Em consulta aos sítios na Internet "Clinical Trials.com" e "Registro Brasileiro de Ensaios Clínicos (ReBEC) não foi encontrado nenhum outro estudo referente ao crescimento facial, desempenho fonoarticulatório, relacionado com fissura labiopalatina. No site "International Standard Randomised Controlled Trial Number (ISRCTN.org)", encontra-se em andamento outro ensaio clínico, o Scandcleft ${ }^{190}$, este sendo multicêntrico e também analisando múltiplos protocolos o que exige uma amostra bem maior e que em virtude de suas características apresenta um nível bem maior de complexidade na análise de seus desfechos. Em outubro de 2016, foi publicado o primeiro estudo deste grupo de pesquisadores relacionado ao crescimento maxilar. Apresentam uma amostra de 448 sujeitos submetidos a tratamento, dos quais foram obtidos 418 modelos para análise e avaliação. 
Múltiplos estudos têm sido realizados utilizando o índice FYOI (Atack) que apresenta altos níveis de confiança e reprodutibilidade, relacionando sempre seus resultados de forma longitudinal, com outros obtidos em idades mais tardias, mantendo as mesmas expectativas clinicas $59,76,77,176,184,185,189,191$. Para a avaliação da confiabilidade das avaliações foram realizados testes estatísticos (kappa de Cohen) que indicaram uma concordância boa e excelente. Para avaliação da concordância intraexaminadores foram selecionados randomicamente $40 \%$ dos modelos em cada grupo, e que foram avaliados simultaneamente. O mesmo procedimento foi seguido pelos investigadores do Scandcleft ${ }^{185}$, embora com um número menor de modelos reexaminados. $\mathrm{O}$ fato dos modelos terem sido obtidos entre os quatro e seis anos de idade (idade média 55,5 meses) evitou a exposição dos sujeitos da pesquisa a outros tratamentos - variáveis não controladas - que poderiam influenciar os desfechos estudados. A classificação da relação maxilo-mandibular por meio dos índices Goslon Yardstick e o FYOI, propostos por Mars et al. ${ }^{69}$ e Atack et $a l .{ }^{76}$ respetivamente, são referidos por alguns críticos, como grosseiros (sic “coarse") ${ }^{180}$ mas os idealizadores dos índices contra-argumentam, reafirmando que de fato isso é intencional pois permite minimizar subtilezas que poderiam prejudicar uma análise objetiva e de todo o conjunto, não permitindo um agrupamento mais simples e por consequência mais eficaz, importante para a comparação dos desfechos. Outros métodos propostos, em virtude de poderem valorizar uma deformidade em prejuízo de outra (mordida cruzada versus mordida aberta, por exemplo) ou podendo em virtude de um sistema questionável atribuir uma severidade maior a uma relação moderadamente alterada de forma geral do que a uma de maior gravidade, mas mais localizada, apresentam limitações no seu uso, para avaliar o desempenho coletivo de um centro. 
A utilização do FYOI é um método eficaz na análise do desempenho de um grupo de pacientes com FLPU submetidos a cirurgia, não para analises individuais, em que deverão ser considerados outros métodos como o Huddart/Bodenham Index ${ }^{70}$, um sistema de pontuação para avaliar as relações interdentais em que não é possível avaliar as relações entre as bases apicais, tendo uma capacidade relativamente fraca para discriminar casos com vários prognósticos ${ }^{192}$.

Foi escolhido um método de coleta e uso das classificações realizadas pelo painel de avaliadores para o índice FYOI conforme o proposto por Flinn et al. ${ }^{186}$, Mikoyaet $a l .{ }^{193} \mathrm{em}$ virtude de podermos minimizar vieses de avaliação e consequente análise. $\mathrm{O}$ uso da mediana conforme o que foi escolhido por Ozawa ${ }^{168}$ e Jonhsonet al. ${ }^{194}$, em que algumas das avaliações não foram consideradas (Tabela 12) pode aumentar a imprecisão destes instrumentos de avaliação, e tornar indefinidos quadros por vezes clinicamente evidentes. A forma usada por Flinn et al. ${ }^{186}$, em que considera todos os escores obtidos por cada paciente, pode ajudar a dirimir pequenas diferenças estatísticas, como a encontrada na avaliação da distribuição entre os grupos e suas pontuações usando as medianas dos índices (Tabelas 15 e 16). Ao analisar as Tabelas 16 e 17 e constatar que a diferença entre os grupos era marcante embora sem significado estatístico, o uso do método aplicado por Flinn et al. ${ }^{186}$ poderá dirimir as dúvidas suscitadas clinicamente. Nollet et al. ${ }^{180}$, propõe o uso de das medias em cada agrupamento de escores, o que no entanto apresenta vício formal pois obtêm a média de variáveis qualitativas categóricas, e que pode alterar de forma substancial a natureza da informação que é transmitida. Também a forma como são informados os resultados obtidos usando a média de todos os escores obtidos além de fornecer informação pobre, conforme o referido por vários autores $^{186}$, principalmente quando se pretende comparar a performance de centros 
diferentes. No entanto e em função do seu uso amplamente disseminado, optou-se também por publicá-la embora conscientes das limitações do seu significado, mas que neste estudo apresenta também diferença estatisticamente significante entre os dois grupos. A apresentação dos resultados agrupando os desfechos em três grupos (1 e 2: 3; 4 e 5) tem sido extensivamente utilizada, e decorre do significado clinico que transmite e que se tornou o cerne da consubstanciação dessa classificação $0^{38,39}$, ou seja, o risco que apresentam os pacientes de serem submetidos a cirurgia secundária para avanço maxilar. As diferenças estatisticamente significantes em relação aos desempenhos dos vários protocolos de tratamento poderão não surgir quando se comparam medias, mas tornamse evidentes quando se compara as suas distribuições entre os vários escores ${ }^{186}$, embora isso não tenha ocorrido neste estudo.

Os níveis de concordância inter e intraexaminadores nesta pesquisa variaram de bom a muito bom, conforme o entendimento de Altman ${ }^{195}$. O erro sistemático, passível de ocorrer neste tipo de avaliação foi controlado por meio de múltiplas capacitações para o uso do FYOI a que foram submetidos os três examinadores, além do fato de serem especialistas em Ortodontia, o que lhes confere maior credibilidade conforme Ozawa ${ }^{168}$, demonstrou em sua tese. Várias estratégias têm sido usadas para esta avaliação, desde o número de peritos, confidencialidade, autonomia dos mesmos, espaçamento das observações e métodos de exposição, e que são desde o início, preocupações dos seus idealizadores. Métodos como o usado por Sinko et al..$^{54}$, torna mais impreciso e passível de inúmeros vieses pois consiste na pactuação entre os dois examinadores, tornando essa avaliação multilateral em unilateral, com a provável expressão da liderança do mais experiente ou com maior autoridade ou prestigio, o que parece contrariar a intenção dos mentores deste método e prejudicar a acurácia na avaliação. Esta estratégia de 
conciliação das avaliações, que foi usada também pelo CSAG Study ${ }^{59}$ é criticada hoje pelos autores que realizam a revisão da situação atual do tratamento das FLP no Cleft Care UK Study $(\mathrm{CCUK})^{173}$, retirando a confiabilidade dos resultados obtidos. Ao escolher o índice pela mediana pode ainda dar uma ideia errônea das avaliações, por não mostrar a frequência de escores que não se encaixavam nesses parâmetros.

A utilização de modelos de gesso digitalizados além de permitir uma melhoria na logística e na acessibilidade, permitirá cotejar melhor as várias avaliações ampliando o número de peritos e também evitar os erros sistemáticos, pois possibilita melhor capacitação dos examinadores. A verificação por auditores independentes de avaliações anteriores e a criação de grandes bancos de dados tornase possível permitindo antever a realização de estudos multicêntricos de maior alcance. A facilidade de armazenamento, o acesso e o maior controle dos modelos além do uso de scanners intraorais que podem facilitar a obtenção dos modelos é hoje uma realidade em alguns centros. Isso permite esperar a sua disseminação pela própria lógica do processo produtivo que vai tornando cada vez mais acessíveis, novas tecnologias. Embora Atack et al. ${ }^{76}$ discordasse da avaliação em modelos fotográficos, o surgimento de novos dispositivos e "softwares" após essa postulação permitindo inclusive a visualização de detalhes que são mais dificilmente vistos em modelos físicos, torna este modo mais eficaz e com maior acurácia ${ }^{82,83}$.

Os pacientes com fissuras labiopalatinas formam um grupo heterogêneo com características morfológicas por vezes bem diversas, e assim se faz necessário, analisar um grupo mais homogêneo como o dos portadores de FLPU, mesmo assim, ainda com atributos anatômicos (largura da fissura, banda cutânea labial, agenesias dentarias entre outros) e funcionais diversos. O fato de não terem sido estabelecidos, como critérios de 
inclusão/exclusão esses diferenciais além de evitar um aumento considerável do tamanho da amostra, para contemplar esses subgrupos, se deu em função de que não se encontrou na literatura consultada, evidencias irrefutáveis da sua influência nos resultados obtidos. Semb ${ }^{127}$ em estudo que faz uma ampla revisão dos casos atendidos no Centro de tratamento de fissuras em Oslo, não encontraram diferenças dos desfechos entre os pacientes com e sem banda cutânea labial. Já Ozawa ${ }^{168}$, revisando amostras do Centrinho encontrou no entanto em sujeitos com bandas cutâneas labiais mais amplas, desfechos mais favoráveis. Embora não negligenciáveis esses achados veem sua importância diminuída nesta pesquisa em virtude da alocação dos sujeitos, realizada de forma randomizada, e de não ter havido uma diferença na prevalência da banda cutâneas entre os dois grupos (Tabela 2). Também é relevante considerar que a influência desse fator foi minimizada pelo fato de todos os sujeitos terem sido submetidos a queiloplastia previamente, e assim relegando a importância da banda como fator restritivo, e não se observando diferença entre os pacientes com ou sem essa característica (Tabela 5).

Outras variáveis como gênero ${ }^{196-199}$, e etnia ${ }^{193,200}$ também podem interferir nos desfechos estudados. Neste estudo não foi investigada a existência de diferença entre os gêneros quanto ao crescimento facial reveladas pelos escores do FYOI obtidos pelas crianças no grupo GI e no GC. Entretanto, possivelmente esta variável não interferiu nos resultados alcançados uma vez que prevalência dos gêneros foi semelhante nos grupos GI e GC, sem diferença significante entre eles (Tabela 1), corroborando os dados da literatura ${ }^{4,5,8,201}$. Em virtude das características étnicas da população brasileira, que apresenta uma ampla miscigenação, a etnia não foi objeto de investigação nesta pesquisa.

A possibilidade de outras variáveis interferirem no crescimento facial foi levantada por $\operatorname{Ross}^{33}$ de forma sistemática, investigando fatores presumivelmente 
iatrogênicos. A cirurgia, principalmente a palatoplastia, tem um papel preponderante no tratamento destas malformações determinando de forma direta ou indireta seus desfechos. Variáveis de menor monta como potencial genético, displasia intrínseca, procedimentos adjuvantes além da inteligência e motivação do paciente, também podem influenciar os desfechos ${ }^{33}$.

A cronologia das cirurgias, a queiloplastia, a dimensão da fissura, as técnicas cirúrgicas são algumas variáveis que podem influenciar alterações esqueléticas ${ }^{92}$, embora sejam assuntos controversos. A possibilidade de confundimento em função da ação destes fatores fez com que tivessem sua influência minimizada no nosso estudo, com a distribuição randômica e o uso de técnicas e estadiamento uniformes.

A opção por um único cirurgião em todas as etapas e uma só técnica de reconstrução do lábio e nariz evita viés de proficiência, conforme o realçado por vários autores $^{33,176,202}$, já que a habilidade e experiência do cirurgião e o uso de técnicas cirúrgicas adequadas, podem ser responsáveis pelos resultados alcançados. Ao unificar o tratamento do lábio com as mesmas abordagens cirúrgicas, no lábio e nariz, possibilita que seja minimizada a influência do processo cicatricial sobre o arco alveolar e espinha nasal, responsabilizada segundo Normando e Capelozza et al. ${ }^{203,204}$, Liao et al. ${ }^{114,203,204}$, Bardach $^{205}$ e Rousseau et al. $^{206}$, por parte da deficiência no crescimento maxilar. No presente estudo, a opção de realizar a queiloplastia de forma isolada, diferentemente do proposto por Ljla et al. ${ }^{152}$ e Rohrich e Gosman ${ }^{160}$, destinou-se a isolar uma variável que poderia interferir no crescimento anteroposterior da maxila, equalizando para toda a amostra essa influência, pois não havia sido feita ainda a alocação do paciente em qualquer um dos grupos amostrais, aquando da sua efetivação. Esse procedimento também foi adotado por Mikoya et al. ${ }^{193}$, embora tenha previamente escolhido o 
procedimento a ser adotado para a palatoplastia, e esta realizada por cirurgiões diferentes. No estudo em tela escolha da mesma técnica cirúrgica ${ }^{166,167}$ para a execução da queiloplastia, teve o mesmo objetivo, além de ser uma técnica usada de forma frequente pelo cirurgião, evitando o viés de proficiência. Não foi realizado, o fechamento da região alveolar, não interferindo assim com a sutura pré-maxilovomeriana, o que segundo Delaire e Precious ${ }^{93}$, poderia comprometer o crescimento vertical da maxila, ou o seu crescimento anterior ${ }^{33}$.

As técnicas e táticas cirúrgicas usadas na correção da malformação palatina poderão interferir no crescimento facial ${ }^{207,208}$,e algumas das suas características são unanimemente consideradas como tendo influência nos desfechos. A presença de amplo tecido cicatricial, áreas ósseas desnudadas e com cicatrizes por segunda intenção, amplitude dos descolamentos, localização das incisões, áreas a serem preservadas foram algumas das características consideradas na escolha das técnicas cirúrgicas investigadas nesta pesquisa. Evitar incisões amplas na transição do palato duro e palato mole, região considerada importante no crescimento anteroposterior da maxila, além da dissecção ampla da musculatura velar com o intuito de alongamento do véu palatino, tornando-o mais eficiente no fechamento do anel velofaríngeo, foram os cuidados mais presentes na abordagem do palato mole. Evitou-se o uso de retalhos vomerianos como os descritos por Lilja et al. ${ }^{209}$ que mesmo reduzindo a prevalência de fistulas nas suas series, veem o seu uso contestado por diversos autores como detrimental para o crescimento vertical da maxila ${ }^{93,137,210}$, fato constatado também pelo grupo de Gotemburgo ${ }^{211}$. Em contrapartida Ganesh et al. ${ }^{189}$ e Ferdous et al. ${ }^{212}$ encontraram desfechos favoráveis com o uso de retalhos vomerianos não tendo constatado diferenças no crescimento vertical ou sagital da maxila. Mesmo assim optou-se por uma padronização das técnicas e táticas cirúrgicas 
empregadas nesta pesquisa que contribuísse para diminuir o número de variáveis não controladas que pudessem alterar os desfechos analisados.

O uso da técnica de Von Langenbeck ${ }^{155}$ modificada pelos procedimentos advogados por Kriens ${ }^{143}$, Braitwaite e Maurice ${ }^{144}$ e Sommerlad $^{146}$, foi a opção escolhida para o grupo controle (GC) pois além de ser o procedimento adotado no protocolo tradicional seguido no CADEFI, existem inúmeros trabalhos publicados ${ }^{176,213}$ relatando seus desfechos, sem objeções radicalmente contrarias, diferentemente de outras abordagens cirúrgicas ${ }^{134,138}$ e evitando técnicas ${ }^{131,214}$ que comprovadamente apresentam desfechos muito desfavoráveis relacionados ao crescimento facial. A cronologia para realização da palatoplastia completa, no grupo GC, entre os nove e 18 meses (idade média 11,84 ) é adotada em grande número de protocolos cirúgicos ${ }^{215-217}$.

A veloplastia, que consistiu no passo inicial do protocolo a ser avaliado (grupo GI), foi realizada entre os seis e 12 meses de idade (média de 10,62 meses e desvio padrão de 3,06 meses). Houve uma dilatação do prazo proposto inicialmente em virtude de múltiplos fatores, destacando-se a falta de condições clinicas para cirurgia derivada principalmente de infecções respiratórias altas e anemias ferriprivas ${ }^{134}$. A falta de adesão motivada por questões logísticas e econômicas, também foi responsável por adiamentos dos procedimentos cirúrgicos.

A escolha da referida faixa etária foi decorrente do entendimento de que há a necessidade de reconstrução velar de forma a que o esfíncter velofaríngeo se torne o mais precocemente, ativo e eficiente. Lohmander et $a l .{ }^{162}$ constataram que a veloplastia quando realizada dentro desse intervalo etário, a longo prazo não influi no desempenho fono-articulatório. 
A correção adequada da musculatura palatina também pode interferir no crescimento vertical da maxila pois estes músculos tem uma ação que se contrapõe à da musculatura que age sobre a mandíbula. Não obstante a proposta histórica inicial do fechamento tardio do palato duro tenha sido colocado para depois do final da adolescência $^{128,140}$, os problemas derivados do fraco desempenho fonoarticulatório $^{141}$, tem levado à proposição de múltiplas opções cronológicas para a sua execução mais precoce. A opção tomada nesta pesquisa de realizar o fechamento do palato duro entre os três e quatro anos de idade, se relaciona com os bons resultados verificados em várias pesquisas, quando realizada até essa idade e o impacto menor que originou na voz e fala desses pacientes ${ }^{154,211,218,219}$, e tendo em conta as várias etapas do processo de crescimento facial.

Os resultados obtidos por Gaggl et al. ${ }^{138}$ e Tanino et al. ${ }^{134}$, relativos ao crescimento facial, são inferiores aos encontrados por outros autores que usam os protocolos com fechamento tardio do palato duro, o que pode ser devido às técnicas cirúrgicas escolhidas. As técnicas de Wiedmaier, Veau e Wardill, além de deixarem áreas ósseas desnudadas invadem espaços que tem relação com as suturas interósseas e portanto importantes para o crescimento facial ${ }^{220}$, principalmente o crescimento anteroposterior.

A idade média em que foi realizada a palatoplastia anterior no grupo GI, aproximadamente 39 meses se insere na atual tendência de antecipação deste tempo cirúrgico $^{142,217}$ no entanto não se constatou, embora de forma subjetiva, em todos os casos uma diminuição expressiva da amplitude da fissura conforme relatado por Friede $^{89}$. Em cerca de um terço dos pacientes do grupo GI houve a necessidade de serem realizadas incisões liberadoras laterais durante o procedimento cirúrgico para 
o fechamento do palato duro, o que se relaciona diretamente com a dimensão da fissura e as áreas das laminas palatinas. A opção de não ter realizado o retalho vomeriano posterior para o forro nasal, seja talvez segundo Owman-Moll et al. ${ }^{221}$, responsável por esse achado, embora em contrapartida tenha evitado incisões mais amplas na transição do palato duro com o palato mole o que poderá ter influenciado positivamente o crescimento anteroposterior da maxila, e não ter repercutido de forma negativa nas dimensões posteriores do palato.

A ocorrência de complicações pós-operatórias imediatas em procedimentos de palatoplastia, resulta na grande maioria das vezes em fistulas oronasais que além de estabelecer a comunicação entre as duas cavidades podem também interferir no desempenho fonoarticulatório dos pacientes. Estas são muitas vezes relacionadas como um dos indicadores da qualidade dos procedimentos cirúrgicos. Pigott et al. ${ }^{176}$ atribui importância decisiva, ao analisar três protocolos cirúrgicos de palatoplastia, à experiência e proficiência do cirurgião, demonstrado inclusivamente pela menor prevalência de complicações como fistulas oronasais, no decorrer do intervalo de tempo analisado, fato já levantado por Ross ${ }^{33}$, em 1987. A prevalência de fistulas em ambos os procedimentos objeto desta pesquisa (9,4\% no grupo GI e $6,7 \%$ no GC) se enquadra no reportado em outros relatos na literatura que apresentam uma variação entre $0 \%$ e $58 \%$, e com índices de recidiva até cerca de $1 / 3$ dos casos $^{141,187,222-233}$.

Ganesh et al. ${ }^{189}$ reportam baixos números que poderão ser atribuídos à habilidade da equipe cirúrgica, mas prejudicada essa análise pelo elevado número de abandonos e perdas verificados no seu estudo.

Landheer et al. $^{233}$ mostram uma tendência importante na ocorrência de fistulas no grupo em que foi realizado o fechamento tardio do palato, o que não foi observado na 
presente pesquisa, embora o procedimento testado tenha tido uma curva de aprendizado menor que o seu controle. No estudo dos referidos autores os pacientes com fissuras mais severas eram designados para o protocolo com FTPD o que estabelece um viés importante, impedindo assim uma análise mais objetiva. O fechamento tardio do palato duro, muitas vezes em função do estreitamento da fissura residual teve como opção primaria o descolamento da fibromucosa das laminas palatinas conforme o descrito por Friede $^{89}$ relativamente à estratégia cirúrgica seguida no serviço de Gotemburgo. A dificuldade apontada por Cosman e Falk ${ }^{158}$ para o fechamento da fissura remanescente, por vezes mais estreitada, não foi sentida e o risco aumentado de fistulização daí decorrente não foi constatado. A realização de incisões laterais quando do fechamento do palato duro ocorreu (37,5\% no grupo GI e 36,7\% no GC) sempre que foi constatado um risco maior de fistulização por tensão exagerada na sutura entre os dois retalhos palatinos (Tabela 7). Friede et al. ${ }^{89}$ e Rohrich et al. ${ }^{147}$ entre outros defendem esta abordagem e constataram uma menor incidência de fistulas oronasais em seus pacientes. Foi evitado o prolongamento da incisão liberadora para o espaço de Ernst (espaço pterigoideconstritor superior), defendido por Mikoya et al. ${ }^{193}$, pois em muitos procedimentos nos quais se usou esse recurso, no CADEFI, constatou-se o surgimento de cicatrizes retrateis que limitavam a mobilidade do véu palatino.

Analisando os dois grupos GI e GC conjuntamente, constata-se a distribuição nos índices 1 e 2 de 63,44 \% (Tabela 14) comparável como que outros autores ${ }^{184,186,213,234}$, que utilizaram o mesmo índice, relataram usando protocolos variados com técnicas e cronologias diferentes. Mikoya et al. ${ }^{193}$ reportaram desfechos de relação maxilomandibular mais deficiente e atribuiu o fato à maior prevalência de má oclusão de classe III de Angle no grupo étnico oriental ${ }^{53}$. Também Johnson et al. ${ }^{191}$ reportaram desfechos 
menos favoráveis que os encontrados nesta pesquisa que poderão ser explicados pela multiplicidade de cirurgiões envolvidos sem o necessário "case load" defendido pelos CSAG papers $^{62}$ ou em função de protocolos mal definidos. O artigo publicado por Ganesh et al. ${ }^{189} \mathrm{e}$ a série de artigos do serviço de Gotemburgo ${ }^{89,131,132,152,163,235}$ apresentam desfechos notadamente melhores. O somatório dos escores FYOI 1, 2 e 3 correspondeu a 95\%), melhor que aqueles apresentados na presente pesquisa, o que levanta novamente a questão da influência do cirurgião nos resultados ${ }^{168}$, mesmo com protocolos diversos. No entanto, conforme Friede et al. ${ }^{163}$ alguns vieses contaminam os estudos supracitados, como por exemplo, tratamentos complementares realizados pelos sujeitos da amostra, avaliações de modelos por profissionais do próprio centro, além do desenho dos estudos, observacionais e retrospectivos.

O FYOI é utilizado para avaliar as relações maxilo-mandibulares de crianças no estágio final da dentição decídua, por volta dos cinco anos de idade e, portanto, antes do pico de velocidade de crescimento facial. Desta maneira, o processo cicatricial decorrente das cirurgias primárias poderá afetar, em graus variados, o desenvolvimento esquelético. Segundo Mazaheri et al. ${ }^{84,236}$, o potencial genético ativo para o crescimento facial dessas crianças irá se manifestar numa razão inversamente proporcional aos traumatismos teciduais causados pelas cirurgias ${ }^{237,238}$. No entanto em múltiplos trabalhos que tem feito o acompanhamento longitudinal destes pacientes, embora se constatem uma piora nas relações maxilo-mandibulares com o evolver da idade, as proporções relativas entre os escores avaliados pelo FYOI e Goslon Yardstick, se mantem constantes ${ }^{38,39,76}$, ou como no estudo de Wlliams et $a l .{ }^{59}$ que mostra uma migração de pacientes com o escore 3 do índice FYOI, para os escores 1 e 2 do índice Goslon Yardstick. 
A gravidade da fissura é considerada por vários autores como importante para os desfechos encontrados após os tratamentos cirúrgicos para a sua correção, tendo Johnson et al. ${ }^{120}$ proposto inclusive a criação do Birth Severity Index que correlaciona as dimensões da fissura à superfície das laminas palatinas.

Neste trabalho foram utilizadas as metodologias descritas por Mazaheri et $a l .{ }^{84,236}$, Moorees e Gron ${ }^{239}$, DiBiase et al. ${ }^{234}$, Seckel et al. ${ }^{240}$, Kramer et al. ${ }^{241} \mathrm{e}$ Reiser et $a l .{ }^{242}$, que embasam as medições seguidas usualmente no CADEFI, embora outros autores utilizem várias outras, pelo que a comparação com outros relatos se torna precária. Foi também agregada a medição anterior da fissura, que poderá ser relacionada com a gravidade da fissura conforme o constatado por Mello et al. ${ }^{243}$, mas que diferentemente da metodologia adotada para avaliar a relação bimaxilar, não tem uniformidade no uso desse instrumento. A gravidade da fissura labial está relacionada primordialmente com a distorção e o deslocamento dos segmentos labiais e pirâmide nasal, sem alterações dimensionais das estruturas afetadas, no palato poderá haver deficiência tecidual em alguns casos ${ }^{120}$. Em ambos grupos constatamos uma diminuição das dimensões transversais intercaninos, medidas nos modelos obtidos tardiamente (em T2) o que sugere que os efeitos negativos da palatoplastia no crescimento da maxila podem ocorrer independentemente do protocolo cirúrgico empregado (Tabela 3).

Usando o teste estatístico de Spearman não foi encontrado nas séries analisadas neste estudo correlação entre a gravidade da fissura determinada pelas dimensões anteriores e posteriores da fissura aferida nos modelos de estudo aquando do ingresso do paciente no Centro e os desfechos relativos ao crescimento facial avaliados pelo índice FYOI (Tabela18). 
Chiu et al. ${ }^{119,179}$ ao analisarem suas series, encontraram através de regressão linear multivariada, melhores desfechos em pacientes que tinham menores fissuras, mas também naqueles que tinham laminas palatinas maiores, fato constatado pelo mesmo em revisão sistemática realizada posteriormente. No entanto, considera que poderia haver uma correlação do desfecho, não só com a gravidade do defeito mas em virtude deste, com o uso de técnicas mais agressivas e consequentes áreas desnudadas, com cicatrização por segunda intenção, o que também é defendido por Latief et al. ${ }^{238}$. Isso não ocorreu neste estudo, pois as técnicas cirúrgicas utilizadas em ambos os grupos, GI e GC, evitaram grandes áreas desnudadas e retalhos da fibromucosa palatina monopediculados. Na revisão sistemática supracitada, poucos trabalhos apresentavam condições metodológicas que permitissem analisar a influência da gravidade da deformidade e apresentar conclusões sobre a mesma.

Peltomaki et al. ${ }^{117}$ e Honda et al. ${ }^{118}$ encontraram correlação entre a gravidade da fissura e o déficit no crescimento da face, avaliando não apenas o tamanho da fissura, mas também o tamanho das laminas palatinas. No entanto, Suzuki et al. ${ }^{244} \mathrm{e}$ Johnson et al. ${ }^{120}$ não encontraram evidencias de tais correlações.

Ao serem analisadas neste estudo, as dimensões medias anteriores e posteriores da fissura, com os respetivos desvios-padrão, pode-se verificar que não existem diferenças relevantes entre os dois grupos (Tabela 4) o que reforça homogeneidade da amostra estudada, evitando vieses como os considerados por Peltomaki et al. ${ }^{117}$ e Wiggman et al. ${ }^{121}$ Alguns autores acreditam que os resultados das cirurgias primárias estão mais relacionados com o protocolo de tratamento e a proficiência cirúrgica do que com a gravidade da fissura ${ }^{121,245}$.Provavelmente opiniões tão dispares derivam de analises retrospectivas com diferentes grupos 
analisados, mas também como anteriormente destacado, pela falta de instrumentos de aferição usados de forma universal, com metodologias diferentes, com critérios de avaliação diversos.

Ao avaliar as medidas transversais da maxila é possível constatar que houve uma ligeira diminuição na distância intercaninas nos dois grupos analisados (Tabela 3), resultado esperado em função da cinta muscular reconstruída na queiloplastia ${ }^{246}$. Verificou-se um aumento da distância intermolar, também sem diferenças estatisticamente significantes entre os dois grupos o que, segundo Dissaux et al. ${ }^{73}$, pode ser devido à conexão da maxila com a base do crânio. Por outro lado, Mikoya et al. ${ }^{193}$ encontraram diferença entre os dois grupos com protocolos semelhantes aos desta pesquisa, nas dimensões transversais da maxila, com resultados mais favoráveis no grupo com fechamento tardio do palato duro. Os resultados encontrados por esse autor se devem, provavelmente, ao fato dele ter utilizado no grupo controle a técnica de Wardill, que deixa uma área cicatricial importante com repercussões negativas na maxila, tanto no sentido transversal como no anteroposterior, as quais foram amplamente divulgados na literatura ${ }^{247-249}$.

No entanto estes achados divergem do constatado por Richard et al. ${ }^{187}$, em ensaio clinico realizado no Nepal, verificaram uma diminuição das dimensões maxilares após palatoplastia independentemente da técnica e protocolos adotados. Uma interpretação possível para essa diferença nos resultados seria a influência do fator étnico além da diferente proficiência cirúrgica e faixa etária em que a cirurgia foi realizada.

A análise comparativa das relações maxilo-mandibulares os dois grupos estudados (Tabela 14), mostra uma predominância dos escores 1 e 2 do FYOI no grupo GI em relação ao Grupo GC (74\% versus 52,2\%). Estes resultados evidenciam 
diferença estatisticamente significante em relação ao crescimento facial mais favorável no grupo com fechamento tardio do palato duro. No ensaio clinico multicêntrico Scandcleft ${ }^{185}$ não foram testados estes protocolos por uma mesma equipe cirúrgica, pois o braço comum a todos os intervenientes tinha um protocolo de fechamento do palato duro aos 12 meses, precedido de queiloplastia e veloplastia entre terceiro e quatro meses. No entanto os Grupos B e C que testavam protocolos semelhantes aos executados no presente estudo e conforme o mostrado no Gráfico 3, apresentaram distribuição de frequências dos escores 1 e 2 menos favoráveis entre os grupos com FTPD (GI 74\%) versus B 55,9\%), quando comparamos os dois ECR.

Gráfico 3 - Percentagem dos escores do índice de 5 anos de 1 (excelente) a 5 (muito pobre) dentro de cada ensaio

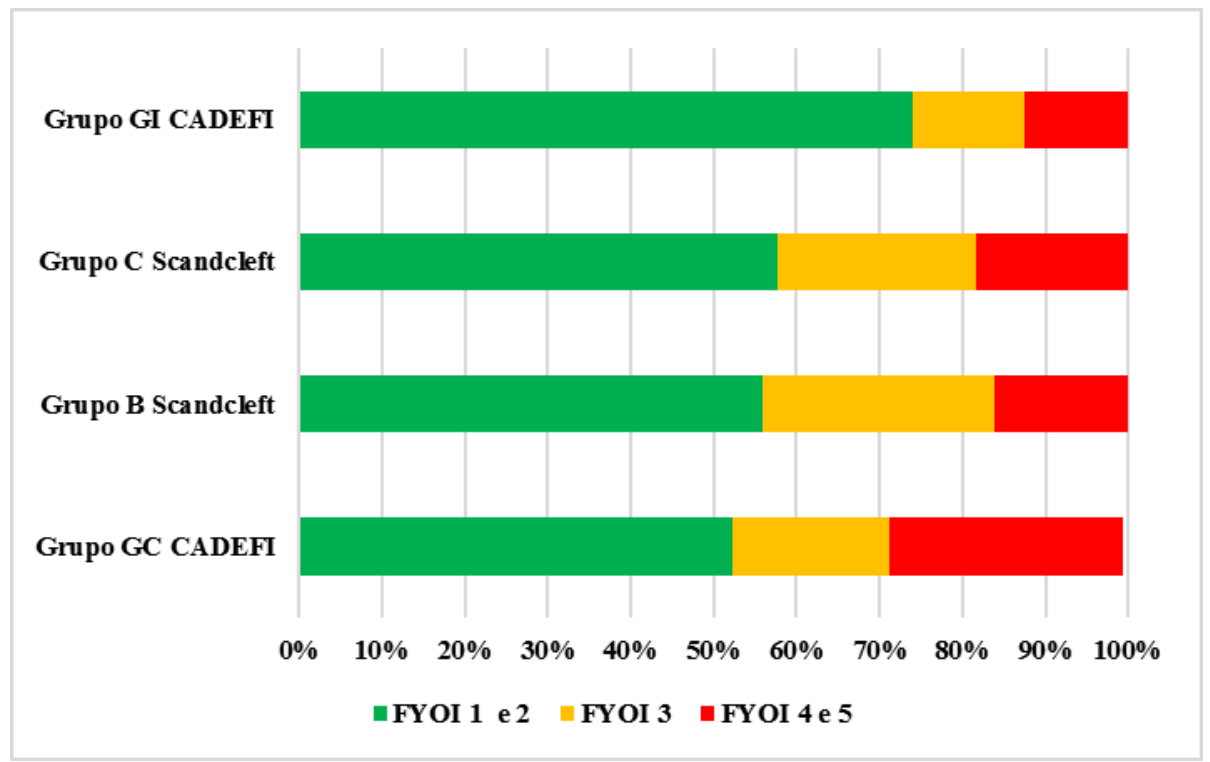


Embora tenha que ser observado com precaução em virtude de serem dados provenientes de amostras diferentes, cirurgiões distintos, etnias diversas, os resultados obtidos nos Grupos dos Protocolos do braço comum do Scandcleft (queiloplastia e veloplastia aos três a quatro meses e fechamento do palato duro aos $12 \mathrm{~m}$ ) mostram uma diferença relativamente pronunciada aos encontrados no Grupo GI deste estudo, o que reforça a convicção da importância do fechamento mais tardio do palato duro como o defendido por vários autores ${ }^{32,54,55,152,163,183}$ (Gráfico 4).

\section{Gráfico 4 - Protocolos com fechamento do palato Duro aos $12 \mathrm{~m}$ e tardios (após 36m)}

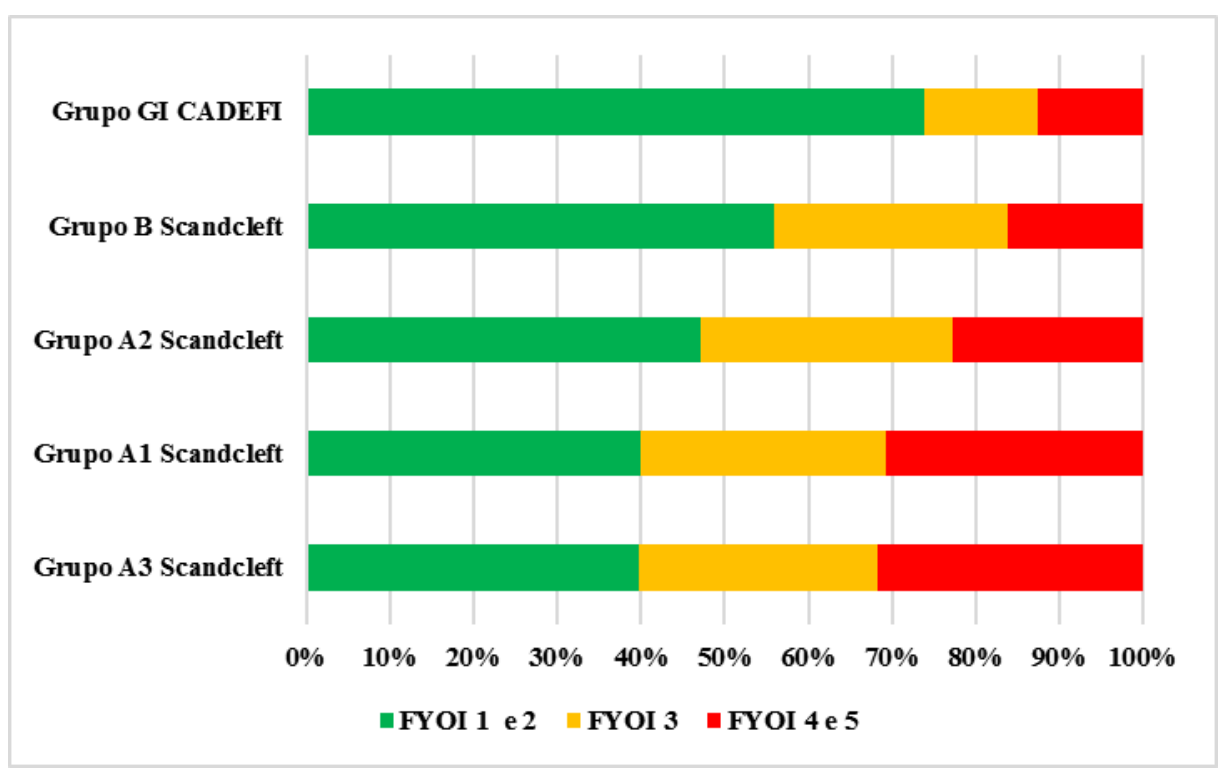

Estes resultados obtido precocemente, evitando a influência de outras variáveis, que não exclusivamente os procedimentos cirúrgicos, além de proporcionar informações temporãs também se relaciona de forma relativa com os desfechos $\operatorname{tardios}^{250}$. Lilja et al. ${ }^{152}$ mostram resultados muito semelhantes aos encontrados na presente pesquisa, no Grupo com FTPD, quando considerada a avaliação realizada aos cinco anos de idade, apresentando uma evolução favorável 
com o aumento da idade, atingindo índices favoráveis em torno dos $85 \%$ na avaliação realizada aos 10 anos de idade, e uma regressão inesperada dos desfechos menos favoráveis. Estes achados deverão ser avaliados cautelosamente porque embora percentualmente isso tenha ocorrido, houve perda da amostra no decorrer das avaliações.

Embora sem os desenhos metodológicos mais adequados, estudos observacionais relativos ao crescimento facial após tratamento cirúrgico de portadores de fissura labiopalatina unilateral, mesmo distante dos números encontrados por Bardach et al. ${ }^{140}$ na amostra de Schweckendiek (cerca de 90\% de boas avaliações) mostram que com equipes de cirurgiões experientes com boa experiência cirúrgica e protocolos bem definidos, o fechamento tardio do palato duro poderia ter repercussões positivas no crescimento da maxila. Uma revisão sistemática conduzida por Nollet et al. ${ }^{180}$ sobre este mesmo tema encontrou diferenças estatisticamente significantes entre protocolos com fechamento do palato duro antes dos três anos e os realizados após essa idade, estes com melhores desfechos relativos ao crescimento facial. Mikoya et al. ${ }^{193}$ não achou em seu estudo diferenças estatisticamente significantes entre os dois grupos quando avaliado pelo índice FYOI, embora tenha encontrado no grupo FTPD melhores resultados quando avaliadas as dimensões posteriores do palato e sem diferenças relativas às dimensões anteroposteriores. Este achado poderá estar relacionado a vários fatores como etnia, técnicas cirúrgicas, proficiência dos cirurgiões entre outros. Ao evitar realizar o fechamento do palato duro para ocasiões muito posteriores após os três anos de vida, depois do período de crescimento mais intenso, conforme Berkowitz ${ }^{65,218}$ conceituou, e outros autores adotaram ${ }^{154,219}$ teve como intuito não colocar em risco o desenvolvimento da fala destes pacientes, como demonstraram Friede et al. ${ }^{251}$ e Rohrich et al. ${ }^{135}$. 
Os levantamentos efetuados pelas iniciativas Eurocleft ${ }^{43} \mathrm{Americleft}^{48}$ e Noverraz $^{75}$ não mostraram também diferenças significantes entre as amostras dos protocolos com FTPD e aqueles com fechamento mais precoce do palato duro quando analisados pelo GOSLON Yardstick. Estudos publicados por Holland et al. ${ }^{141}$ e Gosain ${ }^{252}$ apresentam evidencias contraditórias em relação ao crescimento facial em pacientes com fechamento tardio do palato duro, tendo encontrado nas suas pesquisas piores desfechos no grupo de FTPD, embora baseado em analises retrospectivas e com procedimentos que incluíam o uso de próteses obturadoras. Landheer et $a l^{233}$ levantou a hipótese da ação deletéria que estes dispositivos poderiam ter sobre as estruturas faciais e analisando os desfechos obtidos por Lohmander-Agerskob $^{164}$ não se considerou a necessidade do uso destas órteses.A escolha de técnicas que evitam desnudamento de áreas ósseas com cicatrização por segunda intenção $0^{36,109,127,176,203,204,253}$, principalmente as localizadas na região posterior do palato duro ou sobre a região da sutura entre a premaxila e vômer, utilizada nos paciente do presente estudo, podem ter tido influência positiva no desfecho encontrado, evitando resultados como os publicados por Gaggl et al. ${ }^{138}$, que mesmo fechando tardiamente o palato duro, apresentou piores desfechos quando comparados a outros protocolos, devido a técnica de Widmaier modificada ${ }^{148}$ usada para a veloplastia.

O uso de retalhos vomerianos é controverso e surgem opiniões dispares como aquelas expressadas num estudo de Xue et al. ${ }^{254}$ em que comparam o crescimento da face, baseado em estudos cefalométricos aos cinco anos de idade em pacientes que usaram o retalho vomeriano, num protocolo com fechamento primário precoce, com o de sujeitos que realizaram o fechamento tardio do palato duro tendo sido 
evidenciado um melhor desenvolvimento vertical e sagital da maxila neste grupo. No entanto Ganesh et al. ${ }^{189}$ verificaram que o grupo de pacientes submetidos a palatoplastia com o retalho vomeriano apresenta melhores resultados que aquele submetido ao protocolo com retalhos palatinos bilaterais, desfechos encontrados também por outros autores ${ }^{18,36,43,210}$, o que reforça a interdisciplinaridade destas variáveis. A interação entre estes fatores desempenha um papel fundamental pois certamente apenas a cronologia na reparação desta malformação não seria suficiente para justificar os melhores resultados encontrados nesta pesquisa, embora o desenho adotado permita vislumbrar com mais clareza os fatores que podem influenciar o processo de crescimento facial.

No presente estudo verifica-se no grupo GC (palatoplastia em tempo único) uma distribuição relativamente elevada (28,9\%) dos escores 4 -5 (Tabela 14), a qual não é diferente dos resultados previamente encontrados no CADEFI, em $2012^{58}$, em outros centros brasileiros ${ }^{168,255}$ e até mesmo no exterior ${ }^{51,191}$

\section{Gráfico 5 - Protocolos palatoplastia tempo único}

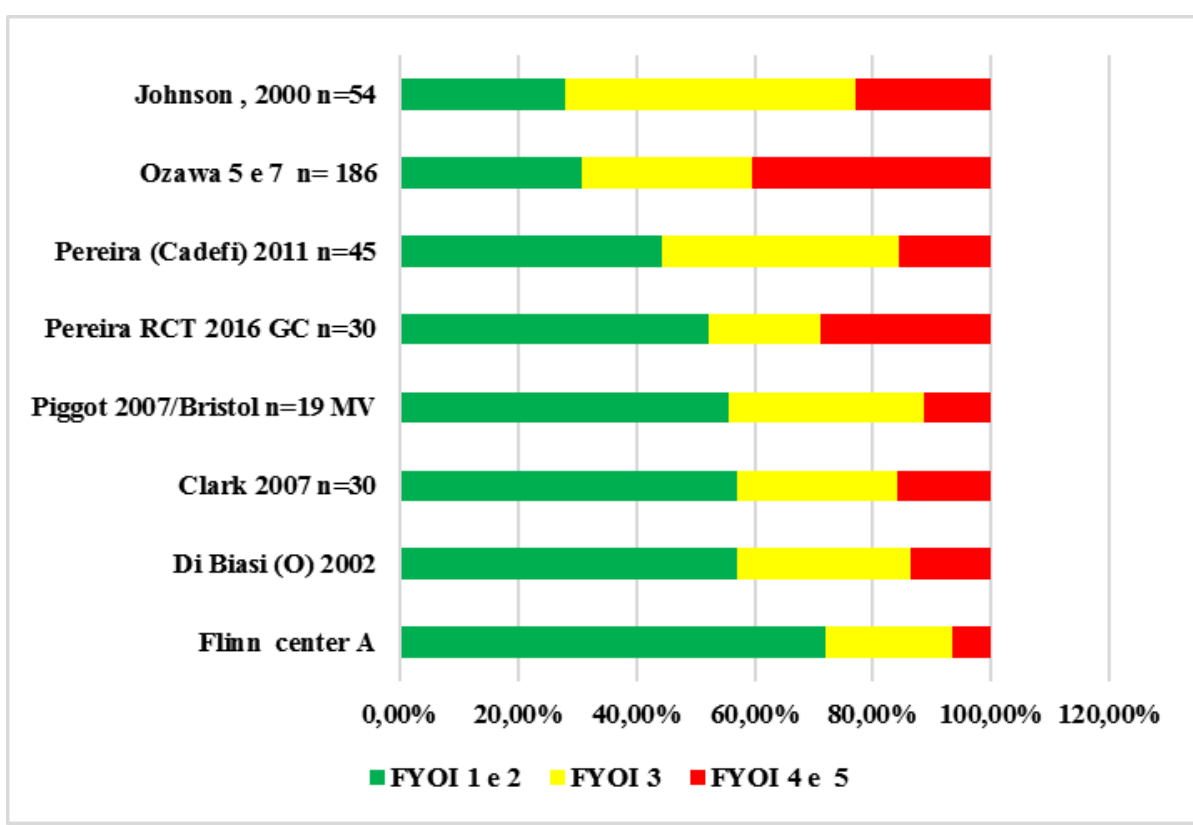


No entanto quando comparados estes resultados com alguns reportados por artigos previamente $\operatorname{citados}^{76,184,189}$, que apresentam protocolo semelhante, se apresentam com percentuais maiores o que pode estar relacionado com inúmeros fatores, como étnicos, técnicas cirúrgicas, estadiamento, e que deverão ser avaliados posteriormente. Friede et al. ${ }^{256}$ aponta cronologias muito diferentes nos diferentes protocolos, assim como técnicas e estratégias cirúrgicas, como incisões entre o palato duro e mole, variações essas que poderão influenciar os desfechos encontrados entre os vários estudos. É importante ressaltar que as avaliações feitas de maneira independente, por examinadores externos, conferem maior confiabilidade aos resultados obtidos, o que foi adotado neste ECR, diferentemente de outros trabalhos aqui citados ${ }^{54,89,185,189}$ que não seguiram esse procedimento.

Liao et $a{ }^{257}$ levanta uma questão primordialmente de ordem ética na cronologia do fechamento tardio do palato duro e suas consequências, negativas, em relação ao desenvolvimento e qualidade da fala' obtidos pelos pacientes submetidos a este protocolo, fato contestado por Lohmander et al. ${ }^{251}$ que referia que a longo prazo não encontrava alterações importantes, ou Van Demark et al. ${ }^{161}$ que encontrou um equilíbrio entre os desfechos fonoarticulatórios e crescimento facial, o que foi também constatado preliminarmente no presente estudo. Assim há a necessidade de serem realizados estudos que analisem objetivamente os desfechos fonoaudiológicos que confirmem os achados clínicos constatados pela equipe de Fonoaudiologia do CADEFI.

A importância de protocolos que evidenciem melhores desfechos deverá sempre ser avaliada considerando o seu custo social ${ }^{186}$ de tal forma que pequenas vantagens que algum deles eventualmente apresente deverá ser sempre avaliada pela 
sua exequibilidade. No entanto a importância de proficiência fonoarticulatória e a dificuldade em melhora-la deve ser um dos balizamentos dessa escolha.

A avaliação dos desfechos e como priorizar qual deles é o mais importante é tarefa que levanta suscita dilemas de ordem técnica e de cunho psicossocial. Uma cirurgia de revisão nem sempre poderá atingir os objetivos aos quais se propõe alcançar $^{258}$ e deverá ter sempre que levar em conta que procedimentos cirúrgicos de revisão aumentam o burden of care do paciente e resulta em aumento dos custos médicos diretos e indiretos para famílias ${ }^{259,260}$ e para o próprio sistema de saúde. A cronologia com o fechamento mais tardio do palato duro e o uso de técnicas cirúrgicas que sejam menos agressivas e deixem menos áreas ósseas desnudadas terão papel importante no processo de crescimento facial. A realização da veloplastia no mesmo momento cirúrgico em que é realizada a queiloplastia diminui o custo social para as famílias e sistema de saúde pelo que deverá ser considerada em protocolos que optem por fechamento tardio do palato duro.

Os resultados deste ensaio clínico fornecem algumas evidencias estatísticas de que o protocolo com FTPD é melhor do que o protocolo mais tradicional com o fechamento precoce do palato, embora careça de uma análise mais aprofundada da possível influência da habilidade cirúrgica individual e da curva de aprendizagem.

É imperiosa a necessidade de aprofundar os estudos colaborativos interinstitucionais, com a consolidação dos instrumentos de medida e a avaliação do desempenho fonoarticulatório, capazes de ampliar os achados desta pesquisa e subsidiar uma mudança no protocolo cirúrgico do CADEFI e de outros Centros, dedicados ao tratamento das pessoas com fissura labiopalatinas. 
A qualidade do atendimento aos pacientes com fissuras labiopalatinas tem que ser monitorada de forma continuada, procurando a assertividade do diagnostico, planejamento e efetivação do tratamento subsequente. Isso só poderá ser alcançado através de auditorias que contemplem avaliações longitudinais dos desfechos, revisões periódicas dos dados e adaptações dos protocolos sempre que necessário. Este processo requer que as instancias reguladoras, governamentais ou institucionais públicas ou privadas, atuem de forma permanente e concertada para que esses objetivos possam ser alcançados.

Apenas duas crianças abandonaram a presente pesquisa, e isto ocorreu antes da intervenção cirúrgica no GC, o que não permite conclusões sobre a influência dos protocolos cirúrgicos estudados na adesão ao tratamento.

Nesta pesquisa, não foi possível avaliar a largura pré-operatória da fissura do palato duro no Grupo GI (palatoplastia em dois tempos cirúrgicos), o que permitiria investigar a existência de uma correlação entre essa variável e o desfecho relativo ao crescimento facial, conforme o proposto por Berkowitz et al. ${ }^{217}$. A referida dimensão não foi avaliada em virtude da dificuldade na obtenção dos modelos de gesso, por falta de cooperação dos pacientes participantes.

É importante salientar que uma das principais limitações deste estudo se refere à falta de avaliação do desempenho fonoarticulatório, devido à inexistência de instrumentos validados para tal finalidade. Esta lacuna constitui um entrave para a abordagem interdisciplinar, fulcral na reabilitação dos portadores de fissura labiopalatina. 


\section{Conclusões}


A palatoplastia realizada em dois tempos cirúrgicos favorece uma melhor relação entre os arcos dentários maxilar e mandibular, do que a palatoplastia em tempo único, em crianças com FLPU completa avaliadas pelo índice FYOI.

Não há correlação entre a largura da fissura não operada e a relação maxilomandibular avaliada pelo índice FYOI em ambos os protocolos cirúrgicos.

Não há diferenças estatisticamente significantes entre os dois protocolos cirúrgicos em relação à ocorrência de fístulas e à diminuição da distância intercaninos e diminuição do comprimento do arco maxila 


\section{Anexos}


Anexo A - Protocolo de Pesquisa - CADEFI - Parte I

PARTE I

PROTOCOLO DE PESQUISA - CADEFI

NOME DA PESQUISA: “PALATOPLASTIA EM DOIS TEMPOS CIRÚRGICOS NO TRATAMENTO DAS FISSURAS TRANFORAME UNILATERAIS"

NÚMERO PROJETO CEP-IMIP

ㅁㅁ- $\square \square$

LOCAL: Centro de Atenção aos Defeitos da Face do Imip - Recife-PE

NÚMERO DA RANDOMIZAÇÃO

$\square \square$

- Dados Pessoais e sócio demográficos do paciente

Data:

1. REGISTRO:

$\square \square \square \square \square \square \square$

2. DATA DO NASCIMENTO:

$\square \square-\square \square-\square \square \square \square$

3. SEXO:

1. Masculino 2. Feminino

4. PROCEDÊNCIA:

1. Zona da Mata

2. Agreste

3. Sertão

4. Região Metropolitana do Recife

5. Cidade (Outro Estado): Qual:

99. Sem informação

5. TELEFONE:

6. ANTECEDENTE FAMILIAR COM FISSURA
1. Sim
99. Não Sabe

2. Não

7. ALEITAMENTO MATERNO

1. Sim

2. Não

8. NÚMERO DE CONSULTA PRÉ-NATAL

9. PESO AO NASCER (GRAMAS)

10. NÚMERO DE HABITANTES POR DOMICÍLIO

11. RENDA TOTAL FAMILIAR (SALÁRIO MÍNIMO)

1. Até 1 salário mínimo

3. Três a quatro salários mínimos

5. De sete a oito salários mínimos
2.Um1a dois salários mínimos

4. Cinco a seis salários mínimos

6. Mais que nove salários mínimos 
12. ESCOLARIDADE DA MÃE

1. Ensino fundamental 1 incompleto 2. Ensino fundamental 1 completo

3. Ensino fundamental 2 incompleto 4. Ensino fundamental 2 completo

5. Ensino médio incompleto

6. Ensino médio completo

7. Ensino superior incompleto

8. Ensino superior completo

9. Estuda ainda

88. Não sabe

99. Não tem

13. TIPO DA FISSURA

1- TIUD

2- TIUE 


\section{PARTE II}

DADOS REFERENTES À CIRURGIA PLÁSTICA

14. DATA DA QUEILOPLASTIA

Técnica de rotação e avanço proposta por Millard

15. DATA DA PRIMEIRA PALATOPLASTIA

$\square \square-\square \square-\square \square \square \square$

Técnica:

16. DATA DA SEGUNDA PALATOPLASTIA

$\square \square-\square \square-\square \square \square \square$

Técnica:

17. EQUIPE CIRÚRGICA

Cirurgião - Rui Pereira

NOME DO(S) MÉDICOS RESIDENTES DE CIRURGIA PLÁSTICA:

\section{REVISÕES CIRÚRGICAS:}

18. PRIMEIRO DIA PÓS-OPERATÓRIO (pós-operatório imediato)

Data:

1. Condição de higiene
1. Boa
2. Deficiente

2. Complicações:
1. Sim
2. Não

3. Tipo de Complicação

1. Infecção (Sinais: Secreção purulenta, Febre, Hiperemia, Dor local, Calor e Edema de partes moles)

Cultura (resultado):

2. Deiscência

Total

Parcial

Local:

3. Necrose

4. Outras

Qual:

Nome do avaliador: 
19. QUINTO DIA PÓS-OPERATÓRIO (pós-operatório imediato)

Data:

1. Condição de higiene
1. Boa
2. Deficiente

2. Complicações:
1. Sim
2. Não

3. Tipo de Complicação

1. Infecção (Sinais: Secreção purulenta, Febre, Hiperemia, Dor local, Calor e Edema de partes moles)

Cultura (resultado):

2. Deiscência

Total

Parcial

Local:

3. Necrose

4. Outras

Qual:

\section{Nome do avaliador:}

\section{DÉCIMO DIA PÓS-OPERATÓRIO}

Data:

1. Condição de higiene
1. Boa
2. Deficiente

2. Complicações:
1. Sim
2. Não

3. Tipo de Complicação

1. Infecção (Sinais: Secreção purulenta, Febre, Hiperemia, Dor local, Calor e Edema de partes moles)

Cultura (resultado):

2. Deiscência

Total

Parcial

Local:

3. Necrose

4. Outras

Qual:

\section{Nome do avaliador:}


21. TRIGÉSIMO DIA PÓS-OPERATÓRIO

Data:

1. Condição de higiene
1. Boa
2. Deficiente

2. Complicações:
1. Sim
2. Não

3. Tipo de Complicação

1. Infecção (Sinais: Secreção purulenta, Febre, Hiperemia, Dor local, Calor e Edema de partes moles)

Cultura (resultado):

2. Deiscência

Total

Parcial

Local:

3. Necrose

4. Outras

Qual:

22. DOIS MESES DE PÓS-OPERATÓRIO

Data:

1. Condição de higiene
1. Boa
2. Deficiente

2. Complicações:
1. Sim
2. Não

3. Tipo de Complicação

1. Infecção (Sinais: Secreção purulenta, Febre, Hiperemia, Dor local, Calor e Edema de partes moles) Cultura (resultado):

2. Deiscência

Total

Parcial

Local:

3. Necrose

4. Outras

Qual:

Nome do avaliador: 
23. TRÊS MESES DE PÓS-OPERATÓRIO

Data:

1. Condição de higiene
1. Boa
2. Deficiente

2. Complicações:
1. Sim
2. Não

3. Tipo de Complicação

1. Infecção (Sinais: Secreção purulenta, Febre, Hiperemia, Dor local, Calor e Edema de partes moles)

Cultura (resultado):

2. Deiscência

Total

Parcial

Local:

3. Necrose

4. Outras

Qual:

\section{Nome do avaliador:}

\section{SEIS MESES DE PÓS-OPERATÓRIO}

Data:

1. Condição de higiene
1. Boa
2. Deficiente

2. Complicações:
1. Sim
2. Não

3. Tipo de Complicação

1. Infecção (Sinais: Secreção purulenta, Febre, Hiperemia, Dor local, Calor e Edema de partes moles)

Cultura (resultado):

2. Deiscência

Total

Parcial

Local:

3. Necrose

4. Outras

Qual:

\section{Nome do avaliador:}


25. UM ANO DE PÓS-OPERATÓRIO

Data:

1. Condição de higiene
1. Boa
2. Deficiente

2. Complicações:
1. Sim
2. Não

3. Tipo de Complicação

1. Infecção (Sinais: Secreção purulenta, Febre, Hiperemia, Dor local, Calor e Edema de partes moles)

Cultura (resultado):

2. Deiscência

Total

Parcial

Local:

3. Necrose

4. Outras

Qual:

26. DOIS ANOS DE PÓS-OPERATÓRIO

Data:

1. Condição de higiene
1. Boa
2. Deficiente

2. Complicações:
1. Sim
2. Não

3. Tipo de Complicação

1. Infecção (Sinais: Secreção purulenta, Febre, Hiperemia, Dor local, Calor e Edema de partes moles) Cultura (resultado):

2. Deiscência

Total

Parcial

Local:

3. Necrose

4. Outras

Qual: 


\title{
Anexo B - Termo de Consentimento Livre e Esclarecido TERMO DE CONSENTIMENTO LIVRE E ESCLARECIDO
}

\author{
(De acordo com os critérios da Resolução 196/96 do Conselho Nacional de \\ Pesquisa do Ministério da Saúde)
}

$\mathrm{Eu}$, responsável pelo menor $\mathrm{RG}$ / I , matriculado no Imip com o registro declaro que fui devidamente informado(a) pelo pesquisador Rui Manoel Pereira ou pela corresponsável responsável Edna Maria Costa de Melo sobre as finalidades da pesquisa: "PALATOPLASTIA EM DOIS TEMPOS CIRÚRGICOS NO TRATAMENTO DAS FISSURAS TRANFORAME UNILATERAIS". Foi explicado que meu (minha) filho (a) pode operar o palato (céu da boca) em uma ou em duas operações. Estou perfeitamente consciente de que:

1. Concordei na participação do menor na pesquisa por livre escolha, sem que recebesse nenhuma pressão dos profissionais que participam do projeto e receberei uma cópia deste termo de consentimento.

2. Foi explicado que a maneira de fechar o lábio (queiloplastia) será em uma operação (proposta por Millard) e a de fechar o palato (céu da boca) em uma ou em duas operações (palatoplastia pela técnica de Von Langenbeck e veloplastiaintravelar). Essa maneira de fechar a fenda labiopalatina vem sendo utilizada há vários anos neste serviço (Cadefi) e em todo o mundo.

3. O fechamento mais tarde do palato duro (céu da boca) faz parte do protocolo de atendimento de vários Serviços na Escandinávia, Holanda e Alemanha. Mas, ainda precisa saber qual das duas operações é a que faz a criança falar melhor, a que ajuda os dentes ficar na boca de forma correta (menos tortos), qual a que faz o rosto crescer melhor e a que provoca menos inflamação depois da cirurgia.

4. Todos os pacientes serão submetidos à queiloplastia primária (fechamento do lábio) por volta dos três meses de vida e a palatoplastia (fechamento do palato) pode ser realizada em uma única cirurgia em torno dos nove meses de idade ou, em duas cirurgias em que será fechada a parte posterior (parte mole do céu da boca) em torno dos seis meses de vida e a anterior (parte dura do céu da boca) aos 36 meses. Responderei a todas as perguntas referentes à pesquisa e consentirei que sejam realizadas fotografias, radiografias e medidas para confecção dos modelos da boca da criança para as avaliações previstas na pesquisa.

5. Sei que, qualquer forma de fechar a abertura tanto do lábio como do céu da boca, tem a possibilidade de complicações pós-operatórias como: deiscências (um lado do lábio mais baixo que o outro), fístulas (pequena comunicação da boca com o nariz), necrose de retalhos (infecções da ferida após as cirurgias) e outras.

6. Fui informado que, ao ocorrer qualquer complicação referente as cirurgias realizadas no menor, minha criança será atendida com toda assistência pelo Cadefi- Centro de Atenção aos Defeitos da Face do Imip.

7. Todas as cirurgias serão custeadas pelo SUS (Sistema Único de Saúde) com o apoio do Imip. Não haverá custos diretos para os pacientes ou familiares.

8. O paciente continuará sendo atendido no Imip e dispondo de toda a atenção devida pelo Centro de Atenção aos Defeitos da Face do Imip, independentemente da sua participação na pesquisa.

9. O menor poderá abandonar a pesquisa sem que isso venha a prejudicar seu atendimento no Imip a qualquer momento que julgue necessário.

10. Tenho direito de perguntar e obter respostas em qualquer momento sobre a pesquisa em qualquer tempo, entrando em contato com o com um dos pesquisadores (telefone do Cadefi 32310328) ou com o Comitê de Ética em Pesquisa do Imip (telefone número: 21224756).

11. Fui informado ter como garantia que a identidade (nome ou qualquer informação que permita identificação) da criança será preservada (não será divulgada). Está claro para mim que todos os dados destas pesquisas podem ser utilizados pelos profissionais do Cadefi investigadores nesta pesquisa desde que tragam esclarecimentos sobre a forma de tratamento que foi utilizada. 
12. Estou consciente que essa pesquisa tem um tempo longo de duração, indo até a criança terminar seu tratamento no Cadefi. Assumo o compromisso de trazer a criança nas datas que estão previstas para o controle do tratamento da criança e comunicarei caso mude de endereço ou não tenha condições de participar.

Recife, de de

Responsável legal (ou polegar)

Testemunha

Testemunha

Assinatura do Pesquisador 


\section{Anexo C - Aprovações}

\section{Hill 1 LI \\ MEDICINA \\ [TSP \\ COMITÊ DE ÉTICA EM PESQUISA}

\section{APROVAÇÃ̃O}

O Comitê de Ética em Pesquisa da Faculdade de Medicina da Universidade de São Paulo, em sessão de o7/11/2012, APROVOU o Protocolo de Pesquisa n ${ }^{\circ}$ 269/12 intitulado: "AVALIAÇÃO DO CRESCIMENTO FACIAL EM DOIS PROTOCOLOS CIRÚRGICOS PRIMÁRIOS UTILIZADOS NO TRATAMENTO DE PACIENTES PORTADORES DE FISSURA LÁBIOPALATINA UNILATERAL: ESTUDO PROSPETIVO RANDOMIZADO" apresentado pelo Departamento de CIRURGIA

Cabe ao pesquisador elaborar e apresentar ao CEPFMUSP, os relatórios parciais e final sobre a pesquisa (Resolução do Conselho Nacional de Saúde $\mathrm{n}^{0}$ 196, de 10/10/1996, inciso IX.2, letra "c").

Pesquisador (a) Responsável: Prof. Dr.Nivaldo Alonso

Pesquisador (a) Executante: Dr. Rui Manuel Rodrigues Pereira

CEP-FMUSP, o8 de Novembro de 2012.

Profa Dra Edna Frasson de Souza Montero

ice-Coordenadora do Programa de Pós-Graduação Clinica Cirúrgica

Prof. Dr. Paulo Eurípedes Marchiori Vice-Coordenador

Comitê de Ética em Pesquisa

Comitê de Ética em Pesquisa da Faculdade de Medicina e-mail: cep.fm@usp.br 
Instituto de Medicina Integral

Prof. Fernando Figueira

Escola de Pós-graduaçẩo em Saúde Matemo Infantil

Instituição Civil Filantrópica

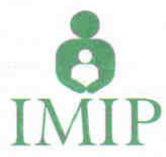

DECLARAÇÃO

Declaro que o Projeto de pesquisa $\mathrm{n}^{\circ} \mathbf{1 2 8 2}$, intitulado "Palatoplastia em dois tempos cirúrgicos no tratamento das fissuras transforamen unilaterais" apresentado pelo pesquisador Rui Manuel Rodrigues Pereira fo APROVADO pelo Comitê de Ética em Pesquisa em Seres Humanos do Instituto de Medicina Integral Prof. Fernando Figueira - IMIP, em reunião ordinária de 13 de novembro de 2008

Recife, 17 de novembro de 2008

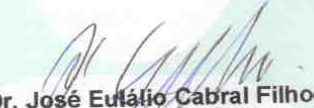

Dr. José Euratio Cabral Filho

Coopdenador do Comitê de Etica

Instituto de Medicina Integral Prof. Fernando Figueira 


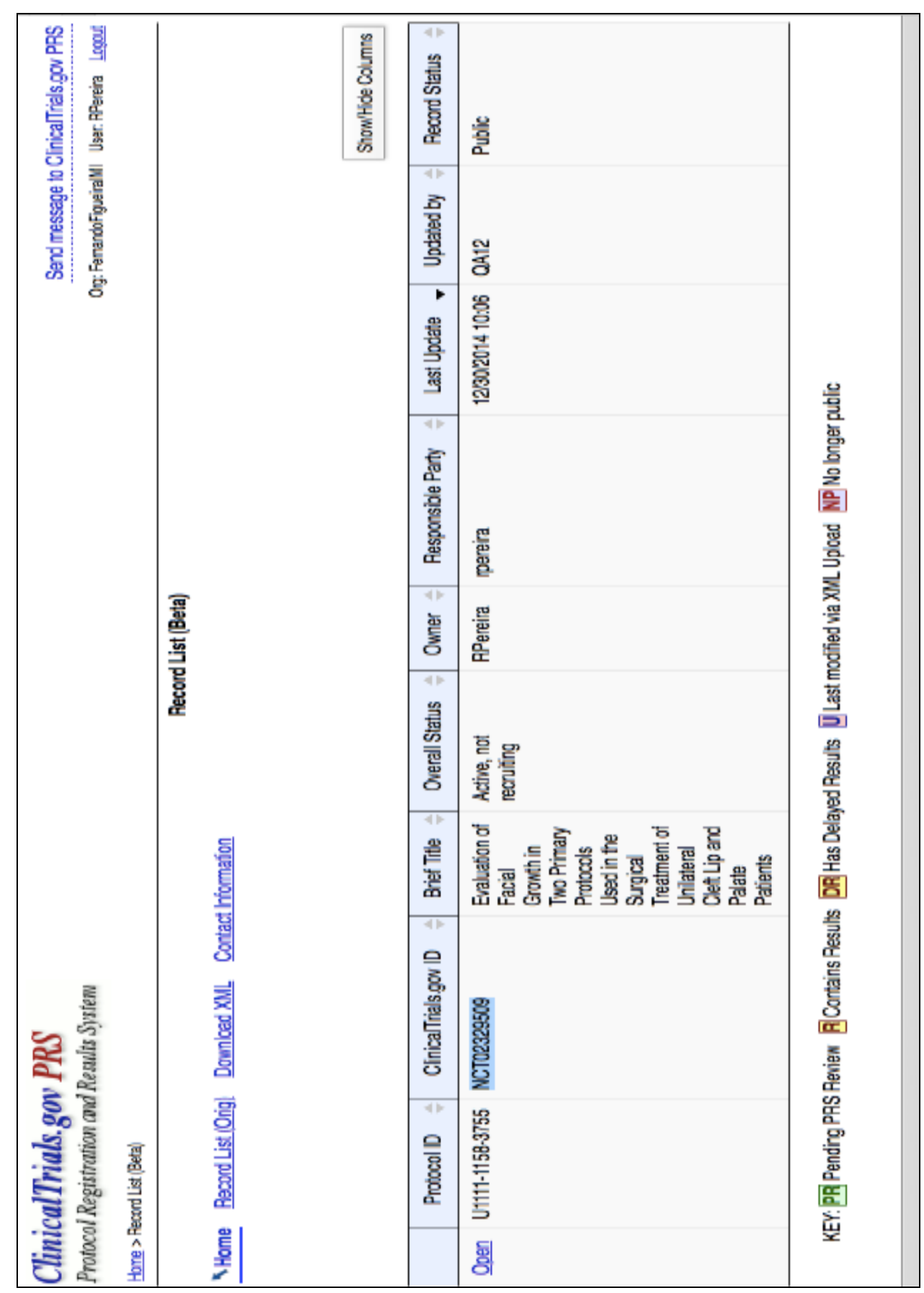


8 REFERÊNCIAS 
1. Sperber GH, Sperber SM, Guttmann GD. Early Orofacial Development. In: USA PsMPH (Ed.). Craniofacial embryogenetics and development. Shelton, Connecticut, USA: People's Medical Publishing House - USA; 2010. p. 37-60.

2. Petersen PE, Bourgeois D, Ogawa H, Estupinan-Day S, Ndiaye C. The global burden of oral diseases and risks to oral health. Bull World Health Organ. 2005; 83(9):661-9.

3. Global strategies to reduce the health care burden of craniofacial anomalies: report of WHO meetings on international collaborative research on craniofacial anomalies. Cleft Palate Craniofac J. 2004, 41(3):238-43.

4. Prevalence at birth of cleft lip with or without cleft palate: data from the International Perinatal Database of Typical Oral Clefts (IPDTOC). Cleft Palate Craniofac J. 2011; 48(1):66-81.

5. Kling RR, Taub PJ, Ye X, Jabs EW. Oral clefting in china over the last decade: 205, 679 patients. Plast Reconstr Surg Glob Open. 2014; 2(10):e236.

6. Wehby GL. Advancing and prioritizing research on oral clefts in Brazil. J Pediatr (Rio J). 2013; 89(2):112-5. 
7. Campana H, Pawluk MS, Lopez Camelo JS. Births prevalence of 27 selected congenital anomalies in 7 geographic regions of Argentina. Arch Argent Pediatr. 2010; 108(5):409-17.

8. Souza J, Raskin S. Clinical and epidemiological study of orofacial clefts. $J$ Pediatr (Rio J). 2013; 89(2):137-44.

9. Nagem Filho H, Moraes N, Rocha RGF. Contribuição para o estudo da prevalência das malformações congênitas lábio-palatais na população escolar de Bauru. Rev Fac Odont S Paulo. 1968; 6:111-28.

10. Loffredo LCM, Freitas JAS, Grigolli AAG. Prevalência de fissuras orais de 1975 a 1994. Rev Saúde Pública. 2001; 35:571-5.

11. Rodrigues K, Sena MF, Roncalli AG, Ferreira MA. Prevalence of orofacial clefts and social factors in Brazil. Braz Oral Res. 2009; 23(1):38-42.

12. Cao Y, Yuan P, Wang YP, Mao M, Zhu J. The profile of newborn screening coverage in China. J Med Screen. 2009; 16(4):163-6.

13. Monlleó IL, Gil-da-Silva-Lopes VL. Anomalias craniofaciais: descrição e avaliação das características gerais da atenção no Sistema Único de Saúde. Cad Saúde Pública. 2006; 22:913-22.

14. Matthews JL, Oddone-Paolucci E, Harrop RA. The epidemiology of cleft lip and palate in Canada, 1998 to 2007. Cleft Palate Craniofac J. 2014; 52(4):4172. 
15. McDonnell R, Owens M, Delany C, Earley M, McGillivary A, Orr DJ, et al. Epidemiology of orofacial clefts in the East of ireland in the 25-year period 1984-2008. Cleft Palate Craniofac J. 2014; 51(4):e63-9.

16. Urbanova W, Kotova M, Vankova Z. The incidence of cleft lip and palate in the Czech Republic in 1994-2008. Bratisl Lek Listy. 2013; 114(8):474-9.

17. Antoszewski B, Fijalkowska M. Comparison of the prevalence of cleft lip and/or palate in children in Lodz province in the period of 1996-2010 in 5years intervals. Pol Merkur Lekarski. 2013; 34(204):339-41.

18. Del Guercio F, Meazzini MC, Garattini G, Morabito A, Semb G, Brusati R. A cephalometric intercentre comparison of patients with unilateral cleft lip and palate at 5 and 10 years of age. Eur J Orthod. 2010; 32(1):24-7.

19. Basseri B, Kianmahd BD, Roostaeian J, Kohan E, Wasson KL, Basseri RJ, Bradley JP. Current national incidence, trends, and health care resource utilization of cleft lip-cleft palate. Plast Reconstr Surg. 2011; 127(3):1255-62.

20. Blocksma R, Leuz CA, Mellerstig KE. A conservative program for managing cleft palates without the use of mucoperiosteal flaps. Plast Reconstr Surg. 1975; 55(2):160-9.

21. Wehby GL, Pedersen DA, Murray JC, Christensen K. The effects of oral clefts on hospital use throughout the lifespan. BMC Health Serv Res. 2012; 12:58.

22. Wehby GL, Collet B, Barron S, Romitti PA, Ansley TN, Speltz M. Academic achievement of children and adolescents with oral clefts. Pediatrics. 2014; 133(5):785-92. 
23. Higashi H, Barendregt JJ, Kassebaum NJ, Weiser TG, Bickler SW, Vos T. The burden of selected congenital anomalies amenable to surgery in low and middle-income regions: cleft lip and palate, congenital heart anomalies and neural tube defects. Arch Dis Child. 2015; 100(3):233-8.

24. Muntz HR, Meier JD. The financial impact of unrepaired cleft lip and palate in the Philippines. Int J Pediatr Otorhinolaryngol. 2013; 77(12):1925-8.

25. Hughes CD, Babigian A, McCormack S, Alkire BC, Wong A, Pap SA, Vincent JR, Meara JG, Castiglione C, Silverman R. The clinical and economic impact of a sustained program in global plastic surgery: valuing cleft care in resourcepoor settings. Plast Reconstr Surg. 2012; 130(1):87e-94e.

26. Alkire B, Hughes CD, Nash K, Vincent JR, Meara JG. Potential economic benefit of cleft lip and palate repair in sub-Saharan Africa. World J Surg. 2011; 35(6):1194-201.

27. Poenaru D, Lin D, Corlew S. Economic Valuation of the Global Burden of Cleft Disease Averted by a Large Cleft Charity. World J Surg. 2016; 40(5):1053-9.

28. Roberts CT, Semb G, Shaw WC. Strategies for the advancement of surgical methods in cleft lip and palate. Cleft Palate Craniofac J. 1991; 28(2):141-9.

29. Sackett DL, Rosenberg WM. The need for evidence-based medicine. J R Soc Med. 1995; 88(11):620-4.

30. Sackett DL. Evidence-based medicine. Spine. 1998; 23(10):1085-6. 
31. Sackett DL, Rosenberg WM, Gray JA, Haynes RB, Richardson WS. Evidence based medicine: what it is and what it isn't. BMJ. 1996; 312(7023):71-2.

32. Bardach J, Morris H, Olin W, McDermott-Murray J, Mooney M, Bardach E. Late results of multidisciplinary management of unilateral cleft lip and palate. Ann Plast Surg. 1984; 12(3):235-42.

33. Ross RB. Treatment variables affecting facial growth in complete unilateral cleft lip and palate. Cleft Palate J. 1987; 24(1):5-77.

34. Lilja $\mathbf{J}$; Friede H ; Johanson B. Changing philosophy of surgery of the cleft lip and palate in Goteborg, Sweden. In: Berkowitz S (Ed.). Cleft lip and palate. San Diego: Singular Publishing Group; 1996. p. 155-70.

35. Mølsted K, Asher-McDade C, Brattstrom V, Dahl E, Mars M, McWilliam J, et al. A six-center international study of treatment outcome in patients with clefts of the lip and palate: Part 2. Craniofacial form and soft tissue profile. Cleft Palate Craniofac J. 1992; 29(5):398-404.

36. Mars M, Asher-McDade C, Brattstrom V, Dahl E, McWilliam J, Mølsted K, Plint DA, Prahl-Andersen B, Semb G, Shaw WC, et al. A six-center international study of treatment outcome in patients with clefts of the lip and palate: Part 3. Dental arch relationships. Cleft Palate Craniofac J. 1992; 29(5):405-8.

37. Asher-McDade C, Brattstrom V, Dahl E, McWilliam J, Mølsted K, Plint DA, PrahlAndresen B, Semb G, Shaw WC, The RP. A six-center international study of treatment outcome in patients with clefts of the lip and palate: Part 4. Assessment of nasolabial appearance. Cleft Palate Craniofac J. 1992; 29(5):409-12. 
38. Shaw WC, Dahl E, Asher-McDade C, Brattstrom V, Mars M, McWilliam J, Mølsted K, Plint DA, Prahl-Andersen B, Roberts C, et al. A six-center international study of treatment outcome in patients with clefts of the lip and palate: Part 5. General discussion and conclusions. Cleft Palate Craniofac J. $1992 ; 29(5): 413-8$.

39. Shaw WC, Brattstrom V, Mølsted K, Prahl-Andersen B, Roberts CT, Semb G. The Eurocleft study: intercenter study of treatment outcome in patients with complete cleft lip and palate. Part 5: discussion and conclusions. Cleft Palate Craniofac J. 2005; 42(1):93-8.

40. Shaw WC, Semb G, Nelson P, Brattström V, Mølsted K, Prahl-Andersen B, Gundlach KK. The Eurocleft Project 1996-2000: overview. J Craniomaxillofac Surg. 2001; 29(3):131-40.

41. Semb G, Brattstrom V, Mølsted K, Prahl-Andersen B, Zuurbier P, Rumsey N, eShaw WC. The Eurocleft study: intercenter study of treatment outcome in patients with complete cleft lip and palate. Part 4: relationship among treatment outcome, patient/parent satisfaction, and the burden of care. Cleft Palate Craniofac J. 2005; 42(1):83-92.

42. Semb G, Brattstrom V, Mølsted K, Prahl-Andersen B, Shaw WC. The Eurocleft study: intercenter study of treatment outcome in patients with complete cleft lip and palate. Part 1: introduction and treatment experience. Cleft Palate Craniofac J. 2005; 42(1):64-8. 
43. Mølsted K, Brattstrom V, Prahl-Andersen B, Shaw WC, Semb G. The Eurocleft study: intercenter study of treatment outcome in patients with complete cleft lip and palate. Part 3: dental arch relationships. Cleft Palate Craniofac J. 2005; 42(1):78-82.

44. Brattstrom V, Mølsted K, Prahl-Andersen B, Semb G, Shaw WC. The Eurocleft study: intercenter study of treatment outcome in patients with complete cleft lip and palate. Part 2: craniofacial form and nasolabial appearance. Cleft Palate Craniofac J. 42(1):69-77.

45. Russell K, Long RE, Jr., Hathaway R, Daskalogiannakis J, Mercado A, Cohen M, Semb G, Shaw W. The Americleft study: an inter-center study of treatment outcomes for patients with unilateral cleft lip and palate part 5. General discussion and conclusions. Cleft Palate Craniofac J. 2011; 48(3):265-70.

46. Mercado A, Russell K, Hathaway R, Daskalogiannakis J, Sadek H, Long RE, Jr., Cohen M, Semb G. The Americleft study: an inter-center study of treatment outcomes for patients with unilateral cleft lip and palate part 4. Nasolabial aesthetics. Cleft Palate Craniofac J. 2011; 48(3):259-64.

47. Long RE, Jr., Hathaway R, Daskalogiannakis J, Mercado A, Russell K, Cohen M, Semb g, Shaw W. The Americleft study: an inter-center study of treatment outcomes for patients with unilateral cleft lip and palate part 1. Principles and study design. Cleft Palate Craniofac J. 2011; 48(3):239-43. 
48. Hathaway R, Daskalogiannakis J, Mercado A, Russell K, Long RE, Jr., Cohen M, Semb G, Shaw W. The Americleft study: an inter-center study of treatment outcomes for patients with unilateral cleft lip and palate part 2. Dental arch relationships. Cleft Palate Craniofac J. 2011; 48(3):244-51.

49. Daskalogiannakis J, Mercado A, Russell K, Hathaway R, Dugas G, Long RE, Jr., Cohen M, Semb G, Shaw W. The Americleft study: an inter-center study of treatment outcomes for patients with unilateral cleft lip and palate part 3. Analysis of craniofacial form. Cleft Palate Craniofac J. 2011; 48(3):252-8.

50. Chapman KL, Baylis A, Trost-Cardamone J, Cordero KN, Dixon A, Dobbelsteyn C, Thurmes A, Wilson K, Harding-Bell A, Sweeney T, Stoddard G, Sell D.. The Americleft Speech Project: A Training and Reliability Study. Cleft Palate Craniofac J. 2016; 53(1):93-108.

51. Dogan S, Semb G, Erbay E, Alcan T, Uzel A, Kocadereli I, Shaw WC. Dental arch relationships in Turkish patients with complete unilateral cleft lip and palate born between 1976 and 1990: a comparison with eurocleft. Cleft Palate Craniofac J. 2014; 51(1):70-5.

52. Mueller AA, Zschokke I, Brand S, Hockenjos C, Zeilhofer HF, SchwenzerZimmerer K. One-stage cleft repair outcome at age 6- to 18-years -- a comparison to the Eurocleft study data. Br J Oral Maxillofac Surg. 2012; 50(8):762-8.

53. Liao YF, Lin IF. Dental arch relationships after two-flap palatoplasty in Taiwanese patients with unilateral cleft lip and palate. Int J Oral Maxillofac Surg. 2009; 38(11):1133-6. 
54. Sinko K, Caacbay E, Jagsch R, Turhani D, Baumann A, Mars M. The GOSLON yardstick in patients with unilateral cleft lip and palate: review of a Vienna sample. Cleft Palate Craniofac J. 2008; 45(1):87-92.

55. Nollet PJ, Katsaros C, van 't Hof MA, Semb G, Shaw WC, Kuijpers-Jagtman AM. Treatment outcome after two-stage palatal closure in unilateral cleft lip and palate: a comparison with Eurocleft. Cleft Palate Craniofac J. 2005; 42(5):512-6.

56. Rullo R, Carinci F, Mazzarella N, Festa VM, Farina A, Morano D, Carls F, Gombos F. Delaire's cheilorhinoplasty: unilateral cleft aesthetic outcome scored according to the EUROCLEFT guidelines. Int $J$ Pediatr Otorhinolaryngol. 2006; 70(3):463-8.

57. Martinot-Duquennoy V, Capon N. Synthesis of the standard of treatment of cleft lip and cleft palate by 11 francophone teams en 2001. Ann Chir Plast Esthet. 2002; 47(2):166-71.

58. Pereira RMR, Melo EMCd, Coutinho SB, Vale DMd, Siqueira N, Alonso N. Avaliação do crescimento craniofacial em portadores de fissuras labiopalatinas submetidos a palatoplastia em tempo único. Rev. Bras Cir Plást. 2011; 26:62430.

59. Williams AC, Bearn D, Mildinhall S, Murphy T, Sell D, Shaw WC, Murray JJ, Sandy JR. Cleft lip and palate care in the United Kingdom--the Clinical Standards Advisory Group (CSAG) Study. Part 2: dentofacial outcomes and patient satisfaction. Cleft Palate Craniofac J. 2001; 38(1):24-9. 
60. Sell D, Grunwell P, Mildinhall S, Murphy T, Cornish TA, Bearn D, Shaw WC, Murray JJ, Williams AC, Sandy JR. Cleft lip and palate care in the United Kingdom--the Clinical Standards Advisory Group (CSAG) Study. Part 3: speech outcomes. Cleft Palate Craniofac J. 2001; 38(1):30-7.

61. Sandy JR, Williams AC, Bearn D, Mildinhall S, Sell D, Murphy T, Shaw WC. Cleft lip and palate care in the United Kingdom--the Clinical Standards Advisory Group (CSAG) Study. Part 1: background and methodology. Cleft Palate Craniofac J. 2001; 38(1):20-3.

62. Bearn D, Mildinhall S, Murphy T, Murray JJ, Sell D, Shaw WC, Williams AC, Sandy JR. Cleft lip and palate care in the United Kingdom--the Clinical Standards Advisory Group (CSAG) Study. Part 4: outcome comparisons, training, and conclusions. Cleft Palate Craniofac J. 2001; 38(1):38-43.

63. Sandy J, Rumsey N, Persson M, Waylen A, Kilpatrick N, Ireland T, Ness A. Using service rationalisation to build a research network: lessons from the centralisation of UK services for children with cleft lip and palate. Br Dent J. 2012; 212(11):553-5.

64. Semb G. International confederation for cleft lip and palate and related craniofacial anomalies task force report: beyond eurocleft. Cleft Palate Craniofac J. 2014; 51(6):e146-55.

65. Berkowitz S. Cleft lip and palate research: an updated state of the art. Section III. Orofacial growth and dentistry. Cleft Palate J. 1977; 14(4):288-301. 
66. Mossey PA, Little J, Munger RG, Dixon MJ, Shaw WC. Cleft lip and palate. Lancet. 2009; 374(9703):1773-85.

67. Moher D, Schulz KF, Altman DG. The CONSORT statement: revised recommendations for improving the quality of reports of parallel-group randomised trials. Lancet. 2001; 357(9263):1191-4.

68. Krauss M, Polaczek T. Late results of the surgical treatment of complete unilateral cleft lip and palate: soft tissue characteristics. Acta Chir Plast. 1993; $35(1-2): 44-56$.

69. Mars M, Plint DA, Houston WJ, Bergland O, Semb G. The Goslon Yardstick: a new system of assessing dental arch relationships in children with unilateral clefts of the lip and palate. Cleft Palate J. 1987; 24(4):314-22.

70. Huddart AG, Bodenham RS. The evaluation of arch form and occlusion in unilateral cleft palate subjects. Cleft Palate J. 1972; 9:194-209.

71. Pruzansky S, Aduss H. Arch form and the deciduous occlusion in complete unilateral clefts. Cleft Palate J. 1964; 30:411-8.

72. Matthews D, Broomhead I, Grossmann W, Orth D, Goldin H. Early and late bone grafting in cases of cleft lip and palate. Br J Plast Surg. 1970; 23(2):115-29.

73. Dissaux C, Grollemund B, Bodin F, Picard A, Vazquez MP, Morand B, James I, Kauffmann I, Bruant-Rodier C. Evaluation of 5-year-old children with complete cleft lip and palate: Multicenter study. Part 2: functional results. $J$ Craniomaxillofac Surg. 2016; 44(2):94-103. 
74. Leonard AG, Kneafsey B, McKenna S, Johnston CD, Burden DJ, Stevenson M. A retrospective comparison of craniofacial form in Northern Irish children with unilateral cleft lip and palate. Cleft Palate Craniofac J. 1998; 35(5):402-7.

75. Noverraz AE, Kuijpers-Jagtman AM, Mars M, van't Hof MA. Timing of hard palate closure and dental arch relationships in unilateral cleft lip and palate patients: a mixed-longitudinal study. Cleft Palate Craniofac J. 1993; 30(4):391-6.

76. Atack NE, Hathorn IS, Semb G, Dowell T, Sandy JR. A new index for assessing surgical outcome in unilateral cleft lip and palate subjects aged five: reproducibility and validity. Cleft Palate Craniofac J. 1997; 34(3):242-6.

77. Atack N, Hathorn I, Mars M, Sandy J. Study models of 5 year old children as predictors of surgical outcome in unilateral cleft lip and palate. Eur J Orthod. 1997; 19(2):165-70.

78. Nollet PJ, Katsaros C, van 't Hof MA, Bongaarts CA, Semb G, Shaw WC, Kuijpers-Jugtman AM. Photographs of study casts: an alternative medium for rating dental arch relationships in unilateral cleft lip and palate. Cleft Palate Craniofac J. 2004; 41(6):646-50.

79. Ali SA, Mossey P, Gillgrass T. A study model based photographic method for assessment of surgical treatment outcome in unilateral cleft lip and palate patients. Eur J Orthod. 2006; 28(4):366-72.

80. Liao YF, Huang CS, Lin IF. Intraoral photographs for rating dental arch relationships in unilateral cleft lip and palate. Cleft Palate Craniofac J. 2009; 46(4):415-9. 
81. Malik $\mathrm{OH}$, Abdi-Oskouei M, Mandall NA. An alternative to study model storage. Eur J Orthod. 2009; 31(2):156-9.

82. Chawla O, Deacon SA, Atack NE, Ireland AJ, Sandy JR. The 5-year-olds' Index: determining the optimal format for rating dental arch relationships in unilateral cleft lip and palate. Eur J Orthod. 2012; 34(6):768-72.

83. Chawla O, Atack NE, Deacon SA, Leary SD, Ireland AJ, Sandy JR. Threedimensional digital models for rating dental arch relationships in unilateral cleft lip and palate. Cleft Palate Craniofac J. 2013; 50(2):182-6.

84. Mazaheri M, Athanasiou AE, Long RE, Kolokitha OG. Evaluation of maxillary dental arch form in unilateral clefts of lip, alveolus, and palate from one month to four years. Cleft Palate-Craniofac J. 1993; 30(1):90-3.

85. Prahl C, Kuijpers-Jagtman AM, Van 't Hof MA, Prahl-Andersen B. A randomized prospective clinical trial of the effect of infant orthopedics in unilateral cleft lip and palate: prevention of collapse of the alveolar segments (Dutchcleft). Cleft Palate Craniofac J. 2003; 40(4):337-42.

86. Dalstra M, Melsen B. From alginate impressions to digital virtual models: accuracy and reproducibility. J Orthod. 2009; 36(1):36-41.

87. Leifert MF, Leifert MM, Efstratiadis SS, Cangialosi TJ. Comparison of space analysis evaluations with digital models and plaster dental casts. Am J Orthod Dentofacial Orthop. 2009; 136(1):16.e1-4. 
88. Shaw WC, Bannister RP, Roberts CT. Assisted feeding is more reliable for infants with clefts--A randomized trial. Cleft Palate Craniofac J. 1999; 36(3):262-8.

89. Friede H. Maxillary growth controversies after two-stage palatal repair with delayed hard palate closure in unilateral cleft lip and palate patients: perspectives from literature and personal experience. Cleft Palate Craniofac J. 2007; 44(2):129-36.

90. Sant'Ana H, Feijó M, Melo E, Pereira R. Comparação do uso de clorexidina versus solução fisiológica na anti-sepsia cutânea dos pacientes portadores de fissura palatina: um projeto piloto randomizado. Rev Soc Bras Cir Craniomaxilofac. 2010; 13:7-11.

91. Baptista E, Salgado I, Pereira R. Incidência de fístula oronasal após palatoplastias. Rev Bras Cirur Plast. 2005; 20(1):26-9.

92. Ye B, Wu Y, Zhou Y, Jing H, Hu J, Zhang G. A comparative cephalometric study for adult operated cleft palate and unoperated cleft palate patients. $J$ Craniomaxillofac Surg. 2015; 43(7):1218-23.

93. Delaire J, Precious D. Avoidance of the use of vomerine mucosa in primary surgical management of velopalatine clefts. Oral Surg Oral Med Oral Pathol. 1985; 60(6):589-97.

94. Latham RA, Scott JH. A newly postulated factor in the early growth of the human middle face and the theory of multiple assurance. Arch Oral Biol. 1970; 15(11):1097-100 
95. Scott, J, H. The analysis of facial growth from fetal life to adulthood. Angle Orthod. 1963; 33(2):110-3.

96. Bergland O, Borchgrevink $H$. The role of the nasal septum in midfacial growth in man elucidated by the maxillary development in certain types of facial clefts. A preliminary report. Scand J Plast Reconstr Surg. 1974; 8(1-2):42-8.

97. Babula WJ, Jr., Smiley GR, Dixon AD. The role of the cartilaginous nasal septum in midfacial growth. Am J Orthod. 1970;5 8(3):250-63.

98. Moss ML, Bromberg BE, Song IC, Eisenman G. The passive role of nasal septal cartilage in mid-facial growth. Plast Reconstr Surg. 1968; 41(6):536-42.

99. Stenstrom SJ, Thilander BL. Effects of nasal septal cartilage resections on young guinea pigs. Plast Reconstr Surg. 1970; 45(2):160-70.

100. Farkas LG, Forrest CR, Phillips JH. Comparison of the morphology of the "cleft face" and the normal face: defining the anthropometric differences. $J$ Craniofac Surg. 2000; 11(2):76-82.

101. Slaughter WB, Pruzansky S. The rationale for velar closure as a primary procedure in the repair of cleft palate defects. Plast Reconstr Surg. 1954; 13(5):341-57.

102. Crabb JJ, Foster TD. Growth defects in unrepaired unilateral cleft lip and palate. Oral Surg Oral Med Oral Pathol. 1977; 44(3):329-35. 
103. Yoshida H, Nakamura A, Michi K, Wang GM, Liu K, Qiu WL. Cephalometric analysis of maxillofacial morphology in unoperated cleft palate patients. Cleft Palate Craniofac J. 1992; 29(5):419-24.

104. Isiekwe MC, Sowemimo GO. Cephalometric findings in a normal Nigerian population sample and adult Nigerians with unrepaired clefts. Cleft Palate J. $1984 ; 21(4): 323-8$.

105. Paradas-Lara I, Casado-Gomez I, Martin C, Martinez-Sanz E, Lopez-Gordillo Y, González P, Rodríguez-Bobada C, Chamorro M, Arias P, Maldonado E, Ortega R, Berenguer B, Martínez-Álvarez C. Maxillary growth in a congenital cleft palate canine model for surgical research. J Craniomaxillofac Surg. 2014; 42(1):13-21.

106. Iwasaki H, Kudo M, Yamamoto Y. Does congenital cleft palate intrinsically influence craniofacial morphology? Craniofacial features in unoperated submucous cleft palate children in prepuberty. J Oral Maxillofac Surg. 2009; 67(3):477-84.

107. Bishara SE, Jakobsen JR, Krause JC, Sosa-Martinez R. Cephalometric comparisons of individuals from India and Mexico with unoperated cleft lip and palate. Cleft Palate J. 1986; 23(2):116-25.

108. Will LA. Growth and development in patients with untreated clefts. Cleft Palate Craniofac J. 2000; 37(6):523-6.

109. Mars M, Houston WJ. A preliminary study of facial growth and morphology in unoperated male unilateral cleft lip and palate subjects over 13 years of age. Cleft Palate J. 1990; 27(1):7-10. 
110. Capelozza L, Taniguchi SM, da Silva OG. Craniofacial Morphology of Adult Unoperated Complete Unilateral Cleft Lip and Palate Patients. Cleft Palate Craniofac J. 1993; 30(4):376-81.

111. Shetye PR, Evans CA. Midfacial morphology in adult unoperated complete unilateral cleft lip and palate patients. Angle Orthod. 2006; 76(5):810-6.

112. Capelozza Filho L, Normando ADC, Silva FilhoOG. Isolated influences of lip and palate surgery on facial growth: comparison of operated and unoperated male adults with UCLP. Cleft Palate Craniofac J. 1996; 33(1):51-6.

113. Li Y, Shi B, Song QG, Zuo H, Zheng Q. Effects of lip repair on maxillary growth and facial soft tissue development in patients with a complete unilateral cleft of lip, alveolus and palate. J Craniomaxillofac Surg. 2006; 34(6): 355-61.

114. Liao YF, Mars M. Long-term effects of lip repair on dentofacial morphology in patients with unilateral cleft lip and palate. Cleft Palate Craniofac J. 2005; 42(5): 526-32.

115. Herfert O. Two-stage operation for cleft palate. Br J Plast Surg. 1963; 16:3745.

116. Schultes G, Gaggl A, Karcher H. A comparison of growth impairment and orthodontic results in adult patients with clefts of palate and unilateral clefts of lip, palate and alveolus. Br J Oral Maxillofac Surg. 2000; 38(1):26-32. 
117. Peltomaki T, Vendittelli BL, Grayson BH, Cutting CB, Brecht LE. Associations between severity of clefting and maxillary growth in patients with unilateral cleft lip and palate treated with infant orthopedics. Cleft Palate Craniofac J. 2001; 38(6):582-6.

118. Honda Y, Suzuki A, Nakamura N, Ohishi M. Relationship between primary palatal form and maxillofacial growth in Japanese children with unilateral cleft lip and palate: infancy to adolescence. Cleft Palate Craniofac J. 2002; 39(5):527-34.

119. Chiu YT, Liao YF, Chen PK. Initial cleft severity and maxillary growth in patients with complete unilateral cleft lip and palate. Am J Orthod Dentofacial Orthop. 2011; 140(2):189-95.

120. Johnson N, Williams A, Singer S, Southall P, Sandy J. Initial cleft size does not correlate with outcome in unilateral cleft lip and palate. Eur J Orthod. 2000; 22(1):93-100.

121. Wiggman K, Larson M, Larson O, Semb G, Brattstrom V. The influence of the initial width of the cleft in patients with unilateral cleft lip and palate related to final treatment outcome in the maxilla at 17 years of age. Eur J Orthod. 2013; 35(3):335-40.

122. de Ladeira PR, Alonso N. Protocols in cleft lip and palate treatment: systematic review. Plast Surg Int. 2012;2 012:562892.

123. Graber TM. A Cephalometric analysis of the developmental pattern and facial morphology in cleft palate. Angle Orthod. 1949; 19(2):91-100. 
124. Bardach J, Kelly KM, Salyer KE. Relationship between the sequence of lip and palate repair and maxillary growth: an experimental study in beagles. Plast Reconstr Surg. 1994; 93(2):269-78.

125. Gillies HD, Fry WK. A new principle in the surgical treatment of "congenital cleft palate," and its mechanical counterpart. Br Med J. 1921; 1(3140):335-8.

126. Shi B, Losee JE. The impact of cleft lip and palate repair on maxillofacial growth. Int J Oral Sci. 2015; 7(1):14-7.

127. Semb G. A study of facial growth in patients with unilateral cleft lip and palate treated by the Oslo CLP Team. Cleft Palate Craniofac J. 1991; 28(1):1-21.

128. Schweckendiek W, Doz P. Primary veloplasty: long-term results without maxillary deformity. a twenty-five year report. Cleft Palate J. 1978; 15(3):268-74.

129. Hotz M, Gnoinski W. Comprehensive care of cleft lip and palate children at Zurich university: a preliminary report. Am J Orthod. 1976; 70(5):481-504.

130. Friede H, Lilja J, Johanson B. Cleft lip and palate treatment with delayed closure of the hard palate. A preliminary report. Scand J Plast Reconstr Surg. $1980 ; 14(1): 49-53$.

131. Friede H, Katsaros C. Current knowledge in cleft lip and palate treatment from an orthodontist's point of view. J Orofac Orthop. 1998;59(6):313-30.

132. Friede H, Enemark H. long-term evidence for favorable midfacial growth after delayed hard palate repair in UCLP patients. Cleft Palate J. 2001; 38(4):323-9. 
133. Robertson NR, Jolleys A. The timing of hard palate repair. Scand J Plast Reconstr Surg. 1974; 8(1-2):49-51.

134. Tanino R, Akamatsu T, Osada M. The influence of different types of hard palate closure in two-stage palatoplasty upon palatal growth: dental cast analysis. Keio J Med. 1997; 46(1):27-36.

135. Rohrich RJ, Love EJ, Byrd HS, Johns DF. Optimal timing of cleft palate closure. Plast Reconstr Surg. 2000; 106(2):413-21.

136. Dingman RO, Grabb WC. A rational program for surgical management of bilateral cleft lip and cleft palate. Plast Reconstr Surg. 1971; 47(3):239-42.

137. Blocksma R, Leuz CA, Beernink JH. A study of deformity following cleft palate repair in patients with normal lip and alveolus. Cleft Palate J. 1975; $12: 390-9$

138. Gaggl A, Feichtinger M, Schultes G, Santler G, Pichlmaier M, Mossbock R, eKarcher H. Cephalometric and occlusal outcome in adults with unilateral cleft lip, palate, and alveolus after two different surgical techniques. Cleft Palate Craniofac J. 2003; 40(3):249-55.

139. Oger P, Malek R, Martinez H, Trichet C. Prise en charge des fentes labiopalatines par l'équipe de l'hôpital Robert Debré à Paris. Ann Chir Plast Esthét. $2002 ; 47(2): 138-42$.

140. Bardach J, Morris HL, Olin WH. Late results of primary veloplasty: the Marburg Project. Plast Reconstr Surg. 1984; 73(2):207-18. 
141. Holland S, Gabbay JS, Heller JB, O'Hara C, Hurwitz D, Ford MD, Sauder AS, Bradley JP. Delayed closure of the hard palate leads to speech problems and deleterious maxillary growth. Plast Reconstr Surg. 2007; 119(4):1302-10.

142. Friede H, Lohmander A, Hagberg C, Elander A, Lilja J. Maxillary dental arch and occlusion in patients with unilateral cleft lip and palate treated with different delays in closure of the hard palate after early velar repair. Scand $J$ Plast Reconstr Surg Hand Surg. 2006; 40(5):261-6.

143. Kriens OB. Fundamental anatomic findings for an intravelar veloplasty. Cleft Palate J. 1970; 7:27-36.

144. Braithwaite F, Maurice DG. The importance of the levator palati muscle in cleft palate closure. Br J Plast Surg. 1968; 21(1):60-2.

145. Sommerlad BC. Surgery of the cleft palate: repair using the operating microscope with radical muscle retropositioning--the GostA approach. B-ent. 2006; 2(Suppl 4):32-4.

146. Sommerlad BC. A technique for cleft palate repair. Plast Reconstr Surg. 2003; $112(6): 1542-8$.

147. Rohrich RJ, Rowsell AR, Johns DF, Drury MA, Grieg G, Watson DJ, et al. Timing of hard palatal closure: a critical long-term analysis. Plast Reconstr Surg. 1996; 98(2):236-46.

148. Perko MA. Two-stage closure of cleft palate (progress report). J Maxillofac Surg. 1979; 7(1):46-80. 
149. Ross RB. Growth of the facial skeleton following the Malek repair for unilateral cleft lip and palate. Cleft Palate Craniofac J. 1995; 32(3):194-8.

150. Markus AF, Smith WP, Delaire J. Primary closure of cleft palate: a functional approach. Br J Oral Maxillofac Surg. 1993; 31(2):71-7.

151. Friede H, Priede D, Moller M, Maulina I, Lilja J, Barkane B. Comparisons of facial growth in patients with unilateral cleft lip and palate treated by different regimens for two-stage palatal repair. Scand J Plast Reconstr Surg Hand Surg. 1999; 33(1):73-81.

152. Lilja J, Mars M, Elander A, Enocson L, Hagberg C, Worrell E, Batra P, Friede H. Analysis of dental arch relationships in Swedish unilateral cleft lip and palate subjects: 20-year longitudinal consecutive series treated with delayed hard palate closure. Cleft Palate Craniofac J. 2006; 43(5):606-11.

153. Agrawal K. Cleft palate repair and variations. Indian J Plast Surg. 2009; 42(Suppl):S102-9.

154. Talmant JC, Lumineau JP, Rousteau G. Prise en charge des fentes labiomaxillo-palatines par l'équipe du docteur Talmant à Nantes. Annales de Chirurgie Plastique Esthétique. 2002; 47(2):116-25.

155. Goldwyn RM. Bernhard Von Langenbeck. His life and legacy. Plast Reconstr Surg. 1969; 44(3):248-54.

156. Bardach J. Two-flap palatoplasty: Bardach's technique. Operative Techniques Plastic Reconst Surg. 1995; 2(4):211-4. 
157. Friede H, Moller M, Lilja J, Lauritzen C, Johanson B. Facial morphology and occlusion at the stage of early mixed dentition in cleft lip and palate patients treated with delayed closure of the hard palate. Scand J Plast Reconstr Surg Hand Surg. 1987; 21(1):65-71.

158. Cosman B, Falk AS. Delayed hard palate repair and speech deficiencies: a cautionary report. Cleft Palate J. 1980; 17(1):27-33.

159. Witzel MA, Salyer KE, Ross RB. Delayed hard palate closure: the philosophy revisited. Cleft Palate J. 1984; 21(4):263-9.

160. Rohrich RJ, Gosman AA. An update on the timing of hard palate closure: a critical long-term analysis. Plast Reconstr Surg. 2004; 113(1):350-2.

161. Van Demark DR, Gnoinski W, Hotz MM, Perko M, Nussbaumer H. Speech results of the Zurich approach in the treatment of unilateral cleft lip and palate. Plast Reconstr Surg. 1989; 83(4):605-13.

162. Lohmander A, Friede H, Lilja J. Long-term, longitudinal follow-up of individuals with unilateral cleft lip and palate after the Gothenburg primary early veloplasty and delayed hard palate closure protocol: speech outcome. Cleft Palate Craniofac J. 2012; 49(6):657-71.

163. Friede H, Lilja J, Lohmander A. Long-term, longitudinal follow-up of individuals with UCLP after the Gothenburg primary early veloplasty and delayed hard palate closure protocol: maxillofacial growth outcome. Cleft Palate Craniofac J. 2012; 49(6):649-56. 
164. Lohmander-Agerskov A. Speech outcome after cleft palate surgery with the Goteborg regimen including delayed hard palate closure. Scand J Plast Reconstr Surg Hand Surg. 1998; 32(1):63-80.

165. Smith DM, Vecchione L, Jiang S, Ford M, Deleyiannis FW, Haralam MA, et al. The Pittsburgh Fistula Classification System: a standardized scheme for the description of palatal fistulas. Cleft Palate Craniofac J. 2007;44(6):590-4.

166. Mohler LR. Unilateral cleft lip repair. Plast Reconstr Surg. 1987; 80(4):511-7.

167. Mohler LR. Unilateral cleft lip repair. Operative Techniques Plastic Reconst Surg. 1995; 2(3):193-9.

168. Ozawa T. Avaliação dos efeitos da queiloplastia e palatoplastia primária sobre o crescimento dos arcos dentários de crianças com complete unilateral cleft lip and palate aos 5-6 anos de idade. Araraquara: UNESP 2001.

169. CONSORT 2010. Lancet. 2010; 375(9721):1136.

170. Allori AC, Kelley T, Meara JG, Albert A, Bonanthaya K, Chapman K, Cunningham M, Daskalagiannakis J, de Gier H, Heggie AA, Hernandez C, Jackson O, Jones Y, Kangesu L, Koudstaal MJ, Kuchhal R, Lohmander A, Long RE Jr, Magee L, Monson L, Rose E, Sitzman TJ, Taylor JA, Thornburn G, van Eeden S, Williams C, Wirthlin JO, Wong KW. A Standard set of Outcome Measures for the Comprehensive Appraisal of Cleft Care. Cleft Palate Craniofac J. 2016 May 25. [Epub ahead of print]. 
171. Sitzman TJ, Allori AC, Thorburn G. Measuring outcomes in cleft lip and palate treatment. Clin Plast Surg. 2014; 41(2):311-9.

172. Colbert SD, Green B, Brennan PA, Mercer N. Contemporary management of cleft lip and palate in the United Kingdom. Have we reached the turning point? Br J Oral Maxilllofac Surg. 2015; 53(7):594-8.

173. Al-Ghatam R, Jones TE, Ireland AJ, Atack NE, Chawla O, Deacon S, Albery L, Cobb AR, Cadogan J, Leary S, Waylen A, Wills AK, Richard B, Bella H, Ness AR, Sandy JR. Structural outcomes in the Cleft Care UK study. Part 2: dento-facial outcomes. Orthod Craniofac Res. 2015; 18(Suppl 2):14-24.

174. Iwasaki H, Kudo M, Yamamoto Y. Influences of palatoplasty by the push-back procedure on craniofacial morphology and growth. J Craniomaxillofac Surg. 2012; 40(8):638-46.

175. Smahel Z, Trefny P, Formanek P, Mullerova Z, Peterka M. Three-dimensional morphology of the palate in subjects with unilateral complete cleft lip and palate at the stage of permanent dentition. Cleft Palate Craniofac J. 2004; 41(4):416-23.

176. Pigott RW, Albery EH, Hathorn IS, Atack NE, Williams A, Harland K, et al. A comparison of three methods of repairing the hard palate. Cleft Palate Craniofac J. 2002; 39(4):383-91.

177. Spriestersbach DC, Dickson DR, Fraser FC, Horowitz SL, McWilliams BJ, Paradise JL, et al. Clinical research in cleft lip and cleft palate: the state of the art. Cleft Palate J. 1973; 10:113-65. 
178. Ye Z, Xu X, Ahmatjian A, Bing S. The Craniofacial Morphology in Adult Patients with Unoperated Isolated Cleft Palate. Bone Res. 2013; 1(2):195-200.

179. Chui YT C, YF L. Is Cleft Severity Related to Maxillary Growth in Patients With Unilateral Cleft Lip and Palate? Cleft Palate Craniofac J. 201249 (5):535-40.

180. Nollet PJ, Katsaros C, Van't Hof MA, Kuijpers-Jagtman AM. Treatment outcome in unilateral cleft lip and palate evaluated with the GOSLON yardstick: a metaanalysis of 1236 patients. Plast Reconstr Surg. 116. 2005; 116(5):1255-62.

181. Pereira R, Oliveira A, Melo D, Sznejder K. Compliance to treatment of patients with clefts lip and palate and related craniofacial anomalies. In: ACPA (Ed.). 12th International Congress on Cleft Lip/Palate and Related Craniofacial Anomalies; Orlando,USA: International Confederation of Cleft Lip and Palate and Related Craniofacial Anomalies; 2013.

182. National Research Council Panel on Handling Missing Data in Clinical T. The prevention and treatment of missing data in clinical trials. Washington (DC): National Academies Press (US) Copyright 2010 by the National Academy of Sciences. All rights reserved.; 2010.

183. Gundlach KK, Bardach J, Filippow D, Stahl-de Castrillon F, Lenz JH. Twostage palatoplasty, is it still a valuable treatment protocol for patients with a cleft of lip, alveolus, and palate? J Craniomaxillofac Surg. 2013; 41(1):62-70. 
184. Clark SA, Atack NE, Ewings P, Hathorn IS, Mercer NS. Early surgical outcomes in 5-year-old patients with repaired unilateral cleft lip and palate. Cleft Palate Craniofac J. 2007 ;44(3):235-8.

185. Heliovaara A, Kuseler A, Skaare P, Shaw W, Mølsted K, Karsten A, Brinck E, Rizell S, Marcusson A, Sæle P, Hurmerinta K, Rønning E, Najar Chalien M, Mooney J, Eyres P, Semb G. Scandcleft randomised trials of primary surgery for unilateral cleft lip and palate: 6 . Dental arch relationships at 5 years. $J$ Plast Surg Hand Surg. 2016; 25:1-6.

186. Flinn W, Long RE, Garattini G, Semb G. A multicenter outcomes assessment of five-year-old patients with unilateral cleft lip and palate. Cleft Palate Craniofac J. 2006; 43(3):253-8

187. Richard B, Russell J, McMahon S, Pigott R. Results of randomized controlled trial of soft palate first versus hard palate first repair in unilateral complete cleft lip and palate. Cleft Palate Craniofac J. 2006; 43(3): 329-38.

188. Shaw WC, Asher-McDade C, Brattstrom V, Dahl E, McWilliam J, Mølsted K, Plint DA, Prahl-andersen B, Semb G, The RP. A six-center international study of treatment outcome in patients with clefts of the lip and palate: Part 1. Principles and study design. Cleft Palate Craniofac J. 1992; 29(5):393-7.

189. Ganesh P, Murthy J, Ulaghanathan N, Savitha VH. A randomized controlled trial comparing two techniques for unilateral cleft lip and palate: Growth and speech outcomes during mixed dentition. J Craniomaxillofac Surg. 2015; 43(6):790-5. 
190. Lohmander A, Willadsen E, Persson C, Henningsson G, Bowden M, Hutter Bs. Methodology for Speech Assessment in the Scandcleft Project-An International Randomized Clinical Trial on Palatal Surgery: Experiences From a Pilot Study. Cleft Palate-Craniofac J. 2009; 46(4):347-62.

191. Johnson N, Williams AC, Singer S, Southall P, Atack N, Sandy JR. Dentoalveolar relations in children born with a unilateral cleft lip and palate (UCLP) in Western Australia. Cleft Palate Craniofac J. 2000; 37(1):12-6.

192. Fudalej P, Hortis-Dzierzbicka M, Obloj B, Miller-Drabikowska D, Dudkiewicz Z, Romanowska A. Treatment outcome after one-stage repair in children with complete unilateral cleft lip and palate assessed with the Goslon Yardstick. Cleft Palate Craniofac J. 2009; 46(4):374-80.

193. Mikoya T, Shibukawa T, Susami T, Sato Y, Tengan T, Katashima H, Oyama a, Matsuzawa Y, Ito Y, Funayama E. Dental arch relationship outcomes in oneand two-stage palatoplasty for Japanese patients with complete unilateral cleft lip and palate. Cleft Palate Craniofac J. 2015; 52(3):277-86.

194. Johnson N, Williams AC, Singer S, Southall P, Atack N, Sandy JR. Dentoalveolar Relations in children born with a unilateral cleft lip and palate (UCLP) in Western Australia. Cleft Palate Craniofac J. 2000; 37(1):12-6.

195. Altman DG. Practical statistics for medical research. London: Chapman and Hall; 1991. 
196. Hopp WM, Meredith HV. A longitudinal study of dental arch width at the deciduous second molars on children 4 to 8 years of age. J Dent Res. 1956; 35(6):879-89.

197. Sillman JH. Some aspects of individual dental development: longitudinal study from birth to 25 years. Am J Orthod. 1965; 51:1-25.

198. Moorrees CF, Gron AM. Principles of orthodontic diagnosis. Angle Orthod. $1966 ; 36(3): 258-62$.

199. Knott VB. Longitudinal study of dental arch widths at four stages of dentition. Angle Orthod. 1972; 42(4):387-94.

200. Zreaqat M, Hassan R, Halim AS. Dentoalveolar relationships of Malay children with unilateral cleft lip and palate. Cleft Palate Craniofac J. 2009; 46(3):326-30.

201. Coutinho ALF, Lima MdC, Kitamura MAP, Ferreira Neto J, Pereira RM. Perfil epidemiológico dos portadores de fissuras orofaciais atendidos em um Centro de Referência do Nordeste do Brasil. Rev Bras Saúde Mat Infantil. 2009;:149-56.

202. Lehner B, Wiltfang J, Strobel-Schwarthoff K, Benz M, Hirschfelder U, Neukam FW. Influence of early hard palate closure in unilateral and bilateral cleft lip and palate on maxillary transverse growth during the first four years of age. Cleft Palate Craniofac J. 2003; 40(2):126-30.

203. Capelozza Filho L, Normando AD, da Silva Filho OG. Isolated influences of lip and palate surgery on facial growth: comparison of operated and unoperated male adults with UCLP. Cleft Palate Craniofac J. 1996; 33(1):51-6. 
204. Normando AD, da Silva Filho OG, Capelozza Filho L. Influence of surgery on maxillary growth in cleft lip and/or palate patients. J Craniomaxillofac Surg. 1992; 20(3):111-8.

205. Bardach J. The influence of cleft lip repair on facial growth. Cleft Palate J. 1990; 27(1):76-8.

206. Rousseau P, Metzger M, Frucht S, Schupp W, Hempel M, Otten JE. Effect of lip closure on early maxillary growth in patients with cleft lip and palate. JAMA Facial Plast Surg. 2013; 15(1): 369-73.

207. Dahl E, Hanusardottir B, Bergland O. A comparison of occlusions in two groups of children whose clefts were repaired by three different surgical procedures. Cleft Palate J. 1981; 18(2):122-7.

208. Liao YF, Lee YH, Wang R, Huang CS, Chen PK, Lo LJ, Chen YR. Vomer flap for hard palate repair is related to favorable maxillary growth in unilateral cleft lip and palate. Clin Oral Investig. 2014; 18(4):1269-76.

209. Lilja J. Cleft lip and palate surgery. Scand J Surg. 2003; 92(4):269-73.

210. Swennen G, Berten JL, Schliephake H, Treutlein C, Dempf R, Malevez C, De MA. Midfacial morphology in children with unilateral cleft lip and palate treated by different surgical protocols. Int J Oral Maxillofac Surg. 2002; 31(1):13-22. 
211. Bakri S, Rizell S, Lilja J, Mark H. Vertical maxillary growth after two different surgical protocols in unilateral cleft lip and palate patients. Cleft Palate Craniofac J. 2014; 51(6):645-50.

212. Ferdous KM, Salek AJ, Islam MK, Das BK, Khan AR, Karim MS. Repair of cleft lip and simultaneous repair of cleft hard palate with vomer flap in unilateral complete cleft lip and palate: a comparative study. Pediatr Surg Int. 2010; 26(10):995-1000.

213. Koskova O, Vokurkova J, Vokurka J, Brysova A, Senovsky P, Cefelinova J, et al. Treatment outcome after neonatal cleft lip repair in 5-year-old children with unilateral cleft lip and palate. Int J Pediatr Otorhinolaryngol. 2016; 87:71-7.

214. Kuijpers-Jagtman AM, Long RE. The influence of surgery and orthopedic treatment on maxillofacial growth and maxillary arch development in patients treated for orofacial clefts. Cleft Palate Craniofac J. 2000; 37(6):527.

215. Katzel EB, Basile P, Koltz PF, Marcus JR, Girotto JA. Current surgical practices in cleft care: cleft palate repair techniques and postoperative care. Plast Reconstr Surg. 2009; 124(3):899-906.

216. Cassell CH, Daniels J, Meyer RE. Timeliness of primary cleft lip/palate surgery. Cleft Palate Craniofac J. 2009; 46(6):588-97.

217. Berkowitz S, Duncan R, Evans C, Friede H, Kuijpers-Jagtman AM, PrahlAnderson B, Rosenstein S. Timing of cleft palate closure should be based on the ratio of the area of the cleft to that of the palatal segments and not on age alone. Plast Reconstr Surg. 2005; 115(6):1483-99. 
218. Berkowitz S. Gingivoperiosteoplasty as well as early palatal cleft closure is unproductive. J Craniofac Surg. 2009; 20(Suppl 2):1747-58.

219. Koberg W, Koblin I. Speech development and maxillary growth in relation to technique and timing of palatoplasty. J Maxillofac Surg. 1973; 1(1):44-50.

220. Johnson CA, Li J, Smith AA, Brunski JB, Helms JA. Midfacial growth and surgically induced growth arrest. Plast Reconstr Surg. 2014; 134(4S-1):20.

221. Owman-Moll P, Katsaros C, Friede H. Development of the residual cleft in the hard palate after velar repair in a 2 -stage palatal repair regimen. $J$ Orofac Orthop. 1998; 59(5):286-300.

222. Gunther E, Wisser JR, Cohen MA, Brown AS. Palatoplasty: furlow's double reversing Z-plasty versus intravelar veloplasty. Cleft Palate Craniofac J. 1998; 35(6):546-9.

223. Mackay D, Mazahari M, Graham WP, Jeffords K, Leber D, Gorman P, et al. Incidence of operative procedures on cleft lip and palate patients. Ann Plast Surg. 1999; 42(4):445-8.

224. Schendel SA, Lorenz HP, Dagenais D, Hopkins E, Chang J. A single surgeon's experience with the Delaire palatoplasty. Plast Reconstr Surg. 1999; 104(7):1993-7.

225. Becker M, Svensson H, Sarnas KV, Jacobsson S. Von Langenbeck or Wardill procedures for primary palatal repair in patients with isolated cleft palate-speech results. Scand J Plast Reconstr Surg Hand Surg. 2000; 34(1):27-32. 
226. Muzaffar AR, Byrd HS, Rohrich RJ, Johns DF, LeBlanc D, Beran SJ, et al. Incidence of cleft palate fistula: an institutional experience with two-stage palatal repair. Plast Reconstr Surg. 2001; 108(6):1515-8.

227. Timmons MJ, Wyatt RA, Murphy T. Speech after repair of isolated cleft palate and cleft lip and palate. Br J Plast Surg. 2001; 54(5):377-84.

228. Savaci N, Hosnuter M, Tosun Z, Demir A. Maxillofacial morphology in children with complete unilateral cleft lip and palate treated by one-stage simultaneous repair. Plast Reconstr Surg. 2005; 115(6):1509-17.

229. Mak SY, Wong WH, Or CK, Poon AM. Incidence and cluster occurrence of palatal fistula after furlow palatoplasty by a single surgeon. Ann Plast Surg. 2006; 57(1):55-9.

230. Ogata H, Nakajima T, Onishi F, Tamada I, Hikosaka M. Cleft palate repair using a marginal musculo-mucosal flap. Cleft Palate Craniofac J. 2006; 43(6):651-5.

231. Salyer KE, Sng KW, Sperry EE. Two-flap palatoplasty: 20-year experience and evolution of surgical technique. Plast Reconstr Surg. 2006; 118(1):193204.

232. Phua YS, de Chalain T. Incidence of oronasal fistulae and velopharyngeal insufficiency after cleft palate repair: an audit of 211 children born between 1990 and 2004. Cleft Palate Craniofac J. 2008; 45(2):172-8. 
233. Landheer JA, Breugem CC, van der Molen AB. Fistula incidence and predictors of fistula occurrence after cleft palate repair: two-stage closure versus one-stage closure. Cleft Palate Craniofac J. 2010; 47(6):623-30.

234. DiBiase AT, DiBiase DD, Hay NJ, Sommerlad BC. The relationship between arch dimensions and the 5-year index in the primary dentition of patients with complete UCLP. Cleft Palate Craniofac J. 2002; 39(6):635-40.

235. Friede H, Lilja J. The Eurocleft Study: intercenter study of treatment outcome in patients with complete cleft lip and palate. Cleft Palate Craniofac J. 2005; 42(4):453-4.

236. Mazaheri M, Harding RL, Cooper JA, Meier JA, Jones TS. Changes in arch form and dimensions of cleft patients. Am J Orthod. 1971; 60(1):19-32.

237. Enlow DH, Bang S. Growth And remodeling of the human maxilla. Am J Orthod. 1965; 51:446-64.

238. Latief BS, Lekkas KC, Schols JG, Fudalej PS, Kuijpers MA. Width and elevation of the palatal shelves in unoperated unilateral and bilateral cleft lip and palate patients in the permanent dentition. J Anat. 2012; 220(3):263-70.

239. Moorrees CF, Gron AM. Principles of orthodontic diagnosis. Angle Orthodontist. 1966; 36(3):258-62.

240. Nicky G. Seckel, Tweel Ivd, G. Anne Elema, Tom F. J. M. C. Specken. Landmark Positioning on Maxilla of Cleft Lip and Palate Infant — a Reality? The Cleft Palate-Craniofacial Journal. 1995; 32(5):434-41. 
241. Kramer GJ, Hoeksma JB, Prahl-Andersen B. Early palatal changes after initial palatal surgery in children with cleft lip and palate. Cleft Palate Craniofac J. 1996; 33(2):104-11.

242. Reiser E, Skoog V, Andlin-Sobocki A. Early dimensional changes in maxillary cleft size and arch dimensions of children with cleft lip and palate and cleft palate. Cleft Palate Craniofac J. 2013; 50(4):481-90.

243. Mello BZ, Fernandes VM, Carrara CF, Machado MA, Garib DG, Oliveira TM. Evaluation of the intercanine distance in newborns with cleft lip and palate using 3D digital casts. J Appl Oral Sci. 2013; 21(5):437-42.

244. Suzuki A, Mukai Y, Ohishi M, Miyanoshita Y, Tashiro H. Relationship between cleft severity and dentocraniofacial morphology in Japanese subjects with isolated cleft palate and complete unilateral cleft lip and palate. Cleft Palate Craniofac J. 1993; 30(2):175-81.

245. Carrara CF. Avaliação do tamanho das lâminas palatinas no resultado do crescimento dos arcos dentários e relação interarcos na dentadura decídua ou mista precoce. Bauru: Universidade de São Paulo; 2011.

246. Ball JV, DiBiase DD, Sommerlad BC. Transverse maxillary arch changes with the use of preoperative orthopedics in unilateral cleft palate infants. Cleft Palate Craniofac J. 1995; 32(6):483-8.

247. Ross RB. The clinical implications of facial growth in cleft lip and palate. Cleft Palate J. 1970; 7:37-47. 
248. Kim T, Ishikawa H, Chu S, Handa A, Iida J, Yoshida S. Constriction of the maxillary dental arch by mucoperiosteal denudation of the palate. Cleft Palate Craniofac J. 2002; 39(4):425-31.

249. Meng T, Shi B, Huang X, Zheng Q, Wang Y, Wu M, Lu Y, Li S. Roles of different areas of palatine bone denudation on growth and development of the maxilla and dental arch: an experimental study. J Craniofac Surg. 2007; 18(2):391-8.

250. Suzuki A, Sasaguri M, Hiura K, Yasunaga A, Mitsuyasu T, Kubota Y, et al. Can occlusal evaluation of children with unilateral cleft lip and palate help determine future maxillofacial morphology? Cleft Palate Craniofac J. 2014; 51(6):696-706.

251. Lohmander A, Friede H, Elander A, Persson C, Lilja J. Speech development in patients with unilateral cleft lip and palate treated with different delays in closure of the hard palate after early velar repair: a longitudinal perspective. Scand J Plast Reconstr Surg Hand Surg. 2006; 40(5): 267-74.

252. Gosain AK. Discussion: two-stage palate repair with delayed hard palate closure is related to favorable maxillary growth in unilateral cleft lip and palate. Plast Reconstr Surg. 2010; 125(5):1511-3.

253. Yang Y, Wang Y, Wu Y, Gu Y, Shi B, Yin H, Zheng Q. What operative or anatomic factors affect dental arch development in the cleft patient? $J$ Oral Maxillofac Surg. 2013; 71(5):929-37. 
254. Xu X, Kwon HJ, Shi B, Zheng Q, Yin H, Li C. Influence of different palate repair protocols on facial growth in unilateral complete cleft lip and palate. $\mathrm{J}$ Craniomaxillofac Surg. 2015; 43(1):43-7.

255. Lacerda RH, Ozawa TO, Ramos TB, Furtado PG, de Oliveira LA, de Oliveira AF. Facial growth evaluation of complete unilateral cleft lip and palate operated patients: a cleft reference center in Paraiba, Brazil, using the "GOSLON" yardstick. Oral Maxillofac Surg. 2014; 18(4):403-7.

256. Friede H. Maxillary Growth Controversies After two-stage palatal repair with delayed hard palate closure in unilateral cleft lip and palate patients: perspectives from literature and personal experience. The Cleft PalateCraniofacial Journal. 2007; 44(2):129-36.

257. Liao YF, Cole TJ, Mars M. Hard palate repair timing and facial growth in unilateral cleft lip and palate: a longitudinal study. Cleft Palate Craniofac J. $2006 ; 43(5): 547-56$.

258. Trotman CA, Faraway JJ, Phillips C, van Aalst J. Effects of lip revision surgery in cleft lip/palate patients. $J$ Dent Res. 2010; 89(7):728-32.

259. Abbott MM, Meara JG. Value-based cleft lip-cleft palate care: a progress report. Plast Reconstr Surg. 2010; 126(3):1020-5.

260. Abbott MM, Meara JG. A microcosting approach for isolated, unilateral cleft lip care in the first year of life. Plast Reconstr Surg. 2011; 127(1):333-9. 